\title{
INTERACTIONS BETWEEN ARSENIC SPECIES \\ AND MARINE ALGAE
}

by

This report was prepared as an account of work sponsored by the United States Government. Neither the United States nor the United States Department of Energy, nor any of their employees, nor any of their contractors, subcontractors, or their employees, makes any warranty, express or implied, or assumes any legal liability or responsibility for the accuracy, completeness

or usefulness of any information, apparatus, product or process disclosed, or represents that its use would not infringe privately owned rights.

James G. Sanders

A Dissertation submitted to the faculty of the University of North Carolina at Chapel Hill in partial fulfillment of the requirements for the degree of Doctor of Philosophy in the Curriculum in Marine Sciences.

\section{Chapel Hill}




\section{DISCLAIMER}

This report was prepared as an account of work sponsored by an agency of the United States Government. Neither the United States Government nor any agency Thereof, nor any of their employees, makes any warranty, express or implied, or assumes any legal liability or responsibility for the accuracy, completeness, or usefulness of any information, apparatus, product, or process disclosed, or represents that its use would not infringe privately owned rights. Reference herein to any specific commercial product, process, or service by trade name, trademark, manufacturer, or otherwise does not necessarily constitute or imply its endorsement, recommendation, or favoring by the United States Government or any agency thereof. The views and opinions of authors expressed herein do not necessarily state or reflect those of the United States Government or any agency thereof. 


\section{DISCLAIMER}

Portions of this document may be illegible in electronic image products. Images are produced from the best available original document. 


\section{The following pages are an exact representation of what is in the original document folder.}




\section{INTERACTIONS BETWEEN ARSENIC SPECIES \\ AND MARINE ALGAE}

\section{by}

\section{James G. Sanders}

A Dissertation submitted to the faculty of the University of North Carolina at Chapel Hill in partial fulfillment of the requirements for the degree of Doctor of Philosophy in the Curriculum in Marine Sciences.

\section{Chapel Hill}

\section{8}

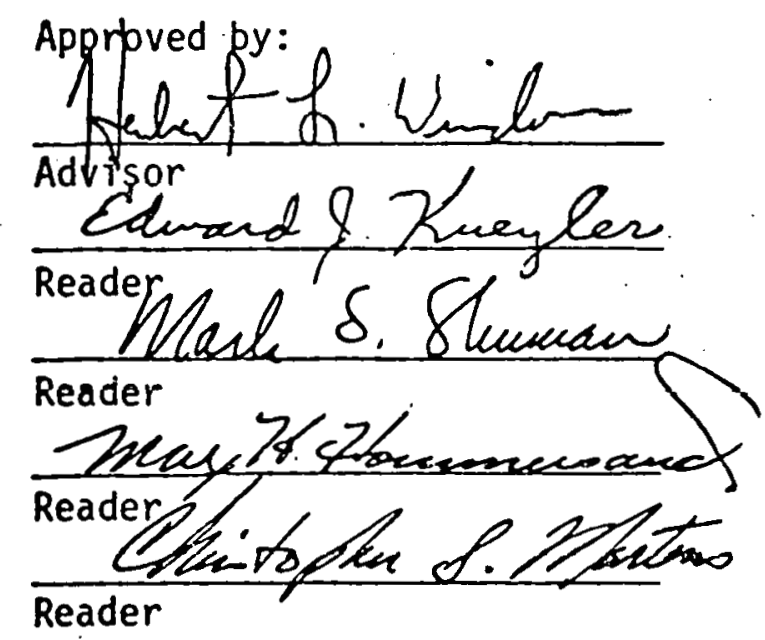


JAMES GRADY SANDERS. Interactions Between Arsenic Species and Marine Algae (Under the direction of Herbert L. Windom).

The arsenic concentration and speciation of marine algae varies widely, from 0.4 to $23 \mathrm{ng} \cdot \mathrm{mg}^{-1}$, with significant differences in both total arsenic content and arsenic speciation occurring between algal classes. The Phaeophyceae contain more arsenic than other algal classes, and a greater proportion of the arsenic is organic. The concentration of inorganic arsenic is fairly constant in macro-algae, and may indicate a maximum level, with the excess being reduced and methylated.

Phytoplankton take up As(V) readily, and incorporate a small percentage of it into the cell. The majority of the $A s(V)$ is reduced, methylated, and released to the surrounding media. This liptake, and subsequent release in a reduced or methylated form, causes large changes in the speciation of arsenic in the culture media; up to $50 \%$ of the As(V) may be reduced. The arsenic speciation in phytoplankton and Valonia also changes when As $(V)$ is added to cultures. The addition generally causes an increase in the proportion of organic arsenic.

Arsenate and phosphate compete for uptake by algal cells. Arsenate is taken up readily due to its chemical similarity to phosphate, and inhibits primary production at concentrations as low as $5 \mu \mathrm{g} \cdot \mathrm{7}^{-1}$ when the phosphate concentration is low. The inhibition is competitive. A phosphate enrichment of $>0.3 \mu M$ alleviates this inhibition; however, the As(V) stress causes an increase in the cell's phosphorus requirement. 
Arsenite is also toxic to phytoplankton at similar concentrations. Methylated arsenic species, such as DMA, did not affect cell productivity, even at concentrations of $25 \mu \mathrm{g} \cdot 1^{-1}$. Thus, the methylation of As(V) to DMA by the cell produces a stable, non-reactive compound which is nontoxic.

The uptake and subsequent reduction and methylation of $A s(V)$ is a significant factor in determining the arsenic biogeochemistry of productive systems, and also the effect that the arsenic may have on algal productivity. Calculations based on the measured reduction rates indicate that 15 to $20 \%$ of the total arsenic is reduced during the spring and fall bloom. Therefore, the role of marine algae in determining the arsenic speciation of marine systems cannot be ignored. 


\section{TABLE OF CONTENTS}

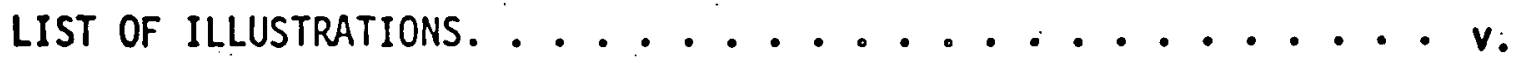

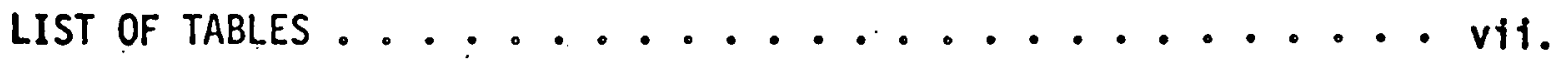

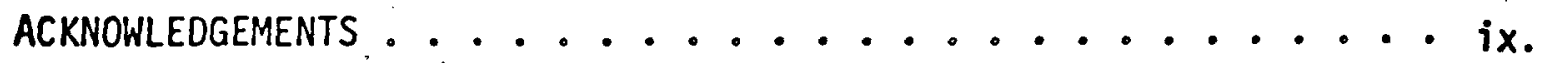

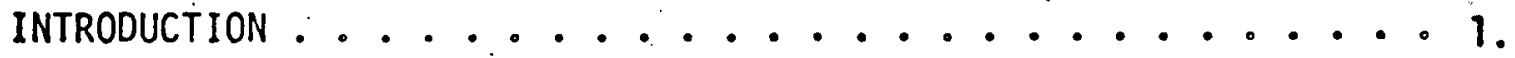
MATERIALS AND METHODS. ............... 5 .

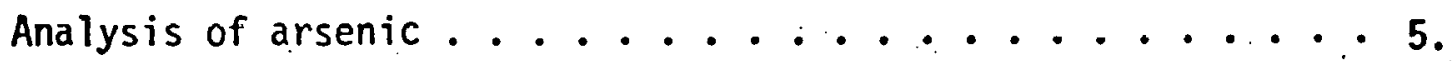
Digestion of biological samples ........... . 5 .

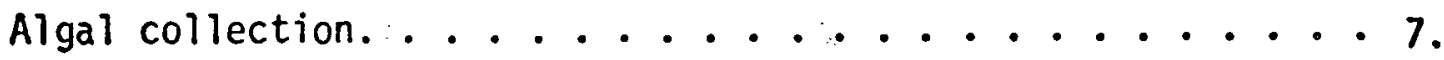

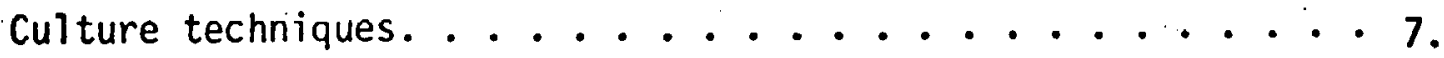

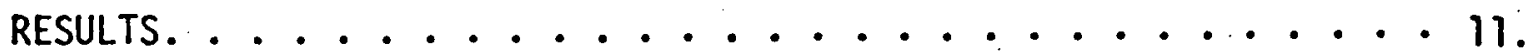
Arsenic concentration and speciation in marine algae. . . . 11 . Arsenic uptake by phytoplankton and Valonia....... 20.

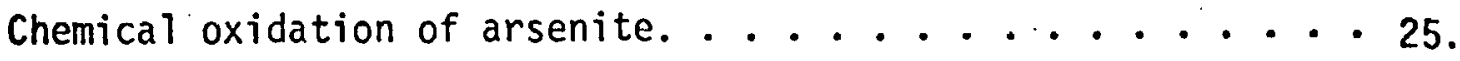
Speciation changes in controlled ecosystem enclosures (CEPEX) . 32. Bacterial interactions with arsenic speciation. ..... 34 .

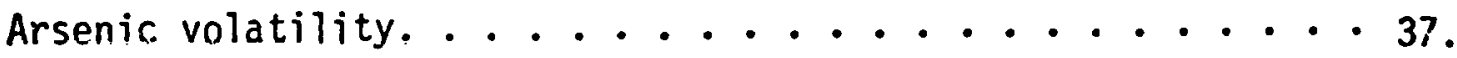

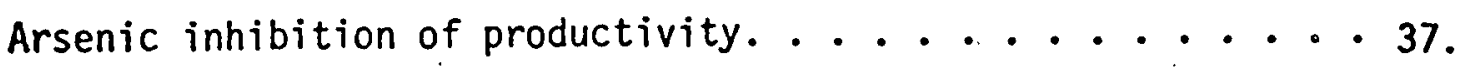

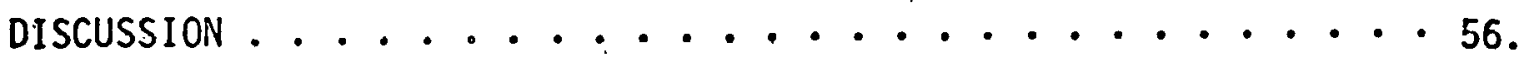

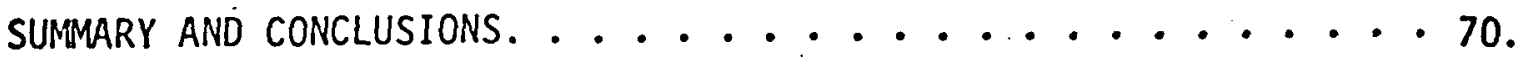
LITERATURE CITED . . . . . . . . . 73. 


\section{LIST OF ILLUSTRATIONS}

\section{Figure}

1. The effect of external As (V) concentration (in $\mu g \cdot l^{-l}$ ) and phosphate concentration (in $\mu(1)$ ) on the $A s(V)$ uptake rate;

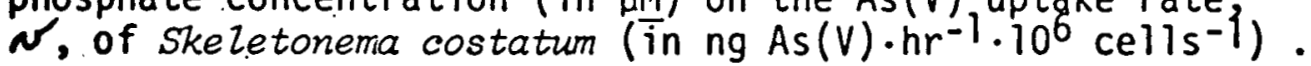

22.

2. Arsenic speciation changes with time in a Skeletonema costatum culture, SC-1-78. Quantities are expressed as $\%$ of total arsenic. Arsenic enrichment: A-nn As(V) added, $B-5 \mu \mathrm{g} \cdot 1^{-1}, C-25 \mu \mathrm{g} \cdot 1^{-1}$. Total arsenic remained unchanged during the course of the experiment

a. Reduction of As(V) . . . . . . . . . . . . . . .

b. Formation of As(III) . . . . . . ........

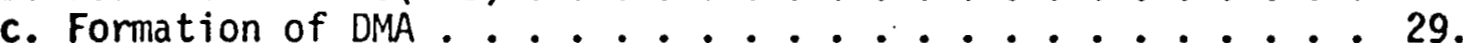

3. The oxidation of As(III) with time in a Skeletonema costatum culture, SC-4-77. Arsenic enrichment: A-no As(III) added, $\mathrm{B}-1 \mu \mathrm{g} \cdot 1^{-1}, \mathrm{C}-20 \mu \mathrm{g} \cdot \mathrm{1}^{-1}$.......... 30

4. The chemical oxidation of $\mathrm{As}$ (III) at $17^{\circ}$ and $27^{\circ} \mathrm{C}$ over the long term.................. 33.

5. Arsenic speciation changes with time, expressed as \% of total arsenic, and phytoplankton carbon, in $\mathrm{mg} \cdot \mathrm{\gamma}^{-9}$, in CEE-B. $5 \mu \mathrm{g} \mathrm{As}(\mathrm{V}) \cdot 1^{-1}$ were added on 30 June 1977. . . . 35.

6. Arsenic speciation changes with time, expressed as \% of total arsenic, in CEE-C. The calculated As(III) oxidation rate is also plotted. $5 \mu \mathrm{gs}$ (III) $\cdot 1^{-1}$ were added on

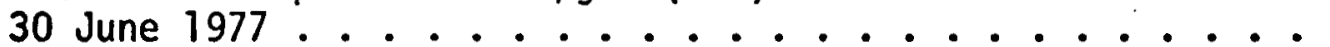

7. Relative growth of a Skeletonema costatwm culture, 2=77-As. Arsenic enricbment: A-no As (V) added, B-6 $\mu \mathrm{g} \cdot \mathrm{I}^{-1}$, $\mathrm{C}-12 \mu \mathrm{g} \cdot 1^{-1}, \mathrm{D}-25 \mu \mathrm{g} \cdot 1^{-1}$...............

8. Relative growth of a skelet.mema costatum culture, SC-3-77. Arsenic enrichment: A-no As $(V)$ added, B-12.5 $\mathrm{\mu g} \cdot \mathrm{1}^{-1}, \mathrm{C}-25 \mu \mathrm{g} \cdot \mathrm{1}^{-1}$..............

9. Relative growth of a Peridinizm trochiodizon culture, PT-9-77. Arsenic enrichment: $A-$ no $A s(V)$ added, $B-2.5 \mu g \cdot 1^{-1}$ (on day $6,20 \mu g \cdot 1^{-1}$ added), $C-5 \mu g \cdot 1^{-1}$, $\mathrm{D}-10 \mu \mathrm{g} \cdot \mathrm{1}^{-1}$ 
10. Relative growth of a Skeletonema costatum culture, SC-4-77. Arsenic enrichment: A-no As(III) added, B- $1 \mu \mathrm{g} \cdot \mathrm{j}^{-1}, \mathrm{C}-20 \mu \mathrm{g} \cdot \mathrm{j}^{-1} \ldots \ldots \ldots \ldots$

11. Relative growth of a Skeletonema costatum culture, SC-4-DMA-72. Arsenic enrichment: A-no DMA added, $C-10 \mu g \cdot l^{-1}$. Culture flask $B$ received a smaller inoculum of cells, and is not shown ........ 46.

12. Four hour ${ }^{14} \mathrm{C}$ uptake by Skeletonema costatum cultures in both $\mathrm{log}$ and stationary growth phase that have been exposed to As(V) enrichment. Expressed as \% of control activity. Each point is the average of 5 replicate determinations. The effect of additional phosphate (20. $\mu \mathrm{M})$ is also shown. The reduction in uptake is significant $(\bar{p}>.99) . \ldots . . .47$.

13. Four hour ${ }^{14} \mathrm{C}$ uptake by Skeletonema costatum cultures in both $\log$ and stationary growth phase that have been exposed to As(III) enrichment. Expressed as \% of control activity. Each point is the average of 5 replicate determinations. The reduction in uptake is significant $(p>.99) \ldots . . .48$.

14. Four hour ${ }^{14} \mathrm{C}$ uptake by Skeletonema costation cultures in both $\mathrm{log}$ and stationary growth phase that have been exposed to DMA enrichment. Expressed as \% of control activity. Each point is the average of 5 replicates. There was no significant reduction in activity $(p<.60) \ldots 49$.

15. Relative growth of a Skeletonema costatum culture, SC-17-77. Arsenic enrichment: A-no As(V) added, $B, C, D-15 \mu \mathrm{g} \cdot 1^{-1}$. Phosphate enrichment: A-0.5 $\mu$ M P., C-0.1 M M B $0.5 \mu \mathrm{M}, \mathrm{D}-2.5 \mu \mathrm{M} . \ldots . . . . . .50$.

16. The growth rate, $\mu$, in divisions per day, of test-tube cultures of skeletonema costation exposed to varying levels of $A s(V)$ and phosphate enrichment. Arsenic enrichment:

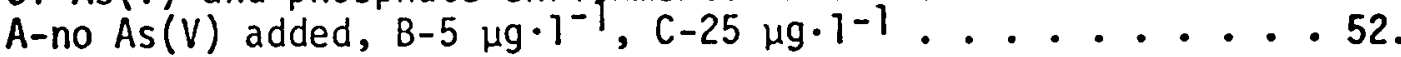

1\%. The effect of exlernal phosphate concentration (in $1, M$ ) and As(V) concentration (in $\mu \mathrm{g} \cdot \mathrm{1}^{-1}$ ) on the phosphate uptake rate, $N$, of SkeZetonema costatum (in $\mathrm{nM} \mathrm{P.hr-1}$.

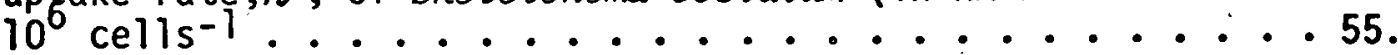




\section{LIST OF TABLES}

Table

Page

1. Arsenic concentration and speciation in marine macroalgae. Concentration is in $\mathrm{ng} \cdot \mathrm{mg}^{-1}$. Classification is according to Fritsch, 1971. . . . . . . . . . 12 .

2. As speciation in cells grown in enriched As media. As concentrations in $\mathrm{ng} \cdot \mathrm{mg}^{-}$.............. 17 .

3. As content and speciation in Valanian rells grown in media enriched with $n s$ fur 34 days. As concentrations in $n g \cdot m g-1$ for cell wall and cytoplasm, $\mu \mathrm{g} \cdot 1^{-}$for sap and culture media............................ 19

4. The uptake of ${ }^{74} \mathrm{As}$ by Skeietonema costatum subjected to a variety of $A s$ and $P$ concentrations, and linear regression analysis of the particulate activity over time. Significant differences between the slope of the control flask (no. P addition) and the treatment flasks are indicated. . . . . . 21.

5. As content and speciation in $S$. costatum cells grown in media enriched with $A s(V)$ and phosphate. As concentrations in $\mathrm{ng} \cdot \mathrm{mg}^{-1}$

6. As speciation changes in culture media, culture $\mathrm{SC}-3-77$, one week after inoculation, with skeletonema costatum.

As concentrations in $\mu g, 1^{-1}$............... 26.

7. As speciation changes in culture SC-4-DMA-77, at beginning of experiment, and 7 days after inoculation with skeletonema costatum. As concentrations in $\mu g^{-1} 7^{-1 . . . . . . . . .31 . ~}$

8. Carbon and Nitrogen content of VaZonia and SkeZetonema costatum grown under conditions of As enrichment. . . . . . 38

9. Linear regression analysis of $\log$ transformations (log relative fluorescence versus time) of batch culture growth curves. Significant differences between the slope of the control flask and the treatment flasks are indicated. . . . 40.

10. Linear regression analysis of log transformations (log relative fluorescence versus time) of batch culture growth curves. Significant differences between the slope of the control flask and the treatment flasks are indicated. . . . 45. 
11. Two-way analysis of variance of $\mu$ by $A$ s and $\mathrm{PO}_{4}$, including As-P interactions in the As-P test-tube cultures of

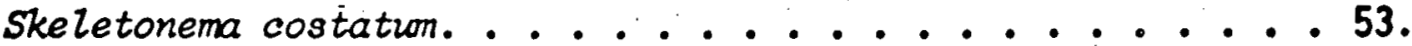

12. $K_{s}$ and $\mu_{\max }$ for phosphate uptake by Skeletonema costatum calculated using a Lineweaver-Burk plot for each As concentration in the As-P test-tube experiment. ..... 53.

13. The uptake of $32 p$ by Skeletonema costatum subjected to a variety of $A s$ and $P$ concentrations and linear regression analysis of the filtrate activity where $Y=$ In filtrate activity. Significant differences between the slope of the control flask (no As) and the treatment flasks are indicated ....................... 54 . 


\section{ACKNOWLEDGEMENTS}

I am grateful to Dr. Herbert L. Windom, my advisor. His support and guidance throughout the study was invaluable. In addition, I thank the members of my committee, Drs. William Dunstan, Edward Kuenzler, Christopher Martens, Mark Shuman, and Max Hommersand for their suggestions and criticism.

I thank the students, staff, and faculty of Skidaway Institute of Oceanography for their suggestions, criticism, and help.

Lastly, I am indebted to my wife, Carmen, for her love and patience, and for her assistance in typing the manuscript.

My studies were supported by the U.S. Department of Energy grant No. EY-76-5-09-0890, NSF Office of the International Decade of Ocean Exploration grant No. OCE 75-06423, Skidaway institute of Oceanography, and the Marine Sciences Program of the University of North Carolina. 
TO CARMEN 


\section{INTRODUCTION}

Arsenic species are present in rather low quantities in marine systems. Earlier studies reported arsenic concentrations up to $75 \mu \mathrm{g} \cdot \mathrm{j}^{-1}$ (Rakestraw and Lutz, 1933; Gorgy et al., 1948; Fondekar and Reddy, 1974), but more recent studies indicate that actual concentrations are much lower. Results for the continental shelf between North Carolina and Florida indicate that total arsenic ranges between 1 and $1.5 \mu \mathrm{g} \cdot \mathrm{j}^{-1}$ (Waslenchuk, 1977, in presș), similar averages have been obtained for the Pacific (this study; Andreae, 1978).

Arsenic can occur in four oxidation states, $+5,+3,0$, or -3 , and all can be stable under varying Eh conditions that occur in natural waters (Ferguson and Gavis, 1972); however, As ${ }^{\circ}$ (metal) is very rare, and the -3 state occurs only under very low Eh values.

In oxygenated natural waters arsenate $(A s(V))$ is the stable oxidation state, with the predominant dissolved form being $\mathrm{HAsO}_{4}{ }^{2-}$ (Ferguson and Gavis, 1972; Lowenthal et al., 1977).. Arsenious acids (As(III)) and organic arsenicals are stable only under mildly reducing Eh conditions, and are not normally found in large concentrations. On occasion, however, both arsenite (As(III)) and organic arsenicals (mainly dimethylarsinic acid, DMA) have been found to comprise significant amounts of the total arsenic (Waslenchuk, 1977, in press; Braman et al., 1977: Johnson and Pilson, 1975; Andreae, 1978) and are thought to be the result of biological reduction of arsenate (Pilson, 1974; Johnson, 1972; Blasco, et ai.; 1971, 1972). 
Very little is known about the arsenic content of marine algae, and even less about arsenic speciation. Johnson and Braman (1975) reported that arsenic in Sargassum sp. ranged from 4.2 to $12.7 \mathrm{ppm}, 80$ to $95 \%$ of which was $A s(V)$. Vinogradov (1953) reported concentrations of 0.1 to 30 ppm. Jones (1922) and Portmann and Riley (1964) found arsenic concentrations of 1.7 to $125 \mathrm{ppm}$ in British algae, Williams and Whetstone (1940) report concentrations of 1 to $12 \mathrm{ppm}$ from Puget. Sound, and Young and Langille (1958) found 2 to $50 \mathrm{ppm}$ in algae from the Atlantic coast of Canada. Trefry and Presley (1976) report that phytoplankton in the Gulf of Mexico contain 3 to $52 \mathrm{ppm}$ arsenic.

Arsenic species are classically considered to be biological poisons, and a few investigations concerning the toxicity of arsenic to organisms have been conducted. Studies performed on yeasts and algae indicate that both $A s(V)$ and As(III) inhibit celiular functions at generally low levels (DaCosta, 1972; Scarborough, 1975; Rothstein, 1963; Lewin, 1954, 1955; Jung et al., 1965; Button et al., 1973; Blum, 1966), but in different ways. Arsenite probably reacts with the $-\mathrm{SH}$ groups of proteins (DaCosta, 1972; Lewin, 1954, 1955). Arsenate competes with phosphate, a chemical analogue, for transport into the cell, inactivates this active transport system, and then may also inhibit glucose metabolism (Rothstein, 1963; Scarborough, 1975). It also competes with phosphate in oxidative phosphorylation (DaCosta, 1972) and esterfication reactions (Jung et al., 1965). Since $A s(V)$ competes with phosphate the external phosphate concentration may be very important in determining the toxicity of As(V), and its inhibition of cellular growth may be greatest in areas where phosphate concentrations are lowest.

Algae may also play a role in regulating arsenic speciation in 
natural waters. Arsenic and many other trace elements are known to participate in a "biological cycle" of speciation changes and transformations by means of the oxidative and reductive reactions of organisms (Wood, 1974). Chzorezla sp. has been found to reduce As(V) to As(III) (Blasco et al., 1971, 1972). Reduction and methylation of inorganic arsenic by bacteria and fungi have been shown to occur both aerobically and anaerobically (McBride et al., 1971; Challenger, 1945; Johnson, 1972) and organic arseno compounds have been identified in Sargassum sp. (Johnson and Braman, 1975) and marine phytoplankton (Lunde, 1973; Irgolic et al., 1977; Andreae, 1978).

The pathways of these reductions and transformations, whether they occur to any extent in marine algal communities, and their relative importance have yet to be determined. Since algae may contain arsenic in concentrations more than 1000 times greater than the surrounding water, they may be a significant reservoir for the marine system. They may also contribute reduced and organic forms of arsenic to higher levels of the food chain, and to the water collimn as well.

Since arsenic may occur in several different forms, its speciation is important in determining arsenic toxicity in any system. Presumably, an algal cell will react differently to separate species of the same element. Several investigators (Sunda and Guillard, 1976; Morel et al., 1978; Anderson and Morel, 1978) have demonstrated that copper inhibition of marine phytoplankton is related to the $\mathrm{Cu}^{2+}$ ion concentration and not the total copper concentration.

- This dissertation presents the results of investigations into the interactions that occur between different arsenic species and marine algae. The objectives of this study were: 
1. to measure the concentration of each arsenic species in phytoplankton and macro-algae in natural systems,

2. to determine the relative toxicity of the separate arsenic species to phytoplankton,

3. to measure the rate of uptake, reduction, and possible release of arsenic species by algae, and

4. to determine the effect of external nutrient concentrations on the uptake, release, reduction, and toxicity of arsenic. 


\section{MATERIALS AND METHODS}

\section{Analysis of arsenic}

Measurement of the separate arsenic species was performed on aqueous samples using the D.C. arc-induced-plasma emission technique of Braman et ar. (1977), modified somewhat for use with biological samples. The technique involves placing an aliquot of a sample into a glass reaction vessel, acidification with oxalic acid, and reduction of the arsenic present to $\mathrm{AsH}_{3}$ gas with a strong reducing agent, $\mathrm{NaBH}_{4}$. Each separate arsenic species is reduced to its unique arsine species; i.e., As(V) forms arsine and DMA forms dimethylarsine. Arsenate is separated from As(III) by a change in the $\mathrm{pH}$ of the sample within the reaction vesser. The arsines are trapped on a glass bead-packed U-tube cooled in liquid $\mathrm{N}_{2}$. Separation and sequential release of the arsines occurs when the $U$-tube is removed, and allowed to warm. The arsines are swept into the D.C. arc by helium carrier gas, where the arsenic plasma is formed. The arsenic emission wavelength $(234.98 \mathrm{~nm})$ is monitored by a GCA-MCPherson Model EU700 spectrophotometer, the resulting pulse is graphed on a Fisher Model 5000 recorder. The detection limit (signal $=2 x$ background) is approximately $0.5 \mathrm{ng}$ for $\mathrm{As}(\mathrm{III})$ and $\mathrm{As}(\mathrm{V})$ and $1 \mathrm{ng}$ for the methyl arsenicais. The maximum sample size is $40 \mathrm{ml}$, giving minimum concentrations of $0.01 \mu \mathrm{g} \mathrm{As.1-1}$ and $0.03 \mu \mathrm{g} \mathrm{As} \cdot 1^{-1}$, respectively. The precision for aqueous samples based on replicate analyses is approximately $\pm 10 \%$.

\section{Digestion of biological samples}

It was necessary to perform a wet digestion on both phytoplankton and macro-algae before arsenic analyses could be performed. Up to 1 
liter of phytoplankton culture was filtered through either a Nucleopore or Millipore membrane filter of $0.45 \mu \mathrm{m}$ pore size. The filter apparatus used was constructed of polycarbonate, and soaked in $20 \% \mathrm{HNO}_{3}$ between uses. The preweighed filters were placed in small, polycarbonate petri dishes, and dried at $60-800 \mathrm{C}$ in an oven. After drying, the filters were re-weighed and the amount of plant material was determined from the weight gain. Macro-algae were dried in an oven at $60-800 \mathrm{C}$. The digestions were carried out on known amounts of plant material (approximately $10 \mathrm{mg}$ of phytoplankton, 20-100 mg of macro-algae). Known quantities of NBS certified orchard leaves, a filter blank (if applicable), and a reagent blank were digested along with each group of samples processed. Analysis of 21 replicates of NBS certified orchard leaves gave an average value of $13.5 \mathrm{ppm}$ with a standard deviation of $2.2 \mathrm{ppm}$. NBS orchard leaves are certified to contain $14 \pm 2 \mathrm{ppm}$ arsenic.

The digestions were performed in loosely capped teflon vials, of 20 ml capacity on a hotplate under low heat $\left(90^{\circ} \mathrm{C}\right.$, slightly higher than the boiling point of $\mathrm{HNO}_{3}$ ). The vials were placed under a teflon hood, and $\mathrm{N}_{2}$ gas was used as an inert atmosphere to minimize contamination. The. acid used for digestion was originally $5 \mathrm{ml}$ of concentrated NBS certified redistilled $\mathrm{HNO}_{3}$. Later, Baker "Ultrex" $\mathrm{HNO}_{3}$ was found to be sufficiently clean to replace the more expensive NBS acid. The acid was evaporated nearly to dryness and, if ner.escary, more acid was added to complete the digestion. The residue remaining was dissolved in $5 \mathrm{mll}$ of $10 \%$ "Ultrex" $\mathrm{HNO}_{3}$. This solution could then be analyzed for arsenic with no further modifications.

On several occasions, filters spiked with all three species of arsenic were digested to determine if speciation changes occured during 
digestion. With the exception of As(III) no changes were observed. Arsenite was sometimes in part (0-50\%) oxidized to As $(V)$.

\section{Algal collection}

Macro-algae was collected from the intertidal zone of several different habitats (Maine, Massachusetts, Georgia, Florida, California, and British Columbia) to be analyzed for arsenic speciation. The algae was collected by hand, placed in plastic bags, then oven dried in the laboratory at $80^{\circ} \mathrm{C}$. The dried algae was digested and analyzed for arsenic as detailed above.

\section{Culture techniques}

1. Macro-algae: The onty alga cultured in bulk was Valonia macrophysa, obtained in pure culture from Carolina Biological Supply Company. In addition to this species, an attempt was made to culture V. ventricosa collected in the Florida Keys; these cells did not survive for more than 2 months, probably due to degradation of the numerous attached epiphytes. The Valonia were kept in $200 \mathrm{ml}$ glass culture dishes under artificial light and a 12 hour photoperiod (intensity = $\left.100 \mu \mathrm{E} \cdot \mathrm{m}^{-2} \cdot \mathrm{sec}^{-1}\right)$ at $20^{\circ} \mathrm{C}$. Various culture media were used including a commercially prepared medium ("Alga-Gro") from Carolina Biological Supply Company. - The basic medium used for all arsenic studies was prepared from seawater collected 50 to 60 miles offshore, with $\mathrm{NO}_{3}^{-}$ added to increase the concentration by $20 \mu \underline{M}$. No other additions were made. Valonia cultured in this. media remained viable for more than 1 year when the medium was changed monthly. Arsenic enrichment studies were performed by adding the appropriate arsenic species to this basic medi inii. 
Valonia was selected for these experiments because each plant is one large cell, 0.2-3 cm in diameter. Because of its size, the cell could easily be separated into 3 components: the vacuolar sap, the cell wall; and the cytoplasm. This separation was accomplished by first drawing off the vacuolar sap with a micro-syringe. The cytoplasm was then carefully scraped from the cell wall. The sap was directly analyzed for arsenic. Both the cytoplasm and cell wall were dried and digested before analysis. The analysis of live tissue (Johinson and Braman, 1975) was attempted on two occasions, but was discontinued due to poor recovery of arsenic.

2. Phytoplankton. Axenic stock cultures of Skeletonema costation isolated by R.R.L. Guillard (clone Skel, WHOI) and Peridinizm trochoidium (isolated by M. Darley, University of Georgia) were maintained in Guillard's f/10 media (Guillard and Ryther, 1962). The Skeletonema culture was transferred weekly, the slower growing Peridinium was transferred monthly $(250 \mu \mathrm{l}$ into $50 \mathrm{ml})$. Care was taken to use-cultures of the same age and physiological state for culture experiments, i.e., week old Skeletonema stocks and 1 month old Peridinium stocks were used. Inoculum size varied from culture to culture, depending on culture size.

Batch cultures were prepared in 2, 4, or 12 liter glass vessels. The medium was seawater collected well offshore, and membrane filtered to remove all other possible biota. Approximately $20 \mu \mathrm{M} \mathrm{NO}{ }_{3}^{-}$and $\cdot \mathrm{SiO}_{3}$ were added to promote growth, phosphate was not usually added.

The inoculum of cells from the stock cultures was designed to give an initial cell density of $10^{6}$ cells: $1^{-1}$. All cultures were placed in large aquaria and maintained at a temperature of $20^{\circ} \mathrm{C}$ and a light intensity of $80 \mu \mathrm{E} \cdot \mathrm{m}^{-2} \cdot \mathrm{sec}^{-1}$. Arsenic was added, *and the cultures were 
run until the population had reached stationary phase, usually 6 to 8 days. The culture density was monitored daily by measurement of in vivo fluorescence; subsamples were taken periodically for cell counts, arsenic concentration and speciation, and particulate carbon concentration. After reaching stationary growth, the cultures were filtered through cleaned membrane filters and digested as above.

The productivity of various cultures was determined by the ${ }^{14} \mathrm{C}$ method. $100 \mathrm{ml}$ aliquots of cultures were placed in $125 \mathrm{ml}$ bottles, inoculated with $5 \mu \mathrm{Ci}$ of ${ }^{14} \mathrm{C}$ as $\mathrm{HCO}_{3}{ }^{-}$, and incubated in place for 4 hours. These bottles were filtered, the filters dried, placed in $15 \mathrm{ml}$ of "Omnifluor", and counted in a Packard "Tri-Carb" liquid scintillation spectrometer.

3. Phosphate-arsenate interactions. A series of experiments was designed to study the effects of phosphate and $A s(V)$ on growth and nutrient uptake by Skeletonema costatum. Thirty test-tube cultures in duplicate containing approximately $10^{4} \mathrm{cells} \cdot \mathrm{ml}^{-1}$ of P-starved cells received varying concentrations. of $\operatorname{As}(V)\left(0,5\right.$, and $\left.25 \mu \mathrm{g} \cdot \mathrm{1}^{-1}\right)$ and phosphate $(0, .007, .02, .07, .17, .33, .67,3.3,6.7$, and $33 \mu \underline{M})$. After 24 hours of incubation, the cultures were fixed with Lugol's. solution and the increase in cell number determined.

${ }^{74}$ As (as $\mathrm{As}(\mathrm{V})$ ) and ${ }^{32} \mathrm{p}$. (as $\mathrm{PO}_{4}$ ) were used to determine the effect of As $(V)$ concentration on the uptake of phosphate and conversely, the effect of phosphate concentrations on As(V) uptake. $.100 \mathrm{ml}$ cultures. of Skeletonema costatum containing approximately $10^{3} \mathrm{cell}^{\mathrm{s}} \cdot \mathrm{ml}^{-1}$ were inoculated with varying concentrations of $\operatorname{As}(V)\left(0,5\right.$, and $\left.25 \mu \mathrm{g} \cdot 1^{-1}\right)$, phosphate $(0, .007, \ldots 17$, and $3.3 \mu \mathrm{M})$, and $10 \mu \mathrm{Ci}$ of ${ }^{74} \mathrm{As}$ per flask, and incubated for 25 hours. Periodically, $5 \mathrm{mli}$ aliquots were removed and 
filtered through $0.4 \mu \mathrm{m}$ Nucleopore filters. The filters were placed in $10 \mathrm{ml}$ of "Aquasol", and counted in a Packard liquid scintillation counter. Other cultures were prepared using four concentrations of As(V) $\left(0,5,15\right.$, and $\left.25 \mu \mathrm{g} \cdot 1^{-1}\right)$, four phosphate concentrations $(0, .007$, .17 , and $3.3 \mu \mathrm{M})$, and $2 \mu \mathrm{Ci}$ of ${ }^{32 \mathrm{p}}$ per flask, and incubated for 5 hours. Periodic samples were taken, filtered, and counted by Cerenkov radiation in $5 \mathrm{ml}$ of water in the Packard counter:

Both the phytoplankton and Vazonia grown under arsenic enrichment were analyzed for $C$ and $N$ to determine their ratio. $100 \mathrm{ml}$ of culture were filtered through a combusted glass-fiber filter, dried at $60^{\circ} \mathrm{C}$, and then analyzed in a Perkin-Elmer model 240 elemental analyzer. Whole Valonia cells, dried at $60^{\circ} \mathrm{C}$ were placed in platinum boats and analyzed as above. 


\section{RESULTS}

\section{Arsenic concentration and speciation in marine algae}

The arsenic concentration of marine algae varies widely (Table 1). Arsenic concentrations range from 0.4 to $23 \mathrm{ng} \cdot \mathrm{mg}^{-1}$ in macro-algae collected on the east and west coasts of North America. The arsenic speciation also varied, with inorganic species comprising from 1 to $80 \%$ of the total concentration. Note that inorganic arsenic contains both the $A s(V)$ and $A s(I I I)$ fractions, as the digestion procedure of ten oxidized the As(III) to As(V). Attempts to determine the As(III)/As(V) ratio by less drastic procedures such as grinding the fresh algae in $0.2 \mathrm{~N} \mathrm{NaOH}$ (Johnson and Braman, 1975) did not give satisfactory results.

The three algal classes contain significantly different arsenic concentrations and speciation (Table $1, p>.99$ ). Brown algae contain the highest average total arsenic concentration and have the lowest percentage of inorganic arsenic. Both red and green algae contain approximately equal percentages of inorganic arsenic, but green algae have a higher average total arsenic concentration.

Arsenic concentrations in cultured phytoplankton ranged from 5 (Peridinium trochoidium) to $23 \mathrm{ng} \cdot \mathrm{mg}^{-1}$ (Skeletonema costation). Arsenic speciation in both algal species was approximately $50 \%$ inorganic, $50 \%$ organic (Table 2).

The cultured Vazonia macrophysa had very low arsenic content, 0.16 $\mathrm{ng} \cdot \mathrm{mg}^{-1}, 75 \%$ of which was inorganic (Table 3 ). 
Table 1. Arsenic concentration and spec:ation in marine macro-algae. Concentration is in $\mathrm{ng}^{\circ} \mathrm{mg}^{-1}$. Classification accerding to Fritsch, $197 i$.

\section{$\therefore$ Species Collected Total As Inorganic Organic Comments}

CHLOROPHYCEAE

Order III - Ulotrichales

Enteromorpha sp. \#3

Enteromorpha sp. \#1

Enteromorpha sp. \#2

Ulva Zactuca

Ulva sp.

$$
\begin{aligned}
& 1^{*}, 3 / 77 \\
& 2^{\theta}, 7 / 77 \\
& 2,7 / 77 \\
& 2,7 / 77 \\
& 6^{\$}, 7 / 77
\end{aligned}
$$

23.3

0.93

0.97

1.19

\begin{tabular}{|c|c|}
\hline $\begin{array}{ll}45 & (42-48) \\
57 & (46-68) \\
29 & (26-32) \\
29 & (24-34)\end{array}$ & $\begin{array}{l}55(54-56) \\
43 .(47-45) \\
71(67-75) \\
77(62-79)\end{array}$ \\
\hline
\end{tabular}

0.56

5.39

$\cdot \cdot \begin{aligned} & \bar{x} \\ & \text { s }\end{aligned}$

10.0

$\vec{x}$

Order IV - Cladophorales

Cladophora sp. \#1

Cladophora sp. \#2

$\begin{array}{ll}2, & 7 / 77 \\ 1, & 9 / 77\end{array}$

0.96

3.91 .

$49(47-51)$
$49(48-50)$

$51(45-57)$

2.44

2.10

49

$51 \quad(50-52)$

$\bar{x}$

1.80

51

5.00

Order VIII - Siphonales

Caulerpa sp.

Derbesia sp.

Codium fragile.

\begin{tabular}{|c|}
\hline $\begin{array}{ll}39 & (30-48) \\
75 & (69-81) \\
12 & (11-13)\end{array}$ \\
\hline
\end{tabular}

$\begin{array}{ll}3 \psi & 9 / 76 \\ 4^{\delta}, & 1 / 77 \\ 2, & 7 / 77\end{array}$

2.55

0.61

3.68 
Table 1., continued.

\begin{tabular}{|c|c|c|c|c|c|}
\hline Species & Collected & Total As & $\begin{array}{c}\% \\
\text { Inorganic } \\
\end{array}$ & $\stackrel{\%}{\%}$ Organic & Comments \\
\hline $\begin{array}{l}\text { Halimeda sp. } \\
\text { Udotea sp. } \\
\text { Valcria macrophysa. } \\
\text { Valcria vertricosa } \\
\text { Anacilomene sp. }\end{array}$ & $\begin{array}{ll}3, & 9 / 76 \\
3, & 9 / 76 \\
4, & 1 / 77 \\
3, & 6 / 77 \\
3, & 9 / 76\end{array}$ & $\begin{array}{l}1.47 \\
2.04 \\
0.17 \\
3.14 \\
0.58\end{array}$ & $\begin{array}{l}37 \cdot(36-38) \\
75(69-81) \\
76(73-79) \\
34(33-35) \\
79(34-96)\end{array}$ & $\begin{array}{l}63(54-72) \\
25(20-30) \\
24(18-30) \\
66(60-72) \\
21(4-66)\end{array}$ & $\begin{array}{l}\text { Calcareous } \\
\text { Calcified }\end{array}$ \\
\hline $\begin{array}{l}\bar{x} \\
s\end{array}$ & & $\begin{array}{l}1.78 \\
1.30\end{array}$ & $\begin{array}{c}52 \\
26.4\end{array}$ & $\begin{array}{c}48^{\circ} \\
27.2\end{array}$ & \\
\hline CHLORGFHYCEAE, overall & & 3.10 & 48 & 52 & \\
\hline $\begin{array}{l}\text { PHAEOFHYCEAE } \\
\text { Order I - Ectocarpales }\end{array}$ & & . & 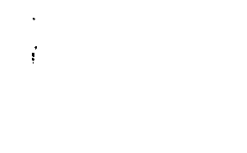 & & \\
\hline $\begin{array}{l}\text { Ectcicarpus sp. } \\
\text { Haplcgloia sp. } \\
\text { Petalonia sp. } \\
\text { Scytcoiphon bullosus }\end{array}$ & $\begin{array}{ll}\because ; & 3 / 77 \\
2, & 7 / 77 \\
2, & 7 / 77 \\
2, & 7 / 77\end{array}$ & $\begin{array}{l}22.2 \\
3.83 \\
3.21 \\
7.44\end{array}$ & $\begin{array}{ll}53 & (50-56) \\
57 & (46-56) \\
33 & (31-35) \\
24 & (22-26)\end{array}$ & $\begin{array}{l}47(46-48) \\
49(44-54) \\
67(65-69) \\
76(70-82)\end{array}$ & \\
\hline$\because \quad \begin{array}{l}\bar{x} \\
s\end{array}$ & “. & $\begin{array}{l}9.17 \\
8.90\end{array}$ & $\begin{array}{l}40 \\
13.5\end{array}$ & $\begin{array}{r}60 \\
13.7\end{array}$ & \\
\hline Order V - Desmarestiales & & ${ }^{\circ}$ & & & \\
\hline Desmarestia sp. & $2, \quad 7 / 77$ & 2.68 & 30. $(22-38)$ & $70(62-78)$ & 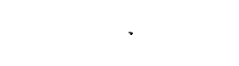 \\
\hline
\end{tabular}


Table 1., continued.

\section{Species}

Order VI - Laminariales

Cymathere triplicata

Postelsia palmoeformis.

Nereocystis Zuetkeana

Macrocystis pyrifera

Alaria marginata

Alaria marginata

Eisenia arborea

Order VIII - Dictyotales

Dictyota sp.

Order IX - Fucales

Ascophylzion sp.

Fucus sp. \#1

Pelvetiopsis limitata

Fucus sp. \#2

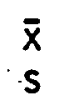

PHAEOPHYCEAE, overali

$\therefore \cdot \overline{\mathrm{x}}$

\section{Collected}

2, $7 / 77$

$2,7 / 77$

$2,7 / 7 \bar{T}$

$5^{\circ}, 7 / 77$

2, $7 / 7 i$

$2, \quad 7 / 77$

$5,7 / 7 i$

ミ, $1 / 78$

6.68

23

$\begin{aligned} 21 & (21) \\ 9 & (8-10) \\ 11 & (10-12) \\ 2 & (1-3) \\ 5 & (4-6) \\ 5 & (2-8) \\ 1 & (0-1)\end{aligned}$

$79(77-87)$

9: $(88-94)$

$87(85-93)$

$93(97-98)$

$95(95-96)$

$95(92-98)$

$99(97-100)$

15.0

7.50

8
5.80

92

7.60

Blades

Blades

Blades

Sporophylls

$\begin{array}{ll}8^{\alpha}, & 2 / 73 \\ 2 & 7 / 77 \\ 2 & 7 / 77 \\ 7^{4}, & 12 / 77\end{array}$

12.5

1.06

5.23

19.0

3

$38(27-55)$

$26(26)$

97

$74(71-77)$

9.45

7.90

24

19.5

76

11.1

21

79 
Table 1., continued.

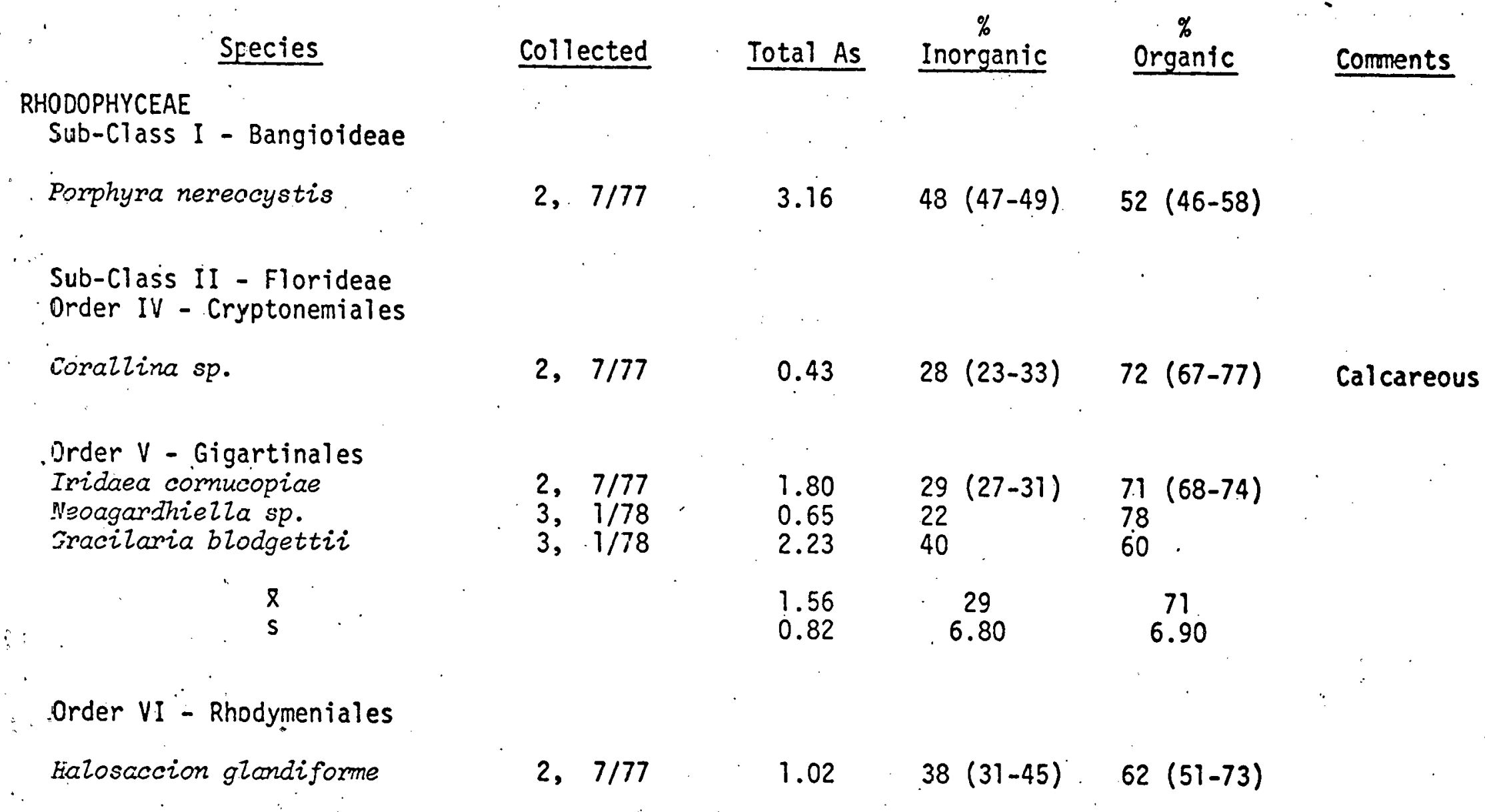


Table 1., continued.

\begin{tabular}{|c|c|c|c|c|}
\hline Species & Collected & Total As & $\begin{array}{c}\% \\
\text { Inorganic } \\
\end{array}$ & $\begin{array}{c}\% \\
\text { Organic } \\
\end{array}$ \\
\hline \multicolumn{5}{|l|}{ Order VII - Ceramiales } \\
\hline \multirow[t]{2}{*}{$\begin{array}{l}\text { Antitharmion sp. } \\
\text { Microcladia sp. } \\
\text { Ceromium sp. } \\
\text { Chondria sp. } \# 1 \\
\text { Chondria sp. } \# 2\end{array}$} & $\begin{array}{ll}2, & 7: 77 \\
2, & 7: 77 \\
3, & 1: 78 \\
3, & 1778 \\
3, & 1: 78\end{array}$ & $\begin{array}{l}1.44 \\
0.73 \\
0.89 \\
0.73 \\
3.04\end{array}$ & $\begin{array}{ll}22 & (19-25) \\
67 & (57-83) \\
38 & \\
65 & \\
75 & \end{array}$ & $\begin{array}{l}78(73-83) \\
33(32-34) \\
62 \\
35 \\
25\end{array}$ \\
\hline & & $\begin{array}{l}1.37 \\
0.98\end{array}$ & $\begin{array}{r}51 \\
24.7\end{array}$ & $\begin{array}{c}49 \\
23.0\end{array}$ \\
\hline RHODOPHYCEAE, overall & 1 & 1.40 & 43 & 57. \\
\hline $\begin{array}{l}1^{\star} \text { - Skidaway River } \\
2^{\theta} \text { - Vancouver Island, } \\
3^{\psi} \text { - Florida Keys } \\
4^{\delta} \text { - Carolina Biologio } \\
5^{\sigma} \text { - Southern Cal ifann } \\
6^{\phi} \text { - Fort Pierce, Flor } \\
7^{\top} \text { - Woods Hole, Massa } \\
8^{\alpha} \text { - Maine }\end{array}$ & $\begin{array}{l}\text { British Cclumbia } \\
\text { al Supply Company } \\
\text { ia. } \\
\text { ida } \\
\text { chusetts }\end{array}$ & $\therefore$ & . & \\
\hline
\end{tabular}


Table 2. As speciation in cells grown in enriched As media. As concentrations in $\mathrm{ng} \cdot \mathrm{mg}-\mathrm{I}^{\prime}$. All cultures were $S$. costatron except PT-9-77 was $P$. trochoidizm.

$$
\text { As (V) Enrichment }
$$

\begin{tabular}{|c|c|c|c|c|c|c|c|c|}
\hline Culture & Flask & $\begin{array}{l}\operatorname{As}(V) \\
\text { Added, } \mu g \cdot I^{-1}\end{array}$ & $\begin{array}{l}\text { Inorganic } \\
\text { As }\end{array}$ & $(\%)$ & $\begin{array}{c}\text { Organic } \\
\text { As }\end{array}$ & $(\%)$ & Total & $\begin{array}{c}\% \\
\text { of Control }\end{array}$ \\
\hline \multirow[t]{2}{*}{ 2-77-AS } & $\begin{array}{l}A \\
B \\
C \\
D\end{array}$ & $\begin{array}{r}0 \\
6 \\
12 \\
25\end{array}$ & $\begin{aligned} 10.8 & (10-11.5) \\
7.2 & (6.7-7.6) \\
11.0 & (9.4-12.6) \\
9.6 & (812-10.9)\end{aligned}$ & $\begin{array}{l}49 \\
23 \\
35 \\
32\end{array}$ & $\begin{array}{l}11.2(8.7-13.5) \\
24.3(24-24.6) \\
20.0(18.1-21.9) \\
20.2(18.6-21.8)\end{array}$ & $\begin{array}{l}51 \\
77 \\
65 \\
68\end{array}$ & $\begin{array}{l}22.0 \\
31.5 \\
31.0 \\
29.8\end{array}$ & $\begin{array}{l}143 \\
141 \\
135\end{array}$ \\
\hline & & $\bar{x}, B, C, D$ & 9.3 & 30 & 21.5 & 70 & 30.8 & 140 \\
\hline \multirow[t]{2}{*}{ Si $-3-77$} & $\begin{array}{l}A \\
B \\
C\end{array}$ & $\begin{array}{l}0 \\
12.5 \\
25\end{array}$ & $\begin{array}{l}7.3(5.8-8.8) \\
8.2(8.0-8.4) \\
8.8(8.2-9.4)\end{array}$ & $\begin{array}{l}33 \\
29 \\
30\end{array}$ & $\begin{array}{l}14.7(14.6-14.8) \\
20.4(18.3-22.5) \\
20.4(19.2-21.2)\end{array}$ & $\begin{array}{l}67 \\
71 \\
70\end{array}$ & $\begin{array}{l}22.0 \\
28.6 \\
29.2\end{array}$ & $\begin{array}{l}-130 \\
133\end{array}$ \\
\hline & & $\bar{x}, B, C$ & 8.5 & 29 & 20.4 & 71 & 28.9 & 131 \\
\hline \multirow[t]{2}{*}{ PT-9-77 } & $\begin{array}{l}A \\
C \\
D \\
B\end{array}$ & $\begin{array}{l}0 \\
5 \\
10 \\
22.5\end{array}$ & $\begin{aligned} 2.3 & (2.3) \\
5.9 & (5.8-6.0) \\
25.3 & (22.7-27.9) \\
35.3 & (30.3-40.3)\end{aligned}$ & $\begin{array}{l}45 \\
37 \\
57 \\
55\end{array}$ & $\begin{array}{cc}2.7 & (2.0-3.4) \\
10.3 & (9.7-10.8) \\
18.8 & (14.9-22.8) \\
28.4 & (26.7-30.2)\end{array}$ & $\begin{array}{l}55 \\
63 \\
43 \\
45\end{array}$ & $\begin{array}{r}5.0 \\
16.2 \\
44.1 \\
63.7\end{array}$ & $\begin{array}{r}--- \\
323 \\
880 \\
1270\end{array}$ \\
\hline & & $\bar{x}, C, D, B$ & & 50 & & 50 & & \\
\hline
\end{tabular}


Table 2., continued.

$$
\text { As (III) Enrichment }
$$

\begin{tabular}{|c|c|c|c|c|c|c|c|c|c|}
\hline Culture & Flask & $\begin{array}{c}\text { As(III) } \\
\text { Added, } \mu g \cdot I-1 \\
\end{array}$ & $\begin{array}{l}\text { Inorgaric } \\
\text { As }\end{array}$ & $(\%)$ & & $\begin{array}{c}\text { Organic } \\
\text { As } \\
\end{array}$ & $(\%)$ & Total & of Control \\
\hline SC-4-77 & $\begin{array}{l}A \\
B \\
C\end{array}$ & $\begin{array}{r}0 \\
1 \\
20\end{array}$ & $\begin{array}{l}14.6(12.9-15.2) \\
20.8(18.5-23.2) \\
25.8(25.2-26.5)\end{array}$ & $\begin{array}{l}56 \\
58 \\
53\end{array}$ & $\begin{array}{l}11.3 \\
15.2 \\
22.8\end{array}$ & $\begin{array}{l}(10.8-11.9) \\
(14-16.4) \\
(21-24.7)\end{array}$ & $\begin{array}{l}44 \\
42 \\
47\end{array}$ & $\begin{array}{l}25.9 \\
36.0 \\
48.4\end{array}$ & $\begin{array}{l}-1-. \\
139 \\
187\end{array}$ \\
\hline & & $\bar{x}, B, C$ & & 56 & & & 44 & & - \\
\hline
\end{tabular}

DMA Enrichment

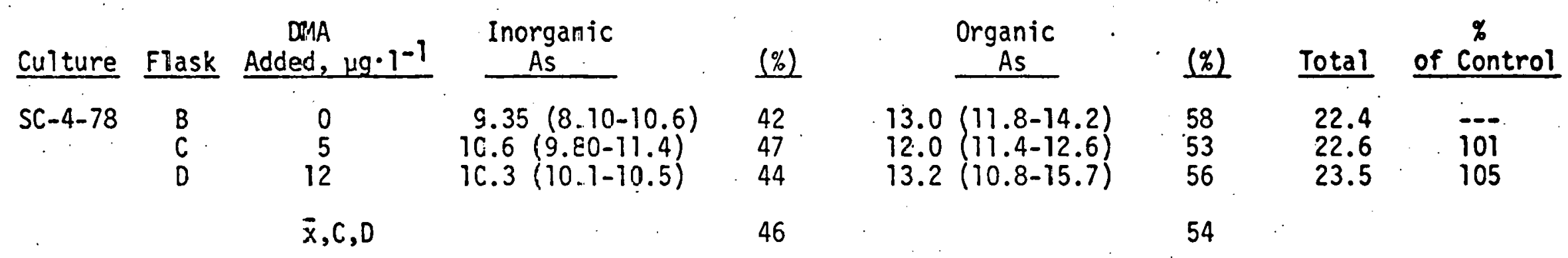


Tajle 3. As content and speciation in Valonia cells grown in medja enriched with As for 34 days. As concentrations in $\mathrm{ng} \cdot \mathrm{mg}^{-1}$ for cell wall and cytoplasm, $\mu \mathrm{g} \cdot \mathrm{1}^{-1}$ for sap and culture media.

Cell Wall and Cytoplasm

\begin{tabular}{|c|c|c|c|c|c|c|}
\hline $\begin{array}{l}\text { Enriched } \\
\text { As sp. }\end{array}$ & $\begin{array}{c}\text { As } \\
\text { Added, } \mu g \cdot \gamma^{-1}\end{array}$ & $\begin{array}{c}\text { Inorganic } \\
\text { As }\end{array}$ & $(\%)$ & $\begin{array}{c}\text { Organic } \\
\text { As } \\
\end{array}$ & (\%) & Total \\
\hline $\begin{array}{l}\text { Control } \\
\text { As (V) } \\
\text { As IIII) } \\
\text { DifA }\end{array}$ & $\begin{array}{r}0 \\
15 \\
15 \\
15\end{array}$ & $\begin{array}{l}0.12(.12) \\
.71(.57-.86) \\
1.78(1.44-2.12) \\
.22(.03-.41)\end{array}$ & $\begin{array}{l}75 \\
52 \\
64 \\
59\end{array}$ & $\begin{array}{l}0.04(.01-.06) \\
.66(.46-.86) \\
.98(.94-1.02) \\
.15(.14-.16)\end{array}$ & $\begin{array}{l}25 \\
48 \\
36 \\
4 !\end{array}$ & $\begin{array}{l}0.16 \\
1.37 \\
2.76 \\
.37\end{array}$ \\
\hline
\end{tabular}

Vacuolar Sap

\begin{tabular}{|c|c|c|c|c|c|c|}
\hline $\begin{array}{l}\text { Enriched } \\
\text { As sp. }\end{array}$ & $\begin{array}{l}\text { As } \\
\text { Added, } \mu g \cdot 1^{-1}\end{array}$ & $\begin{array}{c}\text { Inorganic } \\
\text { As }\end{array}$ & $(\%)$ & $\begin{array}{l}\text { Organic } \\
\text { As } \\
\end{array}$ & $(\%)$ & Total \\
\hline $\begin{array}{c}\text { Control } \\
\text { As(V) } \\
\text { As(III) } \\
\text { DMA }\end{array}$ & $\begin{array}{r}0 \\
15 \\
15 \\
15\end{array}$ & $\begin{array}{r}.9 \\
.7 \\
4.6 \\
.2\end{array}$ & $\begin{array}{c}39 \\
24 \\
70 \\
1\end{array}$ & $\begin{array}{r}1.4 \\
2.2 \\
2.0 \\
14.0\end{array}$ & $\begin{array}{l}61 \\
76 \\
30 \\
99\end{array}$ & $\begin{array}{r}2.3 \\
2.9 \\
6.6 \\
.14 .2\end{array}$ \\
\hline
\end{tabular}

\begin{tabular}{|c|c|c|c|c|c|c|}
\hline $\begin{array}{l}\text { Enriched } \\
\text { As sp. }\end{array}$ & $\begin{array}{c}\text { As } \\
\text { Added, } \mu g \cdot \eta^{-1} \\
\end{array}$ & $\begin{array}{c}\text { Inorganic } \\
\text { As }\end{array}$ & $\begin{array}{l}\text { ure Me } \\
\qquad(\%)\end{array}$ & $\begin{array}{c}\text { Organic } \\
\text { As } \\
\end{array}$ & $(\%)$ & To \\
\hline $\begin{array}{c}\text { Control } \\
\text { As (V) } \\
\text { As (III) } \\
\text { DMA }\end{array}$ & $\begin{array}{r}0 \\
15 \\
15 \\
15\end{array}$ & $\begin{array}{r}.03 \\
2.04 \\
4.72 \\
.21\end{array}$ & $\begin{array}{r}2100 \\
49 \\
84 \\
3\end{array}$ & $\begin{array}{r}\text { trace } \\
2.09 \\
.91 \\
6.40\end{array}$ & $\begin{array}{l}0 \\
51 \\
16 \\
97\end{array}$ & $\begin{array}{l}5.63 \\
6.61\end{array}$ \\
\hline
\end{tabular}


Arsenic uptake by phytoplankton and Valonia

1. As(V). Phytoplankton batch cultures subjected to added amounts of As(V) take up additional arsenic during the log phase of growth. Studies using ${ }^{74}$ As (as $A s(V)$ ) indicate that the net uptake rate varies from $0.15 \mathrm{ng} \mathrm{As}(\mathrm{V}) \cdot \mathrm{hr}^{-1} \cdot 10^{6} \mathrm{cell}^{-1}$ in unenriched cultures to $2.3 \mathrm{ng} \mathrm{As}(\mathrm{V}) \cdot \mathrm{hr}^{-1}$ $.10^{6}$ cell $^{-1}$ in cultures containing $25 \mu \mathrm{g} \cdot \mathrm{1}^{-1}$ (Table 4, Figure 1). Cultured Skeletonema costation increase their arsenic concentrations approximately $40 \%$, from 22 to $29 \mathrm{ng} \cdot \mathrm{mg}^{-1}$ (Table 2, cultures 2-77-As, \$c-3-77) in response to arsenic additions of 6 to $25 \mu \mathrm{gg}^{-1}$. This arsenic increase appears to be largely independent of external arsenic concentrations, above $6 \mu \mathrm{g}: 1^{-1} \mathrm{As}(\mathrm{V})$ added. Peridinium trochoidium, on the other hand, concentrated large amounts of arsenic, and the concentration within the cells varied directly with the $A s(V)$ concentration of the media (Table 2, culture PT-9-77). Enrichments of up to 10 times occured when culture medium was enriched with $22 \mu g^{\cdot} 1^{-1}$ As $(V)$.

2. As(III). When cultures of $S$. costatum were enriched with As(III) (Table 2, culture SC-4-77), cellular arsenic concentrations also increased as above, about $40 \%$ with an enrichment of $1 \mu \mathrm{g} \cdot \mathrm{1}^{-1}$, and $90 \%$ with a 20 $\mu g \cdot 1^{-1}$ enrichment:

3. DMA. Cultures grown under conditions of DMA enrichment showed no increase in cellular arsenic concentration over the contrcl (Table 2, culture SC-4-78).

Additions of phosphate to culture media affected the uptake of ${ }^{74} \mathrm{As}$ (as $\mathrm{As}(\mathrm{V})$ ), at the several different arsenic concentrations tested (Table 4, Figure 1). Increased phosphate concentrations significantly decreased the uptake of arsenic in the culture $(p>.90-.99)$. Phosphate enrichment also reduced the total arsenic concentration found in $S$. 
Table 4. The uptake of ${ }^{74} \mathrm{As}$ by Skeletonema costatum subjected to a variety of $\mathrm{As}$ and $\mathrm{PO}_{4}$ concentrations, and linear regression analysis of the particulate activity over time. Significant differences between the slope of the control flask (no PO4 addition) and the treatment flasks are indicated.

\begin{tabular}{|c|c|c|c|c|c|c|}
\hline Flask & $\begin{array}{l}\text { As (V) } \\
\mu g \cdot \eta-1\end{array}$ & $\begin{array}{l}\mathrm{P} 04, \\
\stackrel{\mu M}{ } \\
\end{array}$ & $\begin{array}{c}\text { As (V) } \\
\text { uptake-i } \\
\text { ng.hr-1 }\end{array}$ & $\begin{array}{l}\text { ng As } \cdot h r^{-1} \\
10^{6} \text { cell }\end{array}$ & $t$ & $\begin{array}{c}\text { Significance } \\
\text { of } t\end{array}$ \\
\hline$A A$ & 1.5 & 0.07 & 1.3 & .15 & $\cdots$ & -.....- \\
\hline$A B$ & 1.5 & .08 & 1.2 & .14 & 1.34 & $.80<p<.90$ \\
\hline$A C$ & 1.5 & .24 & 1.2 & .14 & .94 & $.80<p .<.90$ \\
\hline$A D$ & 1.5 & 3.4 & 1.1 & .13 & 1.90 & $.90<p<.95$ \\
\hline $\mathrm{AE}$ & 6.5 & .07 & 5.2 & .67 & $\cdots$ & $\ldots \ldots$ \\
\hline AF & 6.5 & .08 & 4.4 & .52 & 2.72 & $.95<p<.975$ \\
\hline$A G$ & 6.5 & .24 & 5.1 & .60 & .34 & $.60<p<.70$ \\
\hline$A H$ & 6.5 & 3.4 & 4.9 & .58 & .81 & $.70<p<.80$ \\
\hline AI & 26.5 & .07 & 20 & 2.3 & $\cdots$ & $\cdots$ \\
\hline AJ & 26.5 & .08 & 16 & 1.9 & 2.09 & $.95<p<.975$ \\
\hline AK & 26.5 & .24 & 19 & 2.2 & .36 & $.60<p<.70$ \\
\hline$A L$ & 26.5 & 3.4 & 11 & 1.3 & 9.15 & $p>.9995$ \\
\hline
\end{tabular}


Figure 1. The effect of external As(V) concentration (in $\mu \mathrm{g} \cdot \mathrm{1}^{-1}$ ) and phosphate concentration: (in $\mu$ M ) on the $\dot{A s}(V)$ uptake rate, $V$, of SkeZetonema costatum (in $\mathrm{ng} \mathrm{As}(\mathrm{V}) \cdot \mathrm{hr}^{-1} \cdot 10^{6}$ cells $\mathrm{s}^{-1}$ ). Both significantly affect the uptake rate $(p>.99)$. 


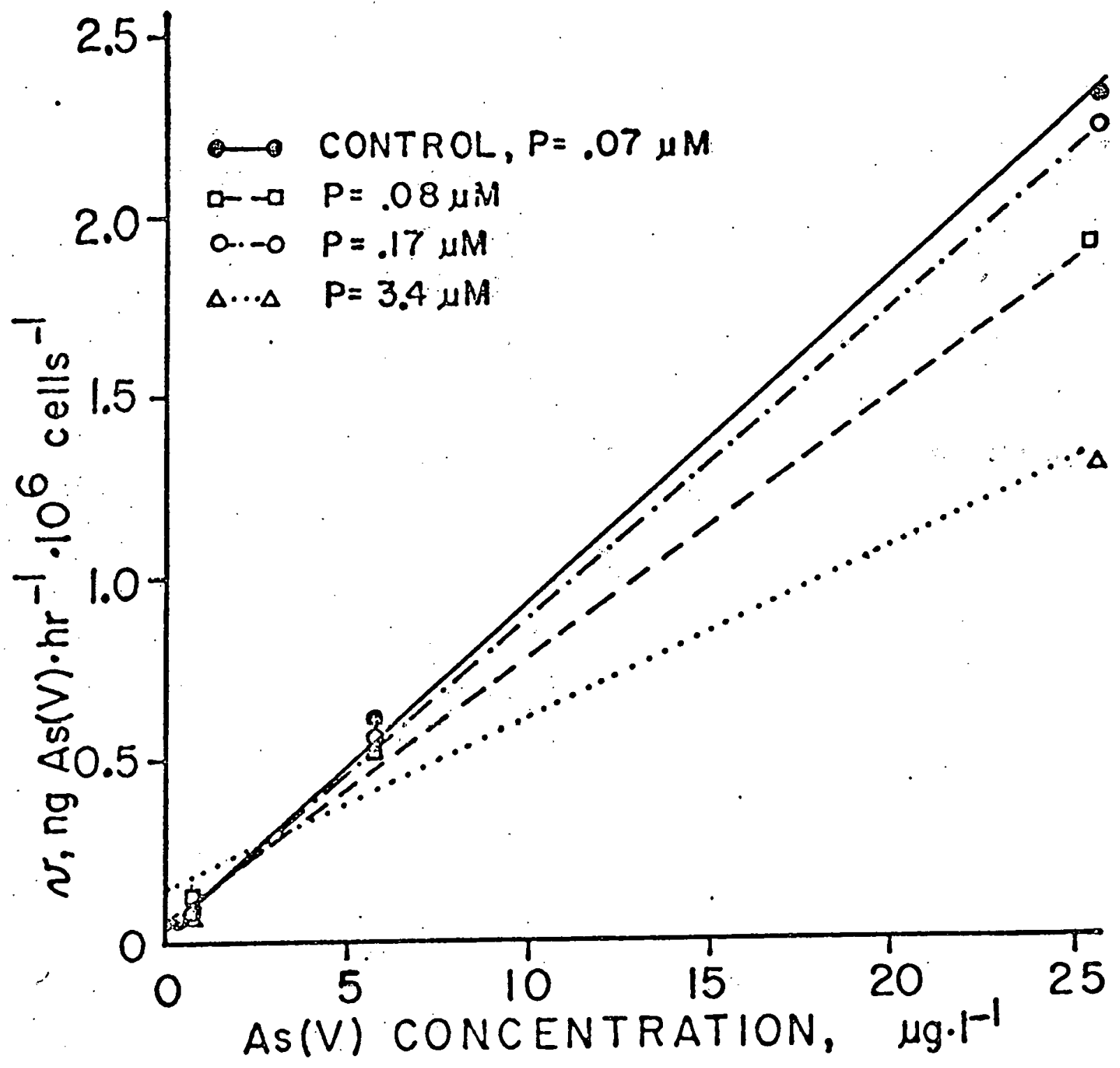


costatum grown under arsenic enrichment (Table 5), by an order of magnitude compared to cells grown without phosphate enrichment (Table 2).

The increased uptake of the various arsenic species from the culture media was small in comparison to total arsenic concentrations, so consequently, total arsenic concentrations in the various cultures remained unchanged (approximately $10 \mathrm{mg}$ cells per liter, uptake of approximately $10 \mathrm{ng} / \mathrm{mg}=100 \mathrm{ng}$, or less than $2 \%$ of total arsenic).

The uptake of arsenic by Vazonia macrophysa is much slower; however, cells grown in arsenic-enriched media for a period of 34 days (Table 3) did increase their arsenic content considerably. Cells grown in either As(III) or As(V) enriched media showed-large increases in arsenic content, while cells grown in media enriched with DMA showed very little uptake.

The increase that occured in Valonia cells was found primarily in the cell wall and cytoplasm. The central vacuole, which originally had been postulated to be a storage area for excess arsenic had concentrations three orders of magnitude less than the cell wall and cytoplasm, the arsenic concentration and speciation was similar to the concentration in the surrounding medium (Table 3 ). The reduction in total arsenic in the medium was due to uptake by the Vazonia, and not to loss of any kind from the culture dish.

\section{Arsenic speciation changes}

Arsenic speciation within the cell changes when cells are grown in arsenic enriched media. The inorganic/organic arsenic ratio in skeletonema cootatzon changed significantly $(.90<p<.95)$ from approximately $45 / 55$ to $30 / 70$ when grown in media enriched with As(V) (Table 2). No speciation changes were seen when $S$. costatum was grown in an As(III) or DMA enriched medium, or when Peridinium trochoidium was 
Tabie 5. As content and speciation in $S$. costatum cells grown in media enriched with $A s(V)$ and phosphate. As concentrations in $\mathrm{ng} \cdot \mathrm{mg}^{-1}$.

\begin{tabular}{|c|c|c|c|c|c|c|c|c|c|}
\hline Flask & $\begin{array}{l}\text { As conc } \\
\mu g \cdot 1-1 \\
\end{array}$ & $\begin{array}{l}P \text { conf } \\
\mu \mathrm{g} \cdot \mathrm{I}^{-f}\end{array}$ & As: $\mathrm{PO}_{4}$ & $\begin{array}{c}\text { Inorganic } \\
\text { As }\end{array}$ & $(\%)$ & $\begin{array}{c}\text { Organic } \\
\text { As }\end{array}$ & $(\%)$ & Total & $\begin{array}{c}\% \\
\text { of Control } \\
\end{array}$ \\
\hline $\begin{array}{l}A \\
B \\
C \\
C\end{array}$ & $\begin{array}{r}0 \\
15 \\
15 \\
15\end{array}$ & $\begin{array}{r}16 \\
16 \\
3 \\
82\end{array}$ & $\begin{array}{l}1: 15 \\
1: 1 \\
5: 1 \\
1: 5\end{array}$ & $\begin{array}{l}1.04(.64-1.44) \\
1.55(1.41-1.69) \\
1.39(1.23-1.55) \\
1.51(1.23-1.79)\end{array}$ & $\begin{array}{l}70 \\
64 \\
63 \\
72\end{array}$ & $\begin{array}{l}0.45(.3-.59) \\
.86(.7-1.03) \\
.82(.8-.83) \\
.59(.45-.73)\end{array}$ & $\begin{array}{l}30 \\
36 \\
37 \\
28\end{array}$ & $\begin{array}{l}1.49 \\
2.41 \\
2.21 \\
2.10\end{array}$ & $\begin{array}{l}--- \\
162 \\
148 \\
141\end{array}$ \\
\hline
\end{tabular}


grown in an As(V) enriched medium (Table 2 ).

Valonia cells grown in arsenic-enriched medium had significant $(p>.95)$ inorganic/organic arsenic ratio shifts of $75 / 25$ to $58 / 42$, with the largest change occurring under As(V) enrichment (Table 3 ).

Arsenic speciation changes within the seawater medium are much more drastic (Table 6). After one week of Skeletonema costatum growth, the concentration of As(V) in the media is reduced by approximately one-half, while both $A s$ (III) and DMA increase. Figures $2 a, b, c$ show the rate at which the above speciation changes occurred in SC-1-78. It is interesting to note that all of the As(V) reduction (and subsequent increase of As(III) and DMA) occurs during the log phase of cell growth. No As(V) reduction occurs while the population is in the stationary growth phase.

When cultures were enriched with As(III), as in SC-4-77 (Figure 3), the As(III) concentration rapidly decreased with time. This decrease is due mainly to the chemical oxidation of As(III) to As(V) (Figure 4, discussed below) and is difficult to separate from any biologically mediated transformations. However, the concentration of As(III) in the control sample did increase (Figure 3), and DMA increased in all three flasks.

No significant speciation changes occurred in cultures that had been enriched with DMA (Table 7), other than the changes caused by the addition of the DMA itself.

Chemical oxidation of arsenite.

The chemical oxidation of As(III) was studied by adding $5 \mu \mathrm{g} \cdot \mathrm{l}^{-1}$ of As(III) to filtered seawater that had been treated in 3 different ways: 1) glass fiber filtered, 2) filtered then autoclaved, and 3) filtered then UV irradiated. These three samples were placed in 2 temperatures, 
Table 6. As speciation changes in culture media, culture SC-3-77, one week after inoculation with skeletonema costatum. As concentrations in $\mu \mathrm{g} \cdot \mathrm{j}^{-1}$.

\begin{tabular}{|c|c|c|c|c|c|c|}
\hline Flask & $\begin{array}{l}\text { As }(V) \\
\mu g \cdot 1-1\end{array}$ & $(\%)$ & $\begin{array}{l}\operatorname{As}(\text { III) } \\
\mu \mathrm{g} \cdot \mathrm{i}-1\end{array}$ & $\left(\begin{array}{c}\infty \\
0\end{array}\right)$ & $\begin{array}{c}\text { DMA } \\
\mu g \cdot 1-1\end{array}$ & (\%) \\
\hline $\begin{array}{l}A, \text { no As } \\
A \text {, control }\end{array}$ & $\begin{array}{l}1.2 \\
1.1\end{array}$ & $\begin{array}{l}80 \\
74\end{array}$ & $\begin{array}{l}.12 \\
.12\end{array}$ & $\begin{array}{l}8 . \\
8\end{array}$ & $\begin{array}{l}.18 \\
.27\end{array}$ & $\begin{array}{l}12 \\
18\end{array}$ \\
\hline $\begin{array}{l}\mathrm{B}, 12.5 \mu \mathrm{g} \mathrm{As}(\mathrm{V}) / \mathrm{I} \\
\mathrm{B}, \text { control }\end{array}$ & $\begin{array}{r}7.0 \\
12.5\end{array}$ & $\begin{array}{l}50 \\
89\end{array}$ & $\begin{array}{l}2.5 \\
.56\end{array}$ & $\begin{array}{r}18 \\
4\end{array}$ & $\begin{array}{l}4.5 \\
.98\end{array}$ & $\begin{array}{r}32 \\
7\end{array}$ \\
\hline $\begin{array}{l}\text { C, } 25 \mu \mathrm{g} \mathrm{As}(\mathrm{V}) / 1 \\
\text { C. control }\end{array}$ & $\begin{array}{l}10.6 \\
23.6\end{array}$ & $\begin{array}{l}40 \\
89\end{array}$ & $\begin{array}{l}7.2 \\
1.1\end{array}$ & 27 & $\begin{array}{l}8.5 \\
1.9\end{array}$ & $\begin{array}{r}32 \\
7\end{array}$ \\
\hline
\end{tabular}


Figure 2. Arsenic speciation changes with time in a Skeletonema costation culture, SC-7-78. 2a. Reduction of As(V). 2b. Formation of As(III). 2c. Formation of DMA. Quantities are expressed as \% of total arsenic. Arsenic enrichment: A-no As(V) added, B-5 $\mu \mathrm{g} \mathrm{As}(V) \cdot 1^{-1}, C-25 \mu \mathrm{g} A s(V) \cdot 1^{-1}$. Total arsenic remained unchanged during the course of the experiment. 


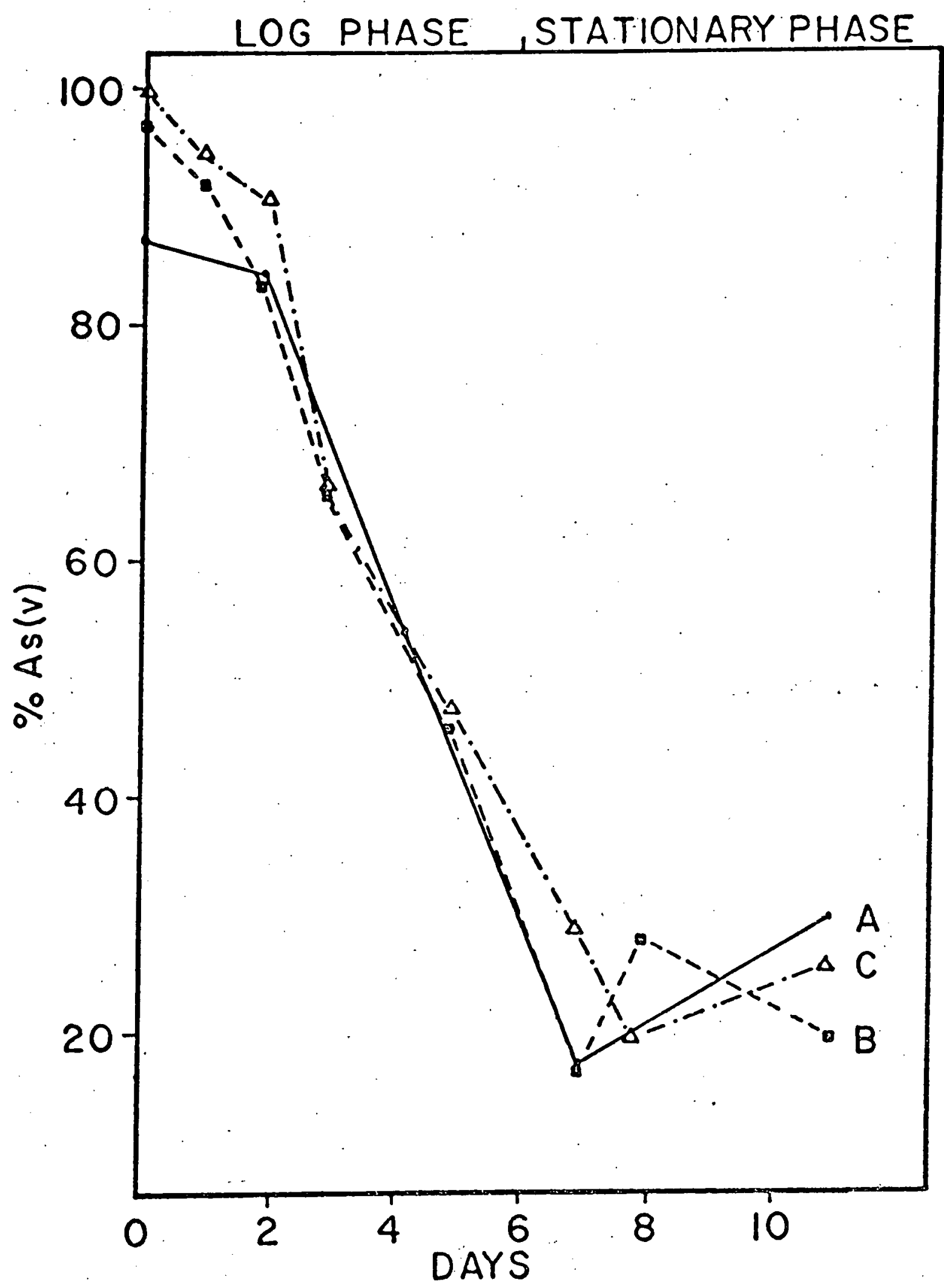




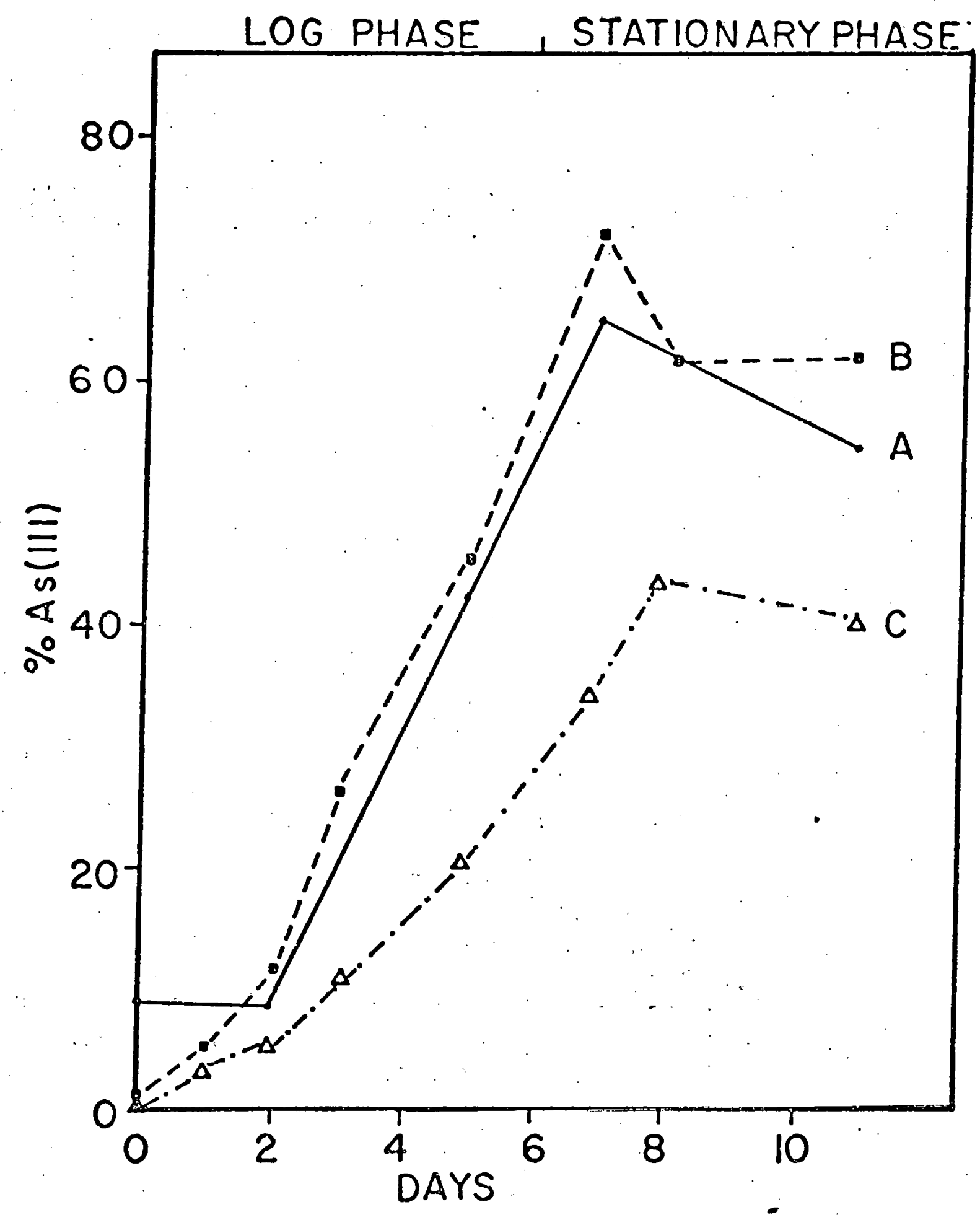




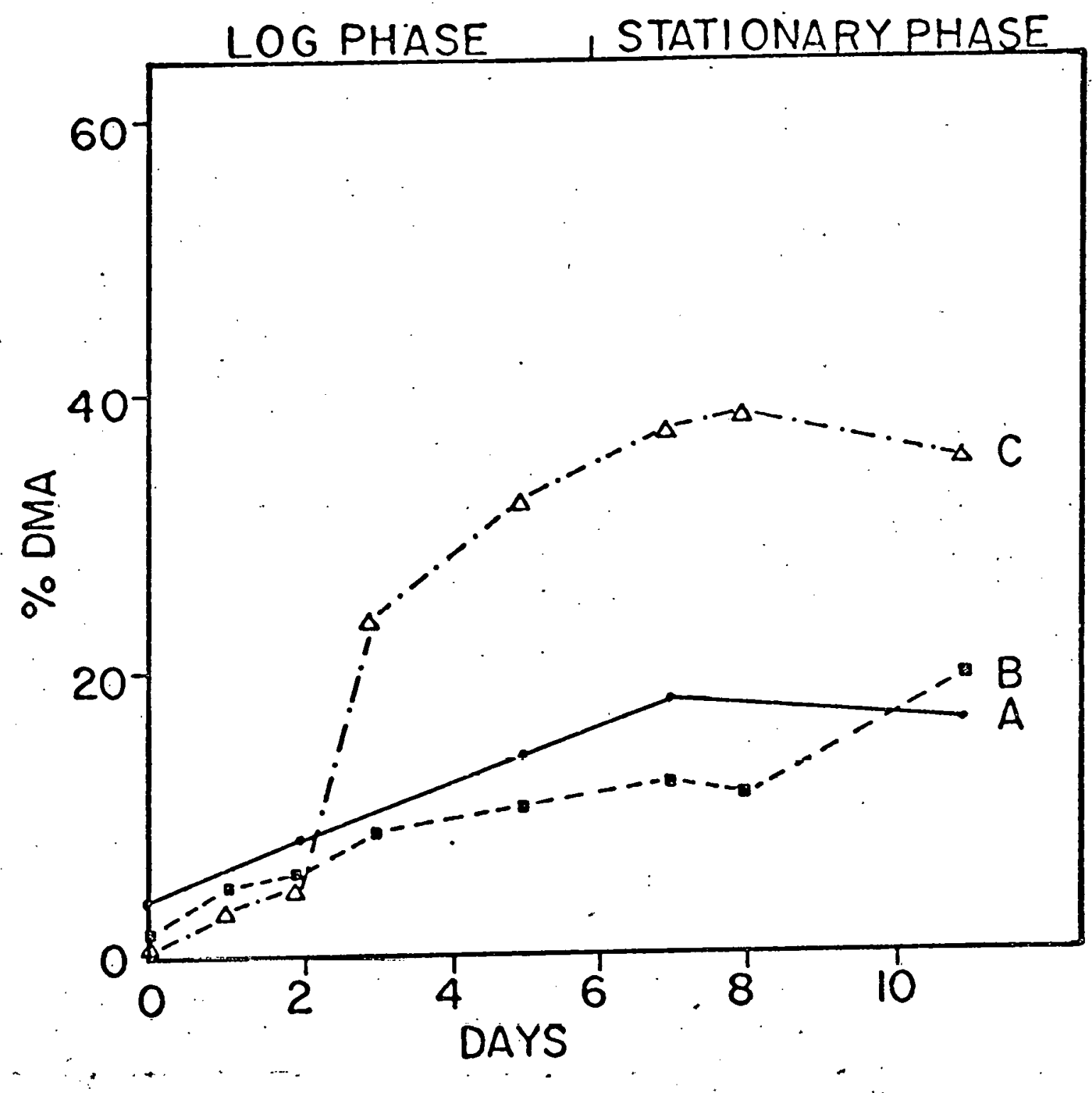


Figure 3. The oxidation of As(III) with time in a Skeletonema costatron culture, SC-4-77. Arsenic enrichment: A-no As(III) added, B-1 $\mu$ g As(III) $1^{-1}, C-20 \mu \mathrm{g} \mathrm{As}$ (III) $\cdot 1^{-1}$. 


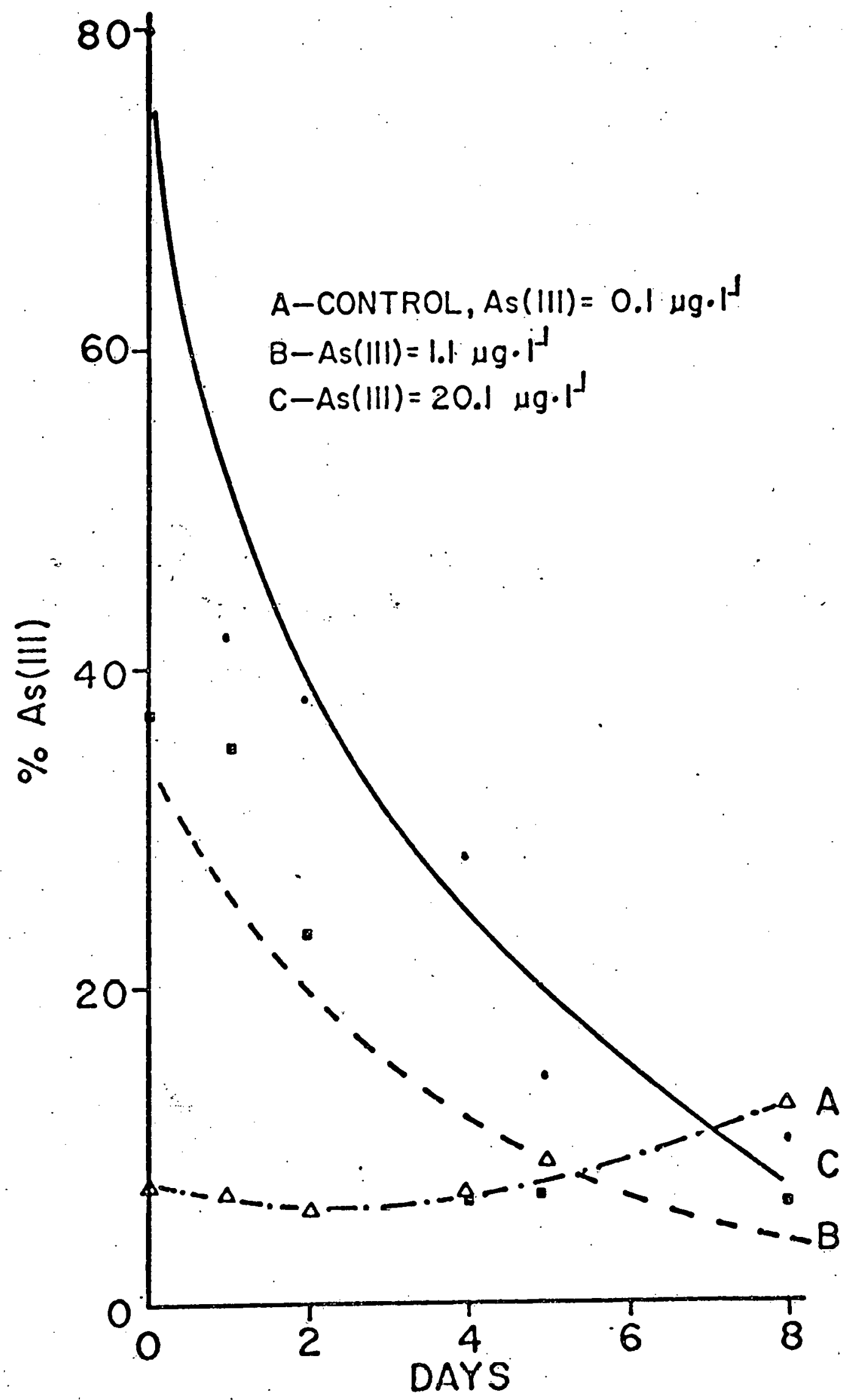


Table 7. As speciation chances in culture SC-4-DMA-77, at beginning of experiment, and $i$-days after inoculation with Skeletonema costatum. As concentrations in $\mu \dot{g} \cdot 7-1$.

\begin{tabular}{|c|c|c|c|c|c|}
\hline Flask & $\begin{array}{l}\text { As }(V) \\
\mu g \cdot 1-1\end{array}$ & $(\%)$ & $\begin{array}{l}A s(I I I) \\
\mu g .7-I\end{array}$ & $\left(x_{1}^{\prime}\right.$ & $\begin{array}{l}\text { DMA } \\
\mu g .7-1\end{array}$ \\
\hline $\begin{array}{l}\text { no DMA } \\
\text { after } 7 \text { days }\end{array}$ & $\begin{array}{l}1.2 \\
1.2\end{array}$ & $\begin{array}{l}79 \\
80\end{array}$ & $\begin{array}{l}.14 \\
.06\end{array}$ & $\begin{array}{l}9 \\
4\end{array}$ & $\begin{array}{l}.18 \\
.24\end{array}$ \\
\hline $\begin{array}{l}5 \mu \mathrm{g} D M A / 1 \\
\text { after } 7 \text { days }\end{array}$ & $\begin{array}{l}1.2 \\
2.1\end{array}$ & $\begin{array}{l}18 \\
33\end{array}$ & $\begin{array}{l}.26 \\
.32\end{array}$ & $\begin{array}{l}4 \\
5\end{array}$ & $\begin{array}{l}5.1 \\
4.0\end{array}$ \\
\hline $\begin{array}{l}10 \mu \mathrm{g} \text { DMA/1 } \\
\text { after } ? \text { days }\end{array}$ & $\begin{array}{l}2.3 \\
2.9\end{array}$ & $\begin{array}{l}20 \\
25\end{array}$ & $\begin{array}{l}.34 \\
.46\end{array}$ & $\begin{array}{l}3 \\
4\end{array}$ & $\begin{array}{l}8.9 \\
8.2\end{array}$ \\
\hline
\end{tabular}


170 and $27^{\circ} \mathrm{C}$, and allowed to incubate for 50 days. Aliquots were withdrawn at frequent intervals, and the arsenic speciation determined.

The chemical oxidation of As(III) was found to be slow; concentrations decreased exponentiallyy (Figure 4). There was no significant difference between the rate of oxidation in any of the three treatments, but the oxidation rate was somewhat faster at $27^{\circ} \mathrm{C}$ (significance, .80<p<.90). The equations generated for the two different temperatures are:

$$
\begin{aligned}
& \log Y=-0.0126 X+1.77, \text { at } 17^{\circ} \mathrm{C} \text {, and } \\
& \log Y=-0.0161 X+1.49, \text { at } 27^{\circ} \mathrm{C} \text {, }
\end{aligned}
$$

where $X$ is time in days and $Y$ is As(III) expressed as \% of total arsenic.

Speciation changes in controlled ecosystem enclosures (CEPEX)

"The Controlled Ecosystem Pollution Experiment (CEPEX) is a cooperative, multidisciplinary research effort designed to test the effects of chronic exposure to low levels of pollutants on pelagic marine organisms" (Menzel and Case, 1977).

As part of the on-going CEPEX project, three $\frac{1}{4}$-scale enclosures $\left(68 \mathrm{~m}^{3}\right)$ were used to study the biogeochemical cycling of arsenic. The enclosures are described in detail by Menzel and Case (1977). One enclosure was used as a control, while the other two received arsenic enrichments of either As(V) or As(III) equaling $5 \mu \mathrm{g} \cdot \mathrm{7}^{-1}$. Arsenic concentration and speciation, nutrient concentration, chlorophyll a, particulate carbon, and phytoplankton abundance and productivity were monitored periodically from 30 June to 21 July 1977 . The total arsenic concentration of both enclosures did not vary during the course of the experiment.

The speciation of arsenic in the controlled ecosystem enclosures (CEE) followed a pattern similar to that seen in cultures, but the 
Figure 4. The chemical oxidation of $A s$ (III) at $17^{\circ}$ and $27^{\circ} \mathrm{C}$ over the long term. $F=$ filtered, UV=UV irradiated, $A=$ autoclaved 
$\dot{m}$

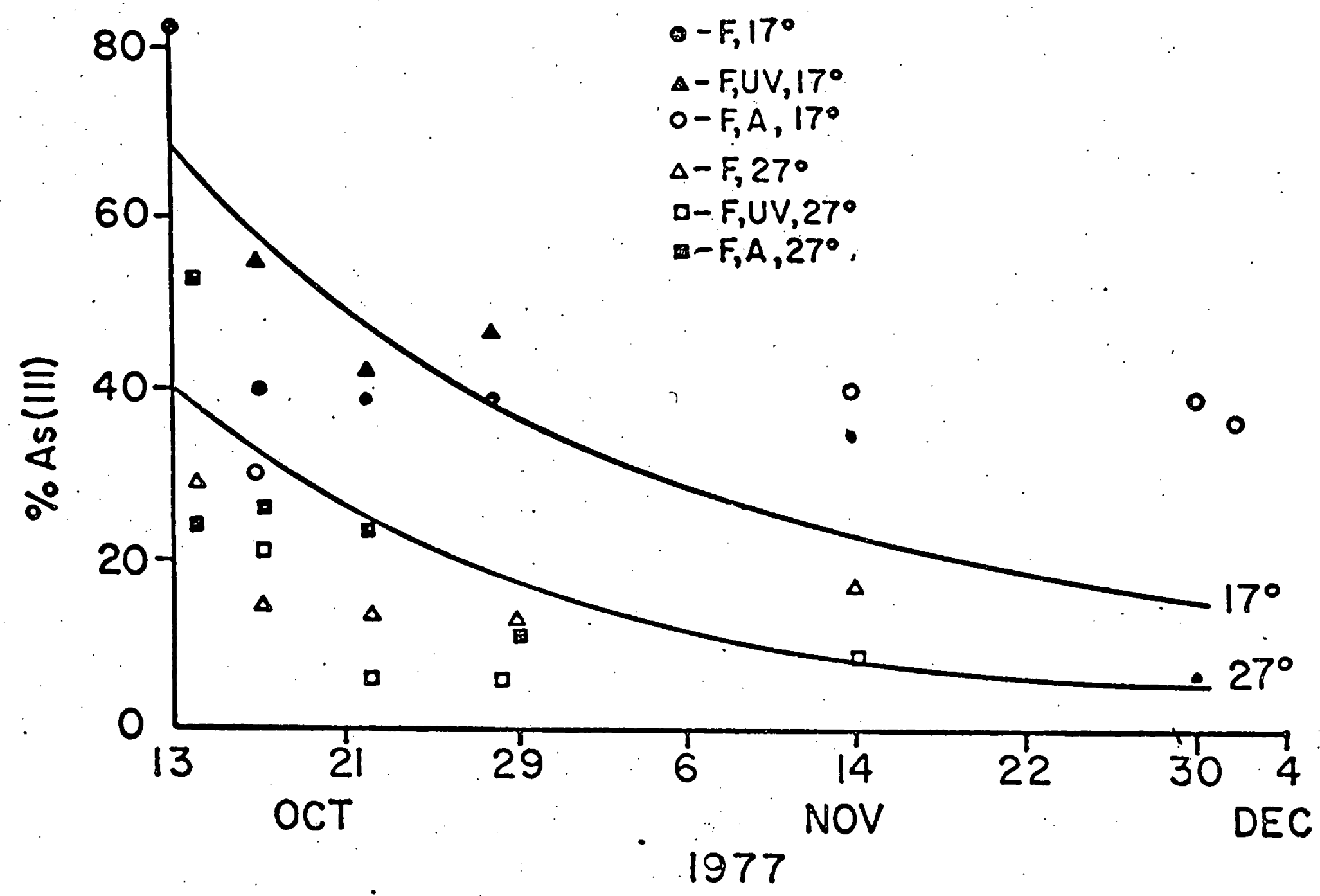


speciation changes were not as large. CEE-B, which received As(V) enrichment equivalent to $5 \mu \mathrm{g} \cdot \mathrm{l}^{-1}$, had a gradual, significant $(p>.999)$ decrease in the As $(V)$ concentration from a maximum of $88 \%$ of total arsenic at the start of the experiment to a minimum of $72 \%$ on 11 July, 12 days after As $(V)$ addition. After this period, no significant changes in arsenic speciation occured (Figure 5). Although the enclosures were sampled at three different depths, no significant differences were seen between them, and the results from all depths were averaged. Primary productivity in CEE-B increased until 11 July, and then decreased (not shown). Both As(III) and DMA increased steadily during the 21 days from approximately 6 to $14 \%$ of total arsenic:

Arsenic speciation changes in CEE-C, the enclosure containing $5 \mu \mathrm{g} \cdot \mathrm{I}^{-1}$ of As(III) was quite different (Figure 6). As(III) concentration decreased from an initial $82 \%$ of total to $24 \%$ by 11 July, then began to increase slowly. Arsenate increased with decreasing As(III), and then decreased slightly. DMA increased from approximately $4 \%$ to $12 \%$.

Arsenic consentrationn and speciation in the surrounding Saanich Inlet did not vary during the course of the experiment. Total arsenic concentration was $1.41 \mu \mathrm{g} \cdot 1^{-1}$, with $A s(V)$ equaling $1.16 \mu g \cdot 7-1$. Small amounts of As(III) (0.06) and DMA (0.19) were also present.

Bacterial interactions with arsenic speciation

on one uccasion, freshly collected offshore water was filtered through a $0.6 \mu \mathrm{m}$ Nucleopore filter. This filtration effectively removes autotrophs, but leaves $60-80 \%$ of all bacterial activity (Azam and Hodson, 1977). The water was placed in a 2 liter flask; and incubated just as the phytoplankton cultures.

Culture BAC-4-78 was monitored for 10 days. No significant changes 
Figure 5. Arsenic speciation changes with time, expressed as $\%$ of total arsenic, and phytoplankton carbon, in $\mathrm{mg} \mathrm{C} \cdot \mathrm{1}^{-1}$, in CEE-B. $5 \mathrm{\mu g} \mathrm{As}(\mathrm{V}) \cdot 7^{-1}$ were added on 30 June 1977. 
in

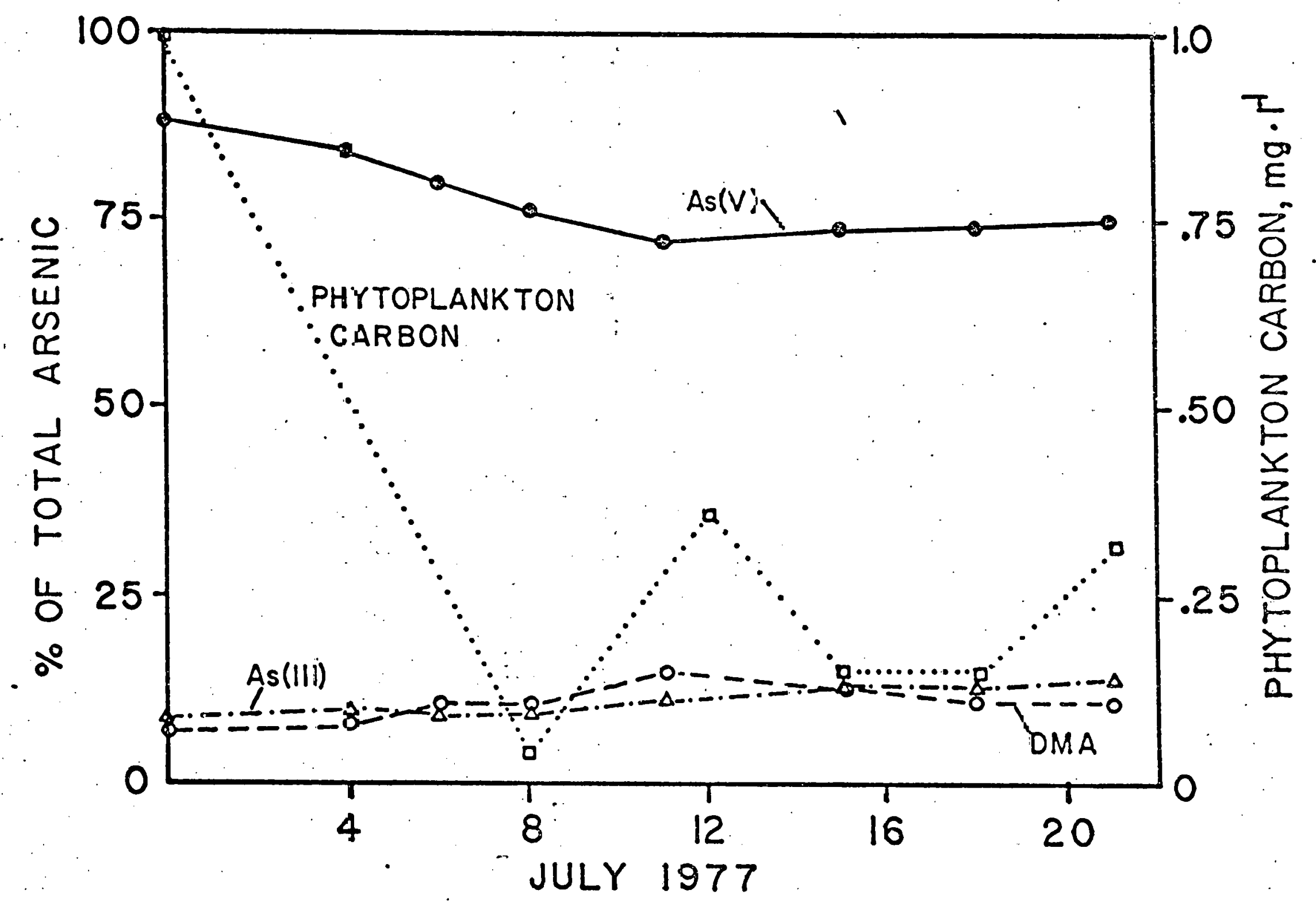


is

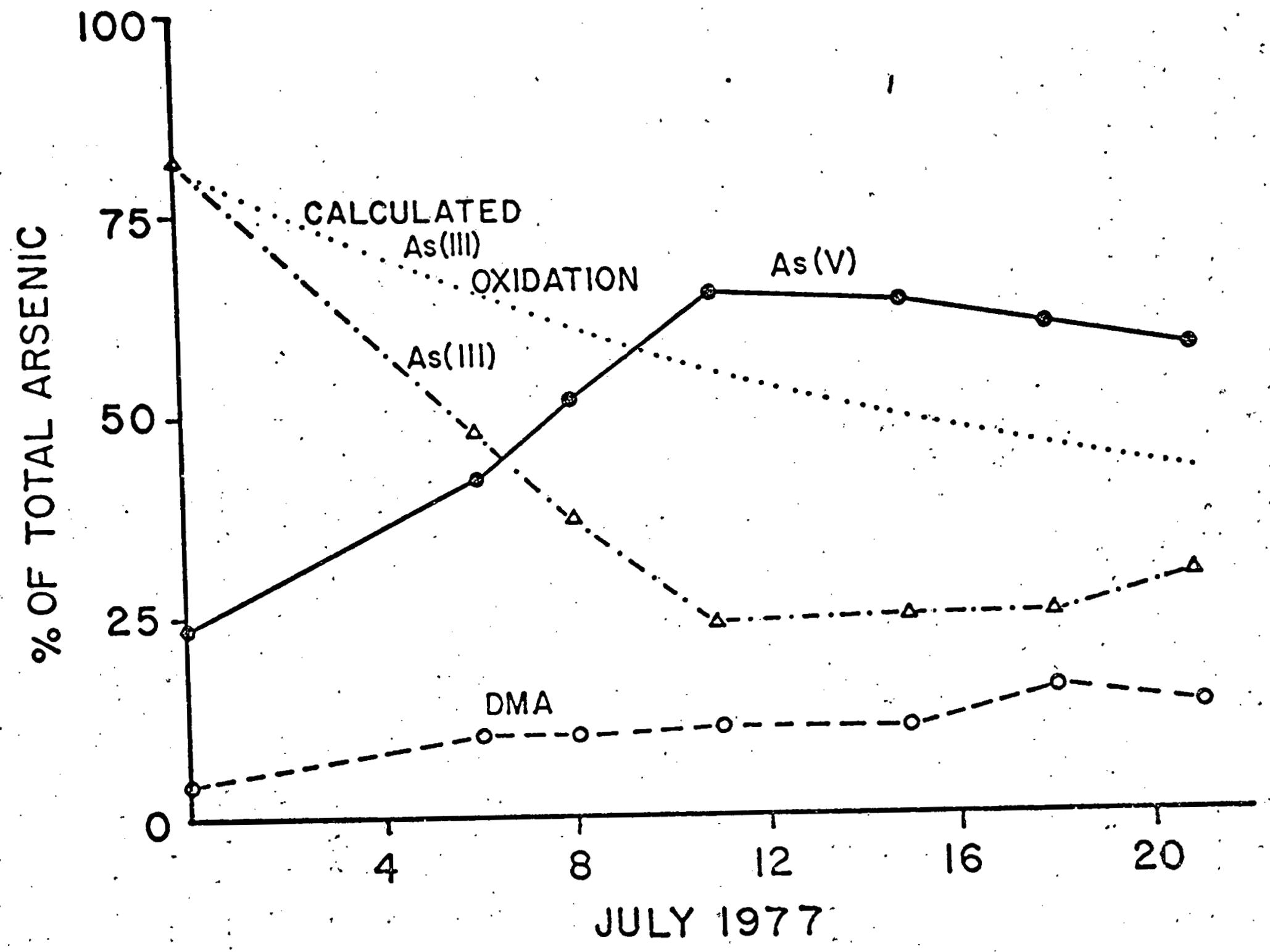


Figure 6. Arsenic speciation changes with time, expressed as $\%$ of total arsenic, in CEE-C. The calculated As(III) oxidation rate is also plotted. $5 \mu \mathrm{g} \mathrm{As}$ (III) $\cdot \mathrm{I}^{-1}$ were added on 30 June 1977. 
in arsenic speciation occurred during this period. Arsenate remained about $1 \mu \mathrm{g} \cdot 1-1$, As(III) averaged $0.09 \mu \mathrm{g} \cdot \mathrm{1}^{-1}$, and DMA remained at $0.20 \mu \mathrm{g} \cdot 1^{-1}$.

\section{Arsenic volatility}

In December 1977, a 12 liter culture of Skeletonema costation was grown in media enriched with $25 \mu \mathrm{g} \cdot 1^{-1}$ of $A s(V)$ to determine if arsenic is volatilized by phytoplankton. After the culture reached stationary growth, the airspace was pumped through a silver coated, glass bead packed tube (Braman, 1975) which adsorbs arsenic species. The tubes were then rinsed with a $2 \mathrm{~N} \mathrm{NaOH}$ solution to remove the arsenic.: The resulting solution was then neutralized, and analyzed for arsenic species. No volatile species were released, even though a large amount of arsenic was reduced by the culture.

\section{C:N ratio}

The $\mathrm{C}: \mathrm{N}$ ratio in Skeletonema costatrom and Valonia cultured in enriched arsenic media was found to vary significantiy from the control (Table 8 ). In both cases, the $C: N$ ratio of cells grown in $A s(V)$ was less than cells grown in other enrichments, or in control media. This reduction of the ratio was primarily due to reduction in the carbon content of both the Valonia and the Skeletonema cultures.

Arsenic inhibition of productivity

The effect of arsenic on primary productivity over the entire growth cycle was evident in cultures enriched with As(V). Growth rate in culture 2-77-As (Figure 7, Table 9) was significantly inhibited by concentrations greater than $12.5 \mu \mathrm{g} \cdot \mathrm{1}^{-1}$. It is interesting to note that the lowest $A s(V)$ addition, $6 . \mu \mathrm{g} \cdot 1^{-1}$, caused a significant growth enhancement; however, this population peaked four days early and did not 
38.

Table 8. Carbon and Nitrogen content of Valonia and Ske Zetonema costatum grown under conditions of As enrichment.

Valonia

\begin{tabular}{cccc} 
As added, $\mu \mathrm{g} \cdot 1^{-1}$ & qC & \%N & C:N \\
\hline Control, no As & $14.8 \pm 2$ & $1.3 \pm .15$ & $11.4: 1$ \\
As (V), 15 & $8.8 \pm 0$ & $1.6 \pm .1$ & $5.5: 1$ \\
As (III), 15 & $14.3 \pm 2.5$ & $1.2 \pm .1$ & $11.9: 1$ \\
DMA, 15 & $14.8 \pm .3$ & $1.7 \pm .1$ & $8.7: 1$
\end{tabular}

Skeletonema costatum

\begin{tabular}{|c|c|c|c|}
\hline As added, $\mu \mathrm{g} \cdot 1^{-1}$ & C, mg. 1-1 & $N, \mu g \cdot 1^{-1}$ & $\underline{C: N}$ \\
\hline $\begin{array}{c}\text { Control, no As } \\
\text { As (V), } 25 \\
\text { As (III) } 220 \\
\text { DMA. } 20\end{array}$ & $\begin{array}{l}2.17 \pm .06 \\
1.07 \pm .05 \\
2.71 \pm 0 \\
2.29 \pm .13\end{array}$ & $\begin{array}{l}115 \pm .5 \\
120 \pm .7 \\
145 \pm .3 \\
104 \pm .8\end{array}$ & $\begin{array}{l}19.7: 1 \\
13.3: 1 \\
18.7: 1 \\
22.2: 1\end{array}$ \\
\hline
\end{tabular}


Figure 7. Relative growth of a Skeletonema costation culture, 2-77-As. Arsenic enrichment: A-no As(V) added, B-6 $\mu \mathrm{g} \cdot \mathrm{As}(\mathrm{V}) \cdot 1^{-1}, \mathrm{C}-12 . \mu \mathrm{g}$ As(V). $1^{-1}, D-25 \mu \mathrm{g} \mathrm{As}(\mathrm{V}) \cdot 1^{-1}$. 
ㅇํํ

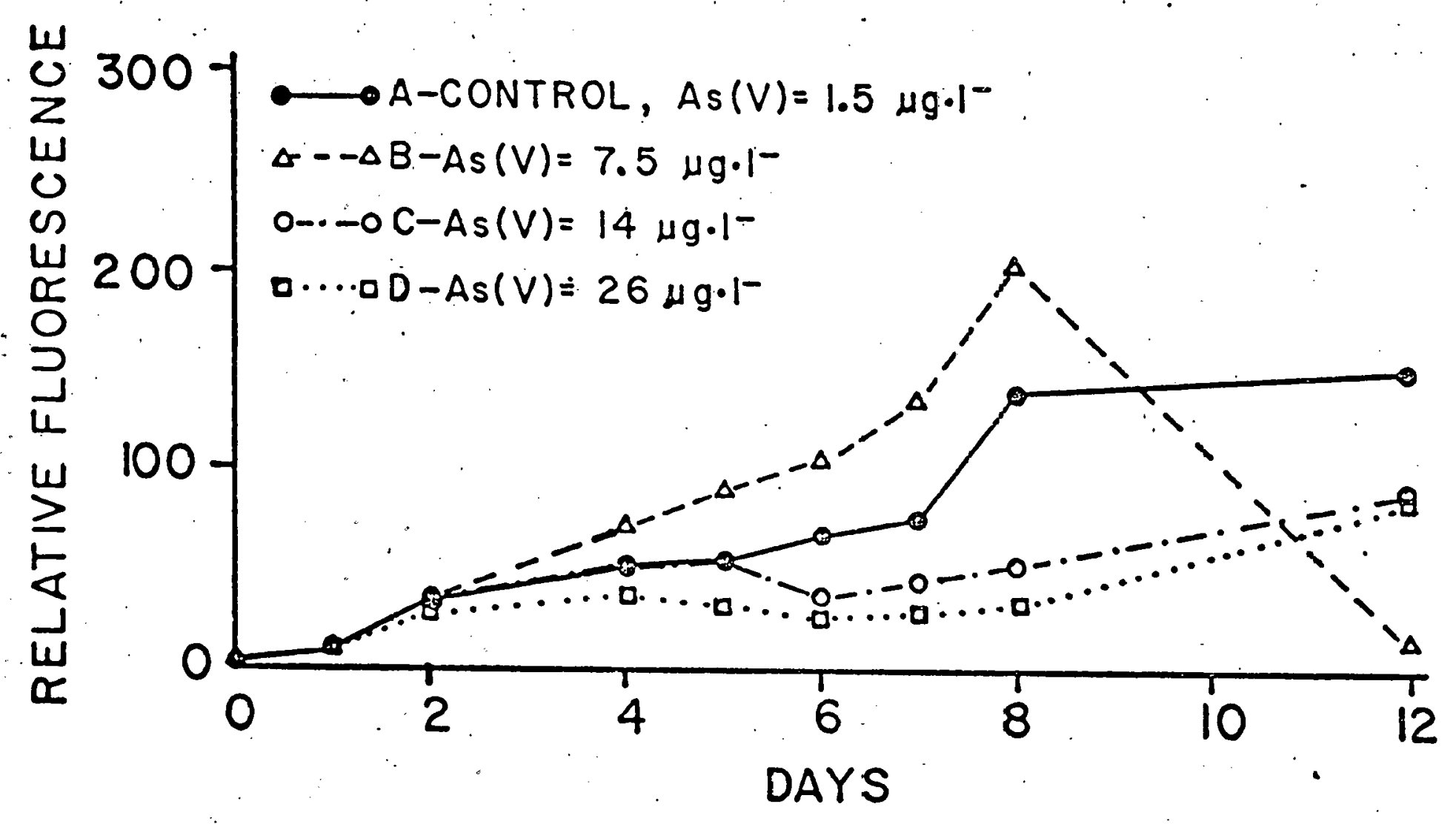


Table 9. Linear regression analysis of $\log$ transformations (log relative fluorescence versus time) of batch culture growth curves during the log phase of growth. Significant differences between the slope of the control flask and the treatment flasks are indicated.

2-77-As (As(V) enrichment, Figure 7)

Added

Flask $\begin{aligned} & \text { As }(V) \\ & \mu g \cdot j^{-1}\end{aligned}$ Slope $\begin{gathered}Y \\ \text { Intercept } t\end{gathered} \quad \begin{gathered}\text { Significance } \\ \text { of } t\end{gathered}$

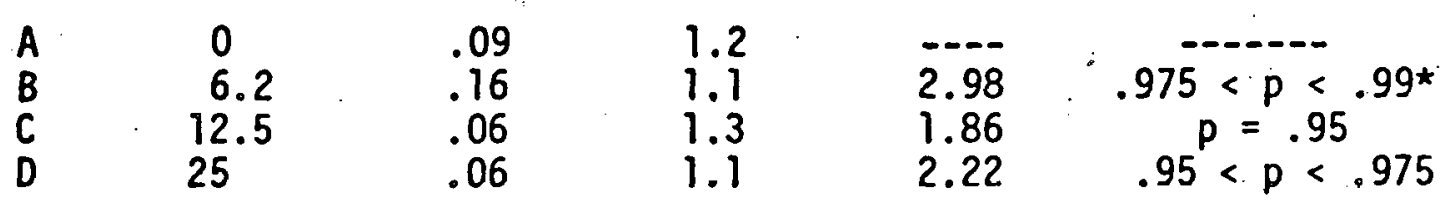

* $B$ has greater slope than control, indicating increased growth due to As $(V)$ addition; however, see text.

SC-3-77 (As(V) enrichment, Figure 8)

\section{Added}

Flask $\begin{gathered}\text { As }(V) \\ \mu g \cdot 1-1\end{gathered} \quad$ Slope $\begin{gathered}Y \\ \text { Intercept } t\end{gathered}$

$\begin{array}{llll}\text { A } & 0 & .09 & 2.1 \\ \text { B } & 12.5 & -.04 & 2.3 \\ \text { C } & 25 & -.08 & 2.3\end{array}$

Significance of $t$

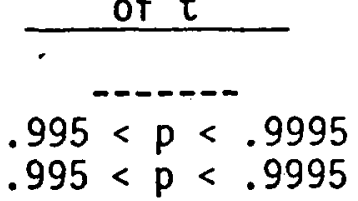

PT-9-77 (As (V) enrichment, Figure 9)

\begin{tabular}{|c|c|c|c|c|c|}
\hline Flask & $\begin{array}{l}\text { Added } \\
\text { As }(V) \\
\mu g \cdot 1-1\end{array}$ & Slope & $\begin{array}{c}Y \\
\text { Intercept }\end{array}$ & $t$ & $\begin{array}{c}\text { Significance } \\
\text { of } t \\
\end{array}$ \\
\hline $\begin{array}{l}A \\
B \\
C \\
D\end{array}$ & $\begin{array}{l}0 \\
2.5 \\
5 \\
10\end{array}$ & $\begin{array}{l}.13 \\
.10 \\
.12 \\
.13\end{array}$ & $\begin{array}{l}0.8 \\
1.1 \\
0.9 \\
0.8\end{array}$ & $\begin{array}{r}--.- \\
.65 \\
1.58 \\
.77\end{array}$ & $\begin{array}{l}.70<p<.80 \\
.90<p<.95 \\
.70<p<.80\end{array}$ \\
\hline
\end{tabular}


enter a stationary growth phase, but immediately died. Inhibition of growth following As(V) addition was also seen in cultures SC-3-77 (Figure 8, Table 9) and in PT-9-77 (Figure 9, Table 9), al though the significance of the inhibition was not as strong in the latter. Arsenite additions also caused significant growth inhibition, as demonstrated in culture SC-4-77 (Figure 10, Table 10). Enrichment with DMA, however, apparently had no effect on growth (Figure 11, Table 10).

Arsenic additions also affected short-term productivity, as measured by ${ }^{14} \mathrm{C}$ uptake. Arsenate additions of $5 \mu \mathrm{g} \cdot 7^{-1}$ or greater significantly inhibit carbon uptake by cells during both $\log$ and stationary growth phases (Figure 12). Arsenite also inhibits carbon uptake (Figure 13), however, DMA additions apparently do not significantly affect productivity (Figure 14).

Additions of phosphate $(20 \mu \mathrm{M})$ to the media eliminated the As(V) inhibition of carbon uptake (Figure 12). Cultures grown under conditions of phosphate enrichment of 0.1 to $2.5 \mu \mathrm{M}$ (SC-11-77, Figure 15, Table 10), were also not affected by $A s(V)$ additions of $15 \mu \mathrm{g} \cdot 1^{-1}$. The culture in flask $D$ was even stimulated because of the higher level of phosphate present.

The results of the As(V)-phosphate test-tube experiment indicate the reduction of arsenic toxicity by increased concentrations of phosphate. The growth rate $(\mu)$ of test-tube cultures grown under varying As(V) and phosphate concentrations was calculated using the following equation:

$$
\mu \text { (in divisions per day) }=35 \frac{\left(\ln n_{t}-\ln n_{0}\right)}{t-t_{0}}
$$

(Eppley and Strickland, 1968), where $n_{t}=$ population density at time $t$, 
Figure 8. Relative growth of a Skeletonema costatum culture, SC-3-77. Arsenic enrichment: A-no As(V) added, B-12.5 $\mu \mathrm{g} \mathrm{As}(\mathrm{V}) \cdot \mathrm{I}^{-1}, \mathrm{C}-25 \mu \mathrm{g}$ $\operatorname{As}(V) \cdot 1^{-1}$. 


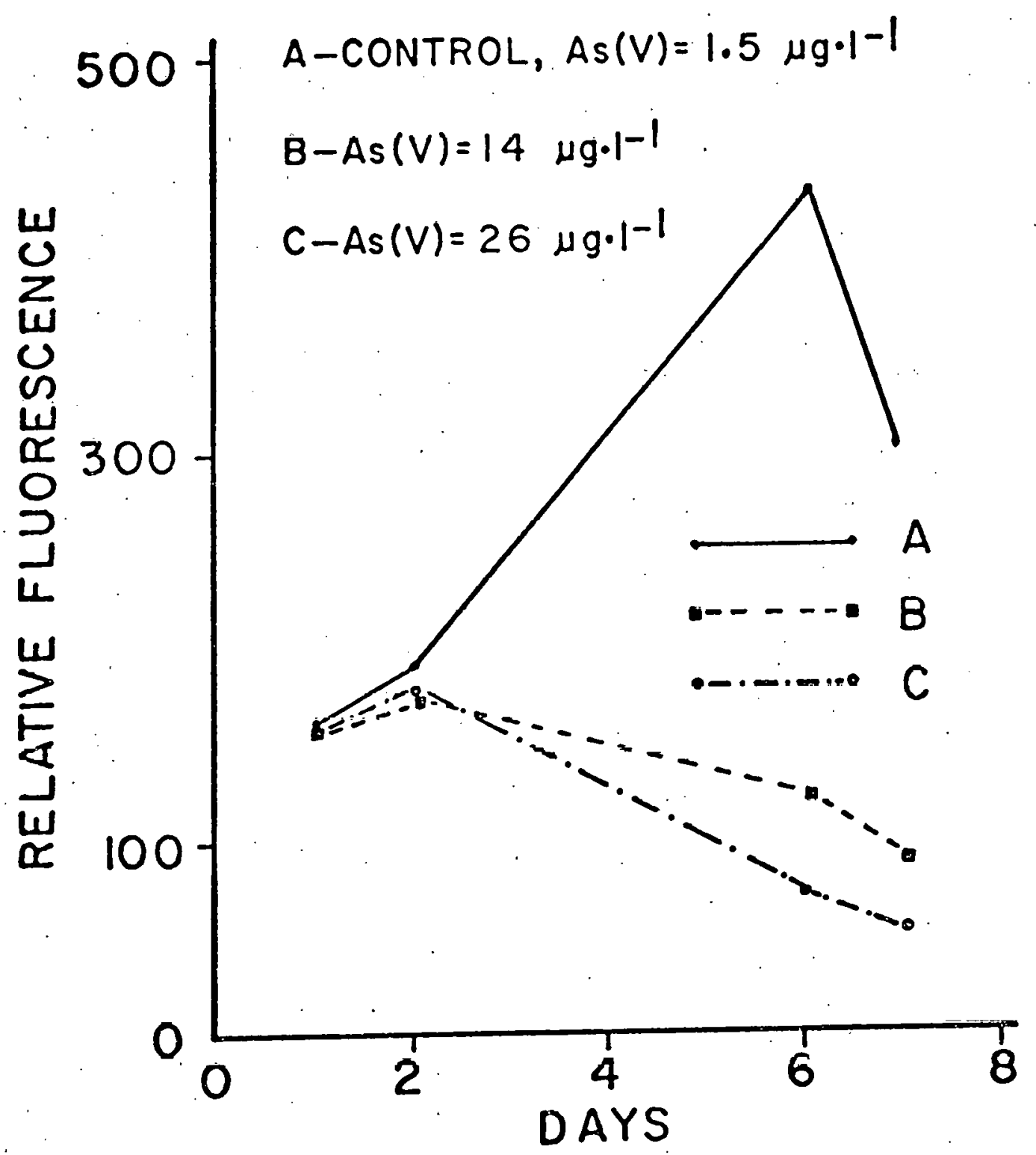


Figure 9. Relative growth of a Peridinizm trochoidizon culture, PT-9-77. Arsenic enrichment: A-no As $(V)$ added, $B-2.5 \mu \mathrm{g} \mathrm{As}(V) \cdot 7^{-1}$ (on day 6 , $20 \mu \mathrm{g} \cdot 1^{-1}$ added), $C-5 \mu \mathrm{g} \mathrm{As}(\mathrm{V}) \cdot 1^{-1}, \mathrm{D}-10 \mu \mathrm{g} \mathrm{As}(\mathrm{V}) \cdot 1^{-1}$. 
$\dot{\xi}$

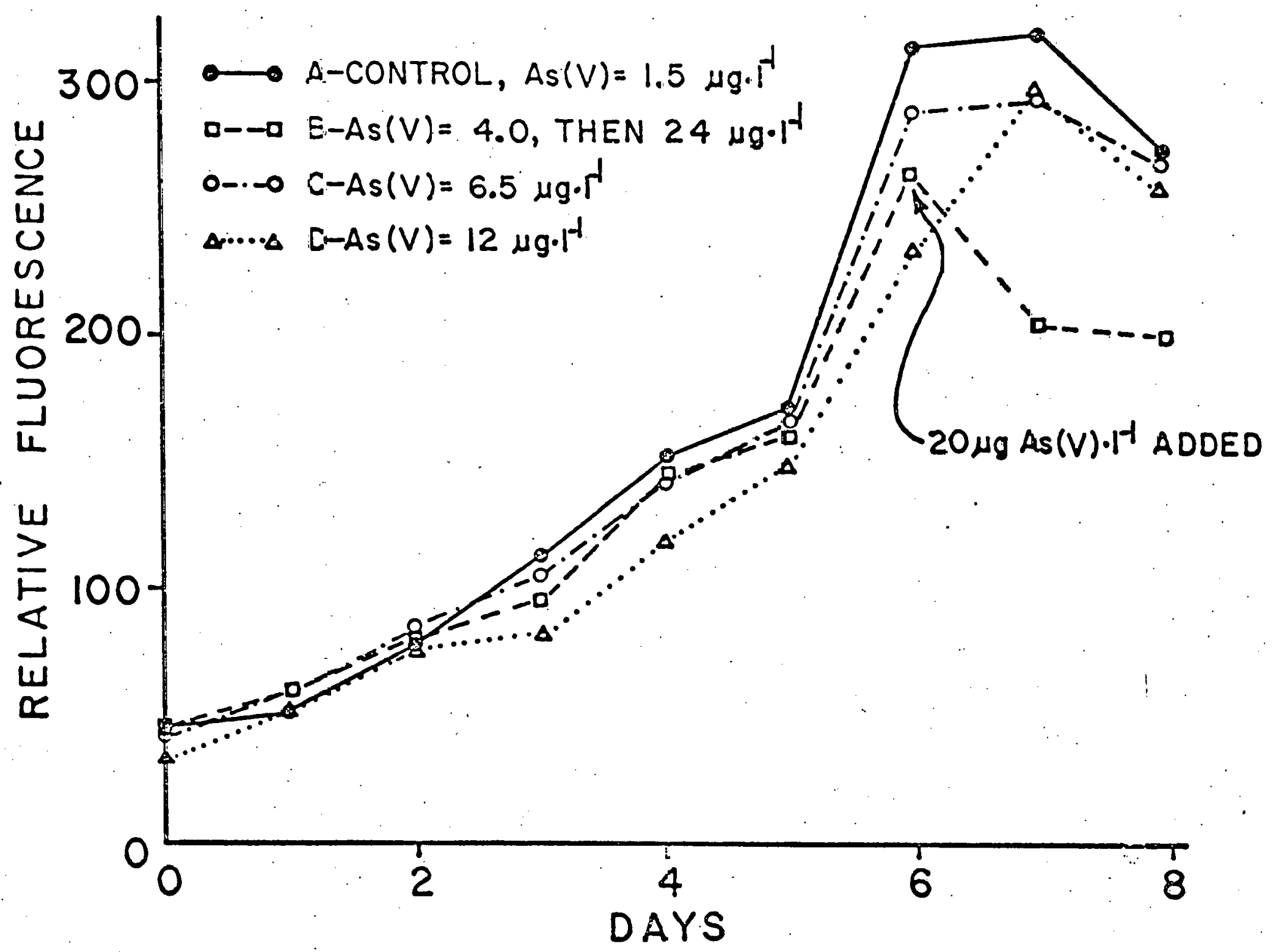


Figure 10. Relative growth of a Skeletonema costatum culture, SC-4-77. Arsenic enrichment: A-no As(III) added, B-1 $\mu \mathrm{g} \mathrm{As}($ III $) \cdot 1^{-1}, \mathrm{C}-20 \mu \mathrm{g}$ $\operatorname{As}($ III $) \cdot 1^{-1}$. 


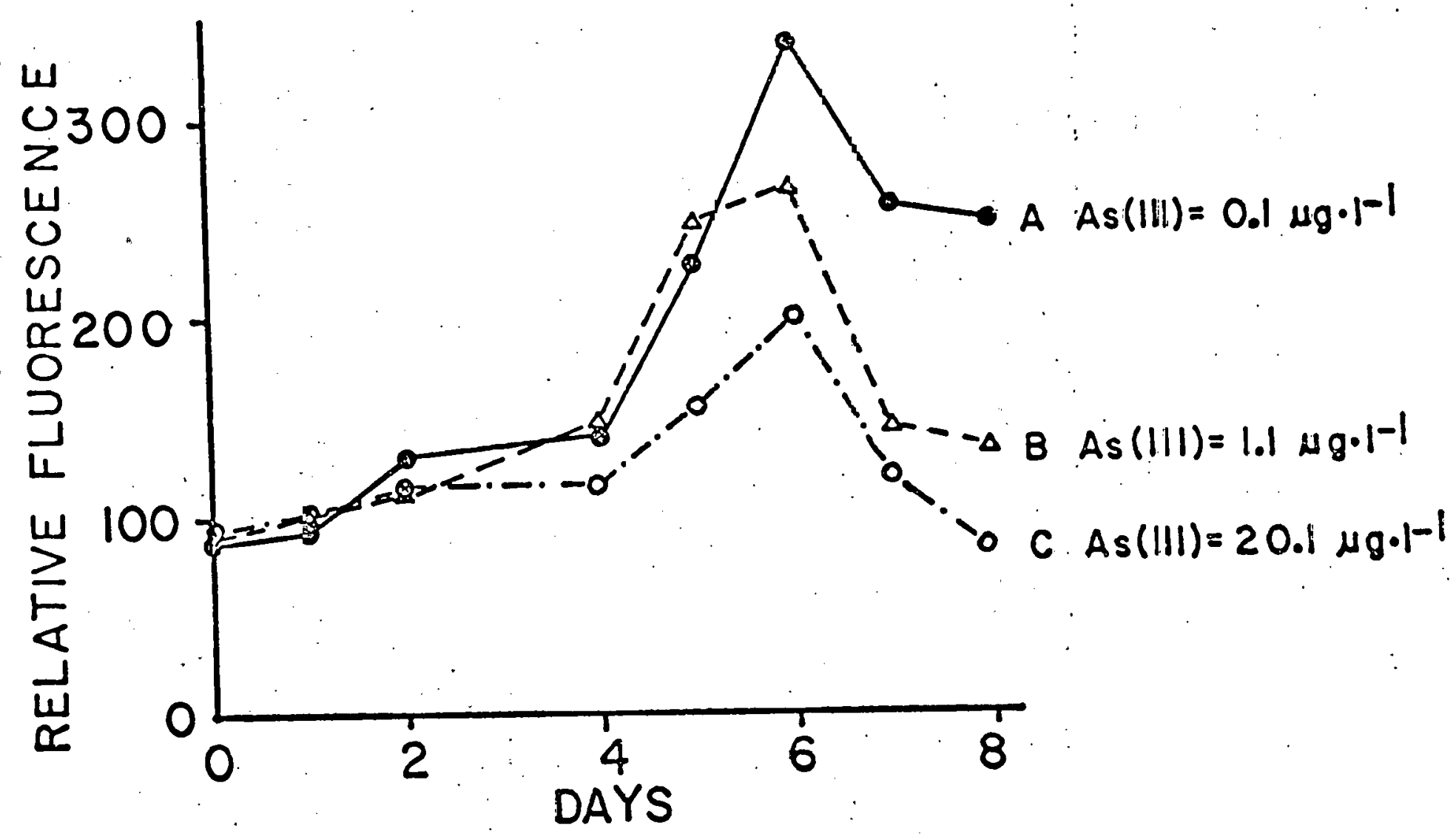


Table 10. Linear regression analysis of log transformations (log relative fluorescence versus time) of batch culture growth curves during the log phase of growth. Significant differences betiveen the slope of the control flask and the treatment flasks are indicated.

SC-4-77 (As(III) enrichment, Figure 10)

Added

As(III)

Flask

$A$
$B$
$C$

$\mu \mathrm{g} \cdot \mathrm{I}^{-1}$

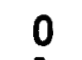

1

20

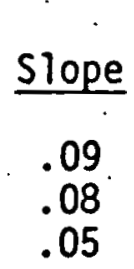

.08

\section{$Y$}

Intercept

1.9

1.9

1.9
Significance

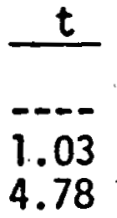
of $t$

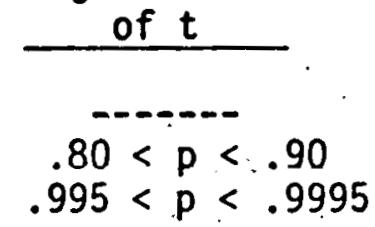

SC-4-DMA-77 (DMA enrichment, Figure 11)

Added

Flask $\quad \begin{gathered}\text { DMA } \\ \underline{\text { g }} \cdot \mathrm{l}^{-1}\end{gathered}$

C

0
10 slope
.11
.11
$Y$

Intercept

2.0

2.1
Significance

of $t$

$\underline{t}$

220

$p<.60$

SC-11-77 (As(V), $\mathrm{PO}_{4}$ enrichment, Figure 12)

Added Added

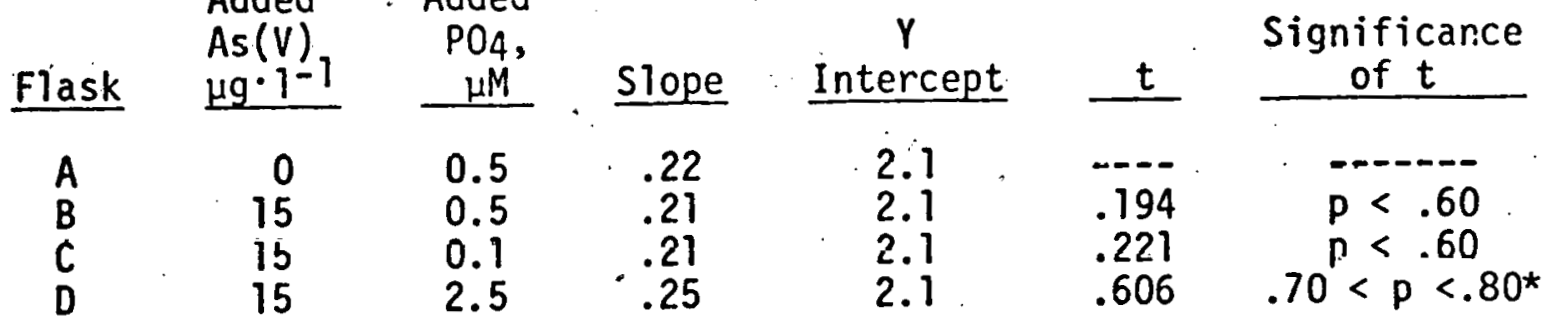

${ }^{*} D$ has greater slope than control, indicating enrichment caused by excess $\mathrm{PO}_{4}$. 
Figure 11. Relative growth of a skeletonema costatum culture, SC-4-DMA-77. Arsenic enrichment: A-no DMA added, $C-10 \mu \mathrm{g} D M A \cdot 7^{-1}$. Culture flask $B$ received a smaller inoculum of celis, and is not shown. 


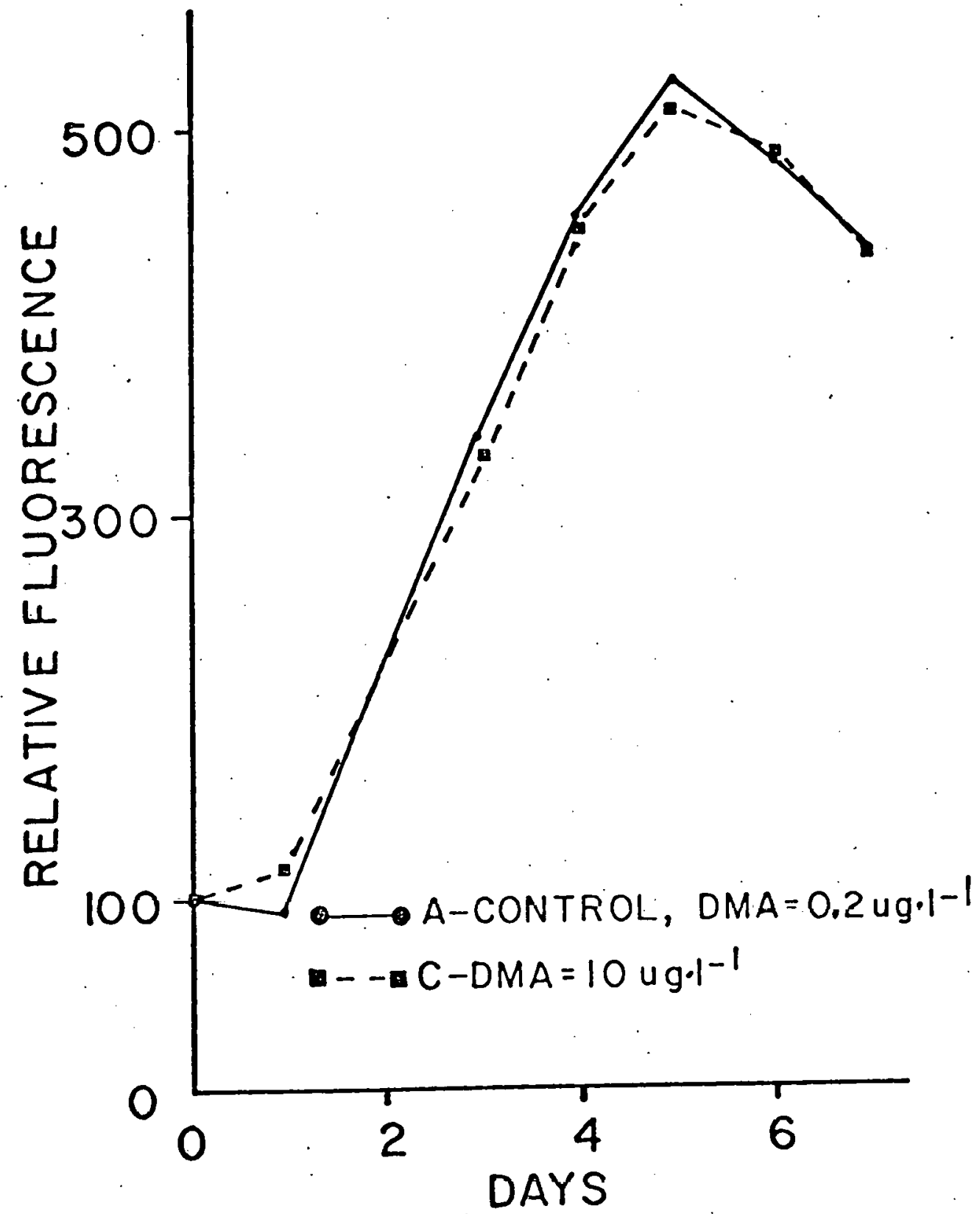


Figure 12. Four hour ${ }^{14} \mathrm{C}$ uptake by Skeletonema costatum cultures in both $\log$ and stationary growth phase that have been exposed to As(V) additions. Expressed as \% of control activity. Each point is the average of 5 replicate determinations. The effect of additional phosphate $(20 \mu \mathrm{M})$ is also shown. The reduction in uptake is significant $(p>.99)$. 


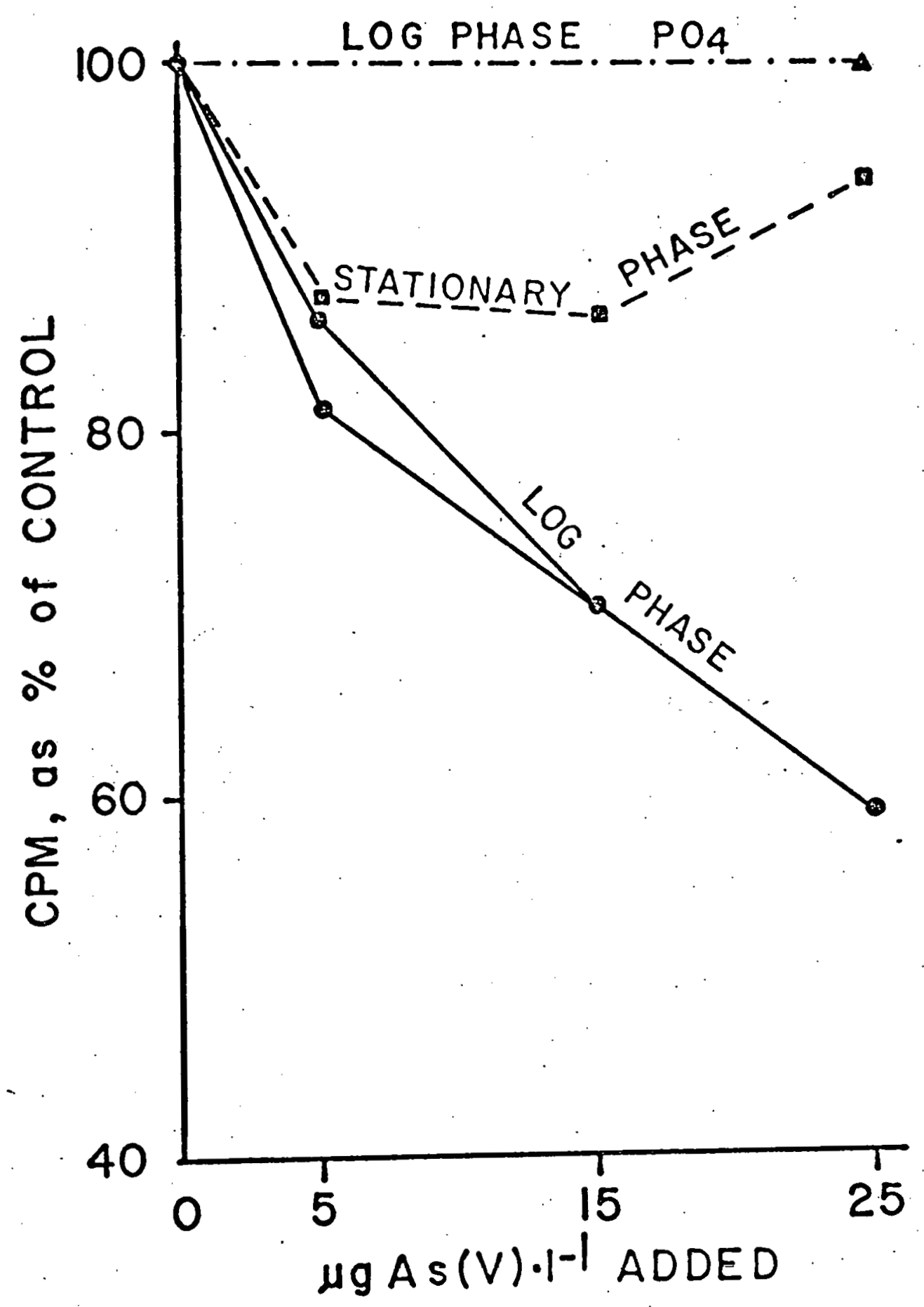


Figure 13. Four hour ${ }^{14} \mathrm{C}$ uptake by Skeletonema costatum cultures in both $\log$ and stationary growth phase that have been exposed to As(III) additions. Expressed as \% of control activity. Each point is the average of 5 replicate determinations. The reduction in uptake is significant $(p>.99)$. 
48.

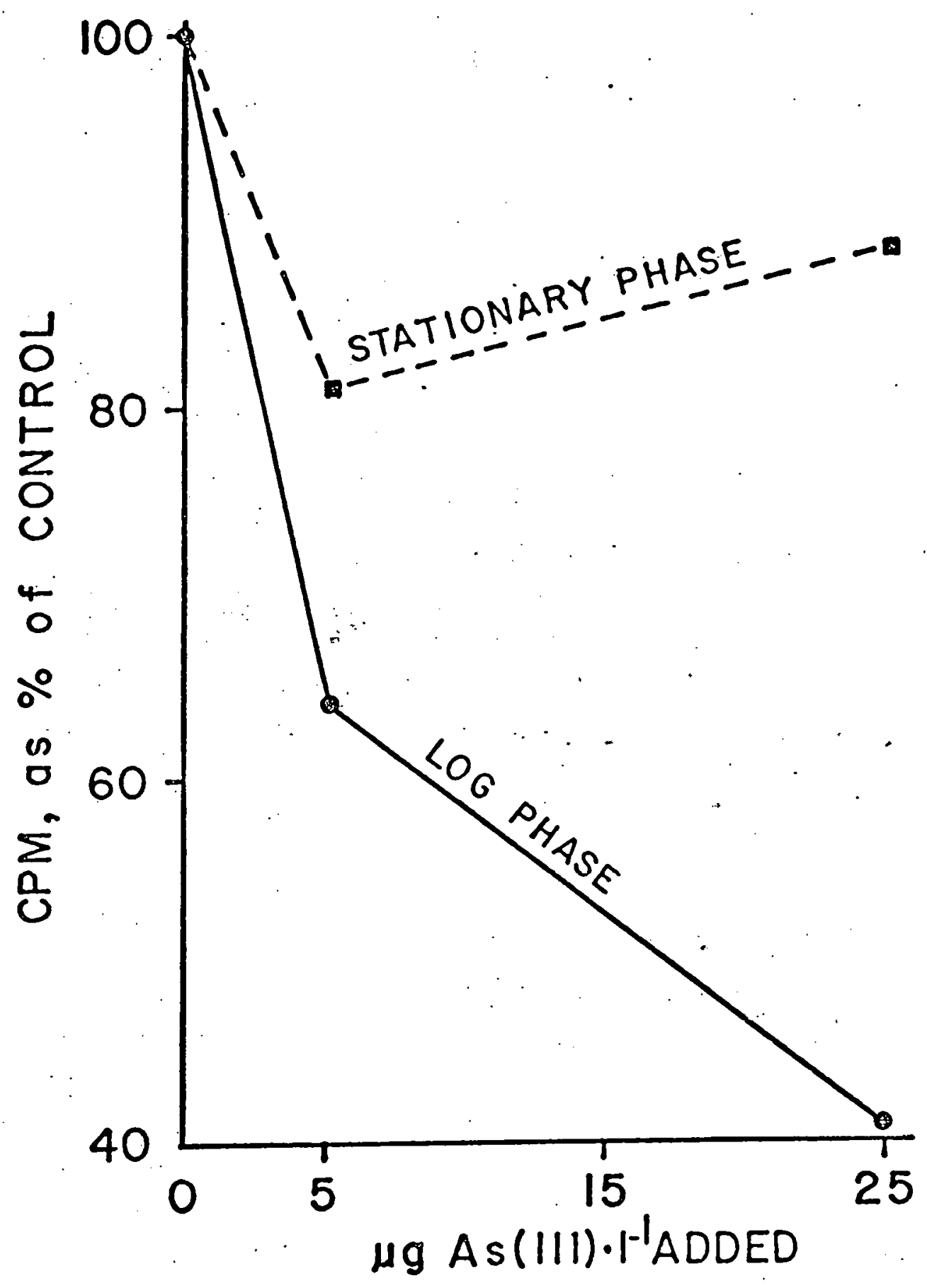


Figure 14. Four hour ${ }^{14} \mathrm{C}$ uptake by Skeletonema costatum cultures in both $\log$ and stationary growth phase that have been exposed to DMA additions. Expressed as \% of control activity. Each point is the average of 5 replicates. There was no significant reduction in activity $(p<.60)$. 
49.

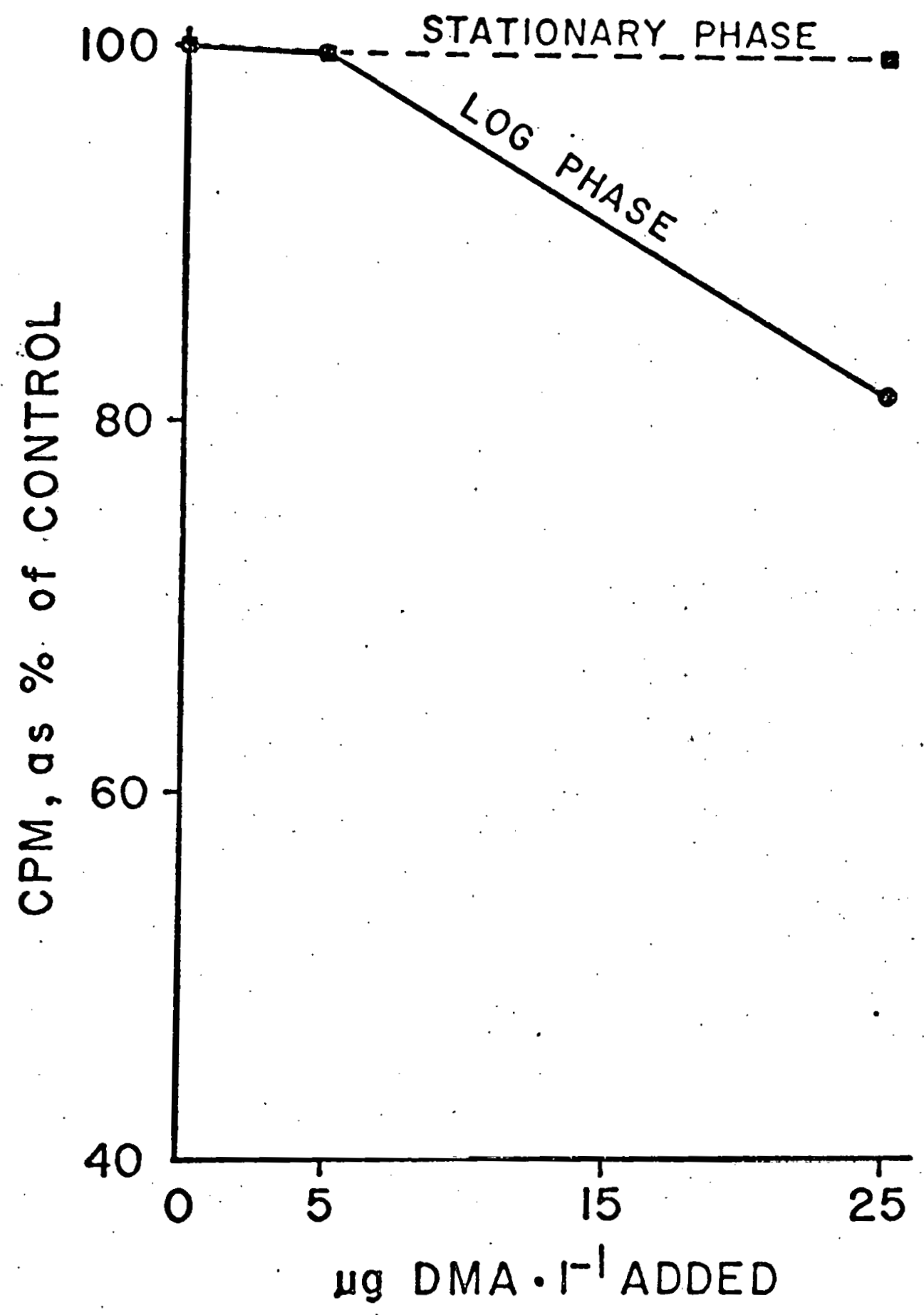




\section{-}

Figure 15. Relative growth of a Skeietonema costatum culture, SC-11-77.

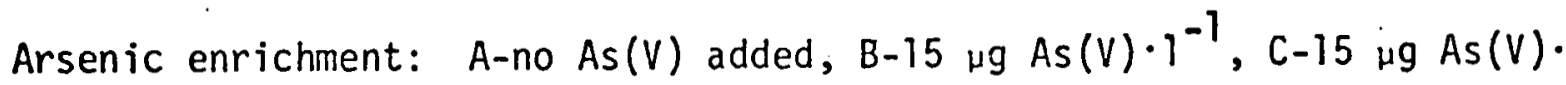

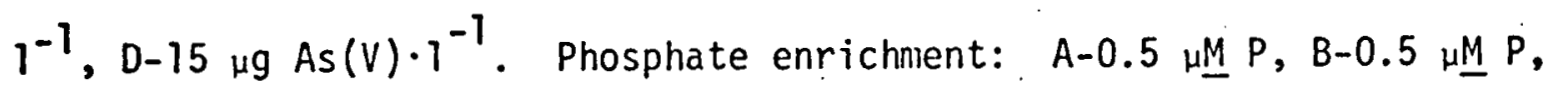

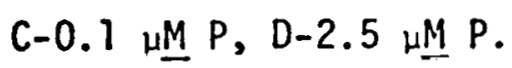


50.

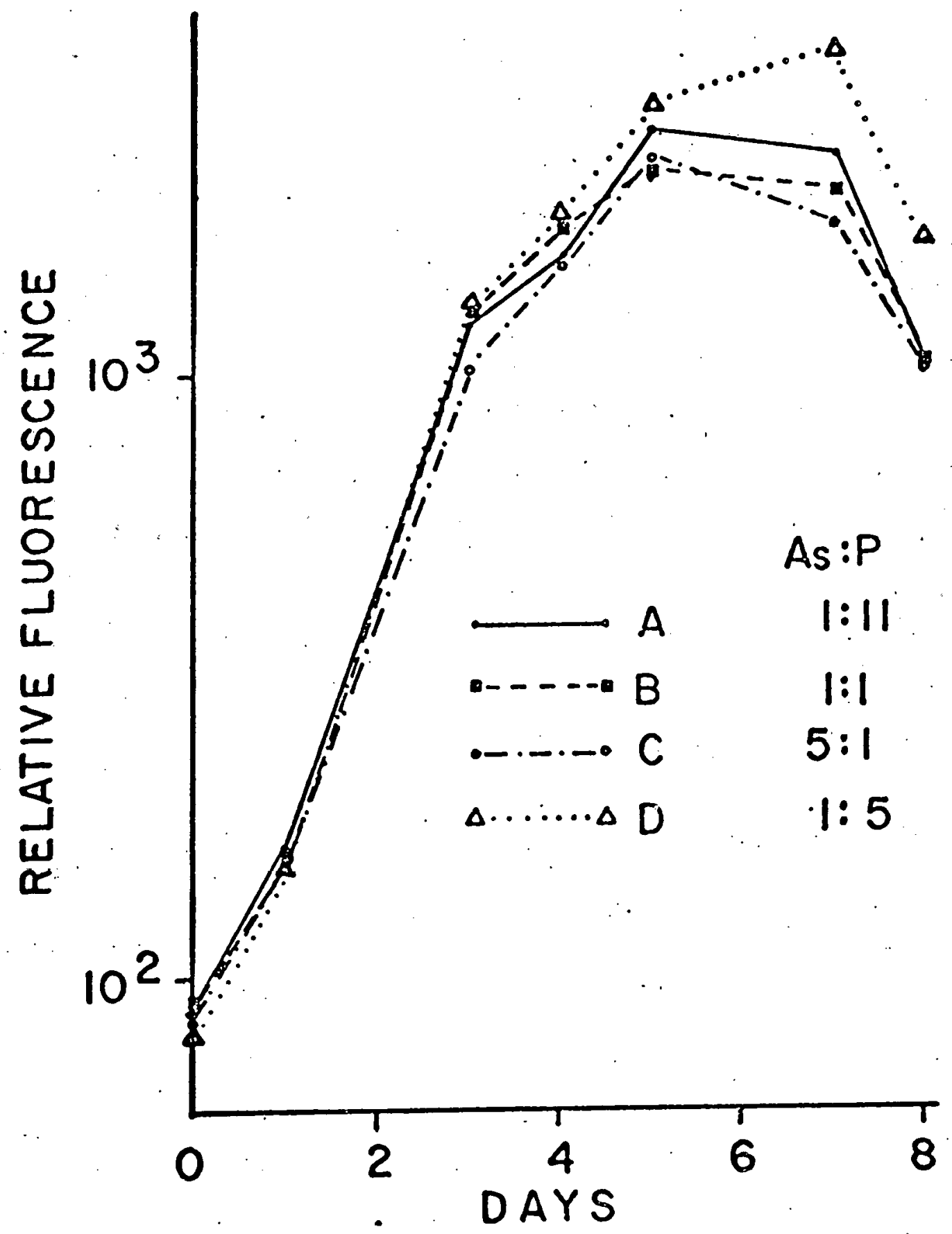


$n_{0}=$ popuiation density at time 0 , and $t=$ hours. The results are plotted in Figure 16, for each As(V) concentration. A two-way analysis of variance of $\mu$ by $A s(V)$ and phosphate, including the As(V)-phosphate interactions, indicates that both significantly affect $\mu$ (Table 11).

A Lineweaver-Burk plot of $1 / \mu$ versus $1 / P$ (Lehninger, 1970) gave good correlations $(r=.97-.98)$. This plot allows calculations of $\mu_{\max }$ and $K_{S}$, the concentration of substrate at which $\mu=1 / 2 \mu_{\max }$, for each of the As $(V)$ concentrations (Table 12). The plots show that moderate additions of $A s(V)$ increase $K_{s}$ without affecting $\mu_{\max }$. Large additions of As $(V)$ not only increase $k_{S}$, but also depress $\mu_{\max }$.

The effect of As $(V)$ concentrations on uptake of phosphate by phytoplankton was studied by examining uptake of $32 \mathrm{p}$ in skezetonema costatum cultures subjected to various levels of $A s(V)$ and phosphate (Table 13). Arsenate additions at each level of phosphate concentration caused significant $(p>.95)$ decreases in phosphate uptake. The phosphate uptake in unenriched cultures $(P=0.0 \overline{7} \mu \mathrm{M})$ averaged $3.5 \mathrm{nM} \dot{\mathrm{P}}$. $h \mathrm{r}^{-1} \cdot 10^{6} \mathrm{cells}^{=1}$. The addition of $25 \mu \mathrm{gs}(\mathrm{V}) \cdot \mathrm{I}^{-1}$ reduced the uptake by approximately one-half to $1.7 \mathrm{nM} P \cdot \mathrm{hr}^{-1} \cdot 10^{6} \mathrm{cell}^{-1}$. Similar reductions in uptake rates due to $A s(V)$ additions cccurred even under phosphate enrichment (Table 13, Figure 17). 
Figure 16, The growth rate, $\mu$, in divisions per day, of test-tube cultures of Skeletonema costatum exposed to varying levels of As(V) and phosphate enrichment. Arsenic enrichment: $A-n o A s(V)$ added, B-5 ug As $(V) \cdot 1^{-1}, C-25 \mu \mathrm{g} \mathrm{As}(V) \cdot 1^{-1}$. 


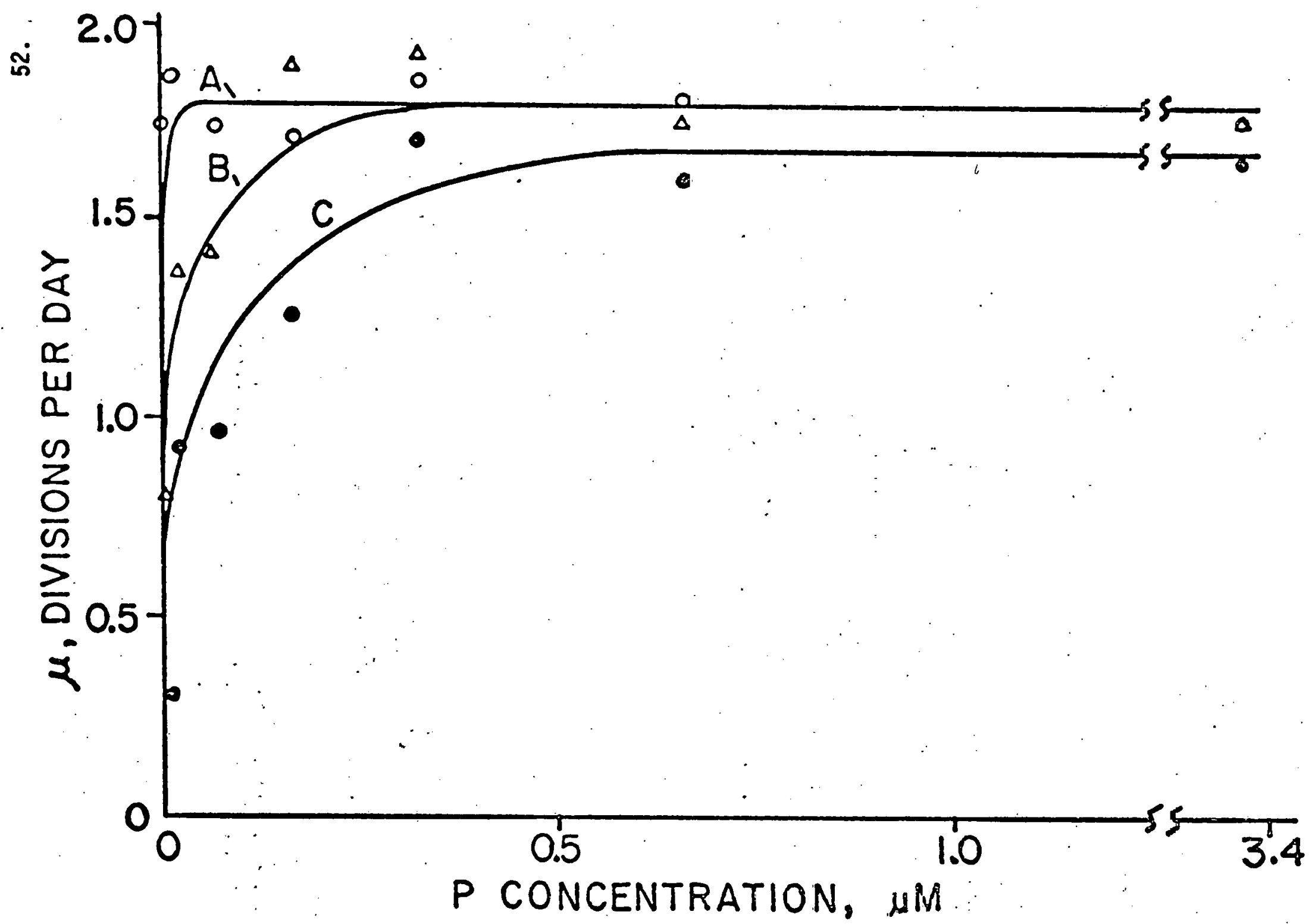


Table 11. Two-way analys is of variance of $\mu$ by $\mathrm{As}$ and $\mathrm{PO}_{4}$, including As-P interactions in the As-P test tube cultures of Skeletonema costation.

Source of Variation

As

$\mathrm{PO}_{4}$

As-P interactions
$\underline{F}$

26.26

13.62

3.06

\section{Significance of $F$}

.001

.001

.005

Table 12. $K_{S}$ and $\mu_{\max }$ for phosphate uptake by Skeletonema costatron calculated using a Lineweaver-Burk plot for each As concentration in the As-P test tube experiment.

\begin{tabular}{ccc}
$\begin{array}{c}\text { As conc } \\
\mu \mathrm{g} \cdot 7^{-1}\end{array}$ & $\frac{K_{s}, \mu \mathrm{M}}{2}$ & $\frac{\mu_{\max }}{0}$ \\
\hline 0 & $\frac{.02}{1.80}$ \\
5 & .08 & 1.78 \\
25 & .61 & 1.68
\end{tabular}


Table 13. The uptake of 32p by Skeletonema costatum subjected to a variety of $\mathrm{As}$ and $\mathrm{PO}_{4}$ concentrations and linear regression analys is of the filtrate activity where $Y=$ In filtrate activity. Significant differences between the slope of the control flasks (no As) and the treatment flasks are indicated.

\begin{tabular}{|c|c|c|c|c|c|c|}
\hline Flask & $\begin{array}{l}\text { As }(V) \\
\mu g \cdot 1-1\end{array}$ & $\begin{array}{l}\mathrm{PO}_{4}, \\
\mu \mathrm{M} \\
\end{array}$ & $\begin{array}{l}\mathrm{PO}_{4} \\
\text { uptake, } \\
\text { nM.min-1 } \\
\end{array}$ & $\begin{array}{l}\text { nM P. hr-1. } \\
10^{6} \mathrm{cells}-1\end{array}$ & $t$ & $\begin{array}{c}\text { Significance } \\
\text { of } t\end{array}$ \\
\hline$P A$ & 1.5 & 0.07 & .36 & 3.5 & $\cdots$ & $-\ldots \ldots$ \\
\hline PB & 6.5 & .07 & .23 & 2.2 & 14.5 & $p>.995$ \\
\hline PC & 16.5 & .07 & .18 & 1.7 & 5.42 & $.99<p<.995$ \\
\hline$P D$ & 26.5 & .07 & .18 & 1.7 & 3.27 & $.975<p<.99$ \\
\hline PE & 1.5 & .08 & .55 & 5.3 & $\cdots$ & $\cdots--\cdots$ \\
\hline PF & 6.5 & .08 & .48 & 4.6 & 1.18 & $.80<p<.90$ \\
\hline PG & 16.5 & .08 & .33 & 3.2 & 2.51 & $.95<p<.975$ \\
\hline PH & 26.5 & .08 & .28 & 2.7 & 4.23 & $.975<p<.99$ \\
\hline PI & 1.5 & .24 & .38 & 3.7 &.--- & $\cdots---$ \\
\hline PJ & 6.5 & .24 & .14 & 1.4 & 3.22 & $.975<\mathrm{p}<.99$ \\
\hline PK & 16.5 & .24 & .07 & 0.7 & 5.54 & $.995<p<.9995$ \\
\hline$P L$ & 26.5 & .24 & .10 & .9 & 5.20 & $.995<p<.9995$ \\
\hline PM & 1.5 & 3.4 & 11.9 & 115 & $\cdots$ & $--\cdots--$ \\
\hline PN & 6.5 & 3.4 & 7.8 & 76 & 1.89 & $.90<p<.95$ \\
\hline PO & 16.5 & 3.4 & 5.8 & 56 & 4.07 & $.99<p<.995$ \\
\hline$P P$ & 26.5 & 3.4 & 5.8 & 56 & 13.3 & $p>.9995$ \\
\hline
\end{tabular}


Figure 17. The effect of external phosphate concentration (in $\mu$ M) and $A s(V)$ concentration (in $\mu g \cdot 1^{-1}$ ) on the phosphate uptake rate, $V^{\prime}$, of Skeletonema costatum (in $\mathrm{nM} \mathrm{P} \cdot \mathrm{hr}^{-1} \cdot 10^{6}$ cellis ${ }^{-1}$ ). Both significantly affect the uptake rate $(p>.99)$. 
55.

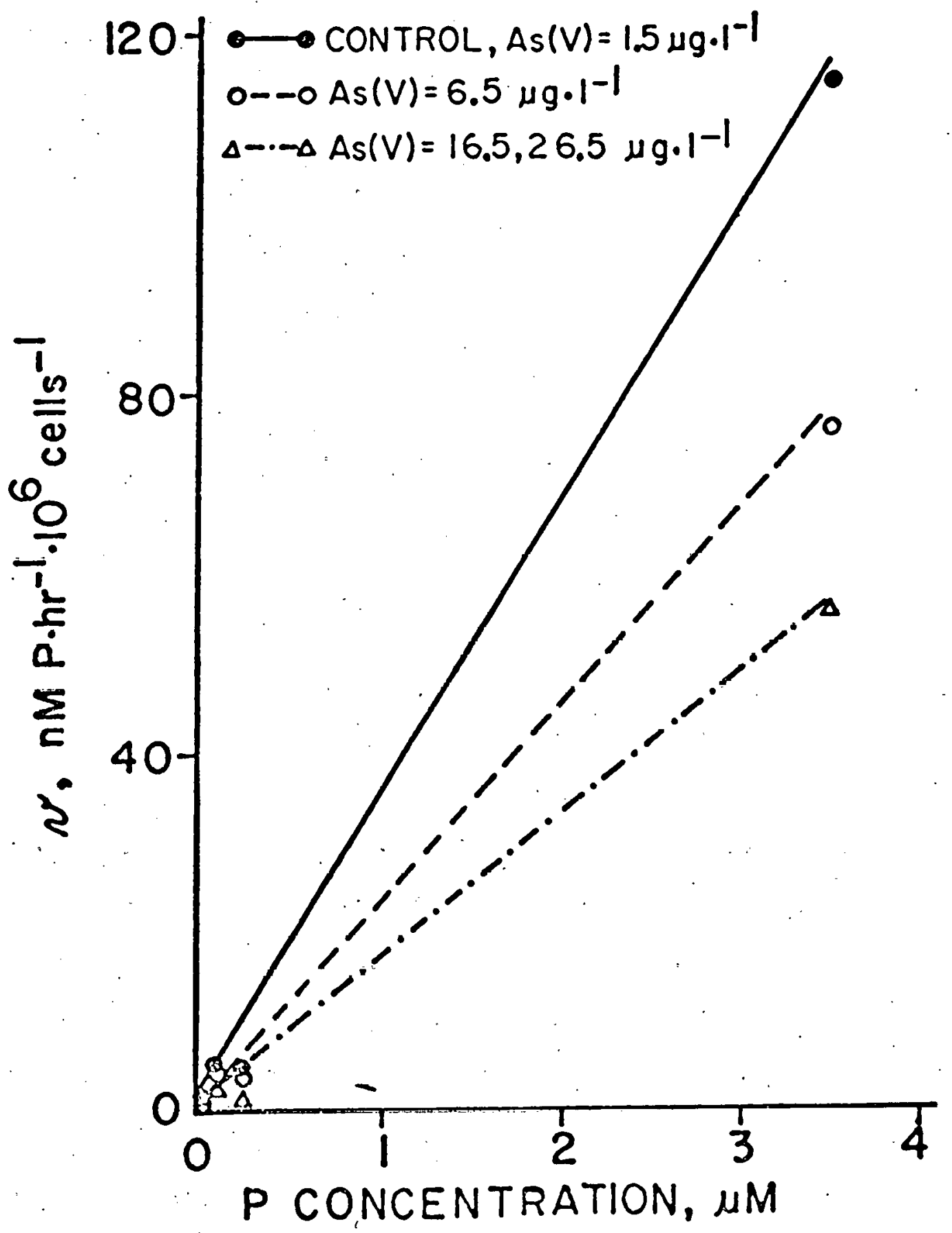




\section{DISCUSSION}

The concentration and speciation of arsenic in marine algae varies widely. Since total arsenic concentrations in seawater are relatively constant, between 1.0 and $1.5 \mu \mathrm{g} \cdot \mathrm{1}^{-1}$ (Waslenchuk, 1977, in press; Andreae, 1978; this study), variations in its concentration in algae are probably not due to differences in natural levels. This conclusion is supported by the observation that arsenic concentrations in algal species collected from a single location vary widely (Table 1).

The significant variation in arsenic concentration and speciation between algal classes is especially striking in the brown algae, in particular the Laminariales (kelps). In this order the inorganic to organic ratio is $10 / 90$, and the total arsenic concentration averages $15.0 \mathrm{ng} \cdot \mathrm{mg}^{-1}$, much different than observed in other orders.

Vinogradov (1953) reported differences in the total arsenic concentration of macro-algae, with browns containing $7.6 \mathrm{ng} \cdot \mathrm{mg}^{-1}$, red algae 4.2, and green algae 3.8. Tagawa and Kojima (1976) also found that brown algae contained significantly more arsenic than did red or green algae ( $34 \mathrm{ng} \cdot \mathrm{mg}^{-1}$ versus 4 ), and that the arsenic content increased with the age of the plant. Further study is required before a complete understanding of these observations can be gained.

It is interesting to note that phosphorus content of macro-algae varies similarly with arsenic. Data presented by Vinogradov (1953) for the brown, red, and green algae, and by Whyte and Englar (1974, 1975) for the brown algae show that the latter contain more phosphorus (as $\%$ 
dry weight) than either red or green algae (0.37\% versus .24 and .26). Although the means are not significantly different $(.75<p<.90$, with the available data), the trend is the same as that found for total arsenic.

The growth of phytoplankton and Valonia in media enriched with As (V) in most cases caused both an increase in total concentration and a shift in the inorganic/organic ratio towards a greater proportion of organic arsenic. The uptake of arsenic by skeletonema costatum is rapid, ranging from $0.15 \mathrm{ng} \mathrm{As}(V) \cdot \mathrm{hr}^{-1} \cdot 10^{6} \mathrm{cells}^{-1}$ in unenriched culturès to $2.3 \mathrm{ng}$ As (V) $\cdot h r^{-1} \cdot 10^{6}$ cell $^{-1}$ in cultures containing $25 \mu \mathrm{gs}(\mathrm{V}) \cdot \mathrm{l}^{-1}$ (Table 4). In skeletonema costatum, this uptake resulted in total arsenic concentrations approximately $30 \%$ higher in enriched cultures than in unenriched cultures. The uptake by Peridinium trochoidizon was different from that of skeletonema costation in that arsenic was concentrated to a much greater extent, and increased As $(V)$ concentrations in the media led to increased cell concentrations.

Andreae (in press) recently completed similar studies on ${ }^{74}$ As ías As (V)) uptake by Platymonas suecica. At ambient arsenic concentrations, he found a rapid initial increase over the first 2 minutes, then a constant uptake equivalent to $0.003 \mathrm{ng} \mathrm{As}(\mathrm{V}) \cdot \mathrm{hr}^{-1} \cdot 10^{6} \mathrm{cells}^{-1}$, or approximately 50 times less than the uptake measured above for skezetonema costatum. A Although not evident from the presentation, the lower uptake rate could be due to the much higher phosphate concentrations in the culture media, and also to the different algal species used.

The uptake of $A \dot{s}(V)$ is dependent on both the $A s(V)$ and phosphate concentrations in the media. Radiotracer experiments have shown that - increased As $(V)$ concentrations caused increased uptake, and at each 
58.

arsenic concentration studied, increasing phosphate concentration decreased the arsenic uptake (Table 4, Figure 1). Rothstein (1963) found that $A s(V)$ uptake by yeasts was similarly depressed by increasing phosphate concentration. Andreae (in press), however, found that increasing phosphate concéntrations actually increased ${ }^{74}$ As uptake from phosphate concentrations of $0.4 \mu \underline{M}$ to $2.4 \mu \underline{M}$, and that uptake decreased significantly only after additions of $100 \mu M$ phosphate were added. This observation may be due to simple equilibration kinetics. As phosphate concentration increases, the phosphorus metabolism rate is increased causing faster equilibration between the internal cell pool and the external medium. He did not investigate the effect of very low phosphate concentrations on As(V) uptake.

Not only the uptake rate, but also the total arsenic concentration of skeletonema costatum grown in batch cultures was affected by the addition of phosphate (Table 5). Arsenic concentrations in SC-11-77 were an order of magnitude lower than those grown under phosphate limited conditions (2-77-As, SC-3-77, Table 2).

The reduction in the $C: N$ ratio in both Valonia macrophysa and Skeletonema costatum exposed to As(V) enrichment (Table 8) may be caused by reduced carbon uptake and incorporation. However, reduction in ${ }^{14} \mathrm{C}$ uptake was also observed in phytoplankton exposed to As(III), but no reduction in cellular carbon content occurred: Very little data are available, and although significantly different; the reduction may therefore merely represent the natural variability in the $C$ and $N$ composition of algae.

The rapid speciation changes that occur within the surrounding media indicate that algal cells are able to reduce, methylate, and release 
arsenic in these forms to the water column. Although some of the additional arsenic is incorporated into the cell, much of it is apparently metabolized and rapidly released to the surrounding water column. Arsenate reduction is rapid. Rates calculated for SC-1-78 (Figure 2a,b,c) ranged between $2 \mathrm{ng} \cdot 10^{6} \mathrm{cells}^{-1} \cdot \mathrm{day}^{-1}$ in unenriched cultures and $50 \mathrm{ng} \cdot 10^{6} \mathrm{cells}^{-1} \cdot \mathrm{day}^{-1}$ in cultures enriched with $25 \mu \mathrm{g}$ As $(v) \cdot 1^{-1}$. These rates are similar to the uptake rates of ${ }^{74} \mathrm{As}$ (as As(V)) calculated for Skeletonema costatum (Table 4, 3.6 to 55

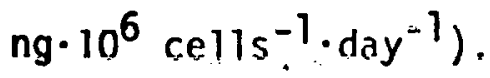

Andreae (in press) has aiso documented reduction and subsequent production of methylated arsenic for several species of algae. Algal growth in chemostat cultures caused large increases of As(III), DMA and mono-methylarsonate. Interestingly, almost all cultures showed a significant depletion in the total arsenic concentration. Unfortunately, no data on either the arșenic content of the cells in culture or the population density is available, so it is not possible to determine whether the loss is due to uptake by cells, or by volatilization. Since no volatilization of arsenic has been detected from cultures during this study, it is likely that the loss is due to cell uptake.

The concentration of As(III) in the oxidation experiment decreased exponentially as described by equations 1 and 2 listed above and shown in figure 4. The chemical oxidation is slow, averaging $0.09 \mu \mathrm{g} \mathrm{As}$ (III) oxidized: $1^{-1} \cdot$ day-1 at the initial concentration of $5 \mu \mathrm{g} \cdot \mathrm{l}^{-1}$. This is very similar to the rate obtained by Johnson and Pilson (1975) of 0.09 $\mu \mathrm{g}$ As(III) $\cdot 1^{-1} \cdot$ day $^{-1}$ at an initial As(III) concentration of $9 \mu \mathrm{g} \cdot \mathrm{1}^{-1}$. The oxidation rate is dependent upon the As(III) concentration, and is more rapid at higher concentrations, as evidenced by the results of 
60.

Johnson and Pilson (1975) and the rapid loss of As(III) from SC-4-77 (Figure 5).

Arsenic in large-volume CEPEX enclosures (CEE-B and CEE-C) experienced speciation changes similar to those occurring in batch cultures. The $A s(V)$ decrease in CEE-B was similar to decreases observed in cultures enriched with As(V), SC-3-77 (Table 6) and SC-1-78 (Figure 2a). The rate of reduction was also very similar, approximately $140 \mathrm{ng} \mathrm{As}(V)$ reduced.mg of phytopiankton $\mathrm{C}^{-1}$. day ${ }^{-1}$ in CEE-B versus $190 \mathrm{ng}$ As(V) reduced.mg $C^{-1} \cdot$ day $^{-1}$ in flask $B$ of $S C-1-78$, which had also been enriched with $5 \mu \mathrm{g} \mathrm{As}(\mathrm{V}) \cdot 1^{-1}$ (the carbon content of flask $B$ was estimated from an average of the carbon content of Skeletonema costation in log phase from SC-1-78, SC-10-77, and SC-3-77). Arsenate reduction ceased after primary productivity declined and phytoplankton populations reached stationary phase in both the batch culture and in the CEPEX enclosures, indicating that only actively growing populations reduce As(V) (Figure $2 a, 5)$.

The oxidation of As(III) in CEE-C was al so similar to observations made on culture SC-4-77 (Figure 3), and during the As(III) oxidation experiment. Using equation 1 calculated from the oxidation study at $17^{\circ} \mathrm{C}$ (the mean temperature in Saanich Inlet in July, 1977 was $16^{\circ} \mathrm{C}$ ), $\log Y=-.0126 X+b$, where $Y=\% A s$ (III) and $X=$ time in days. Setting $b=1.91$ (initial As (III) concentration, $Y,=82 \%$ ), the As(III) concentrations within CEE-C should be approximately $43 \%$ of total at the end of the experiment. The observed As(III) concentrations were 30\%. Both the actual and calculated curves for As(III) oxidation are plotted in Figure 6. The calculated As(III) oxidation shows the rate due to chemical oxidation only, oxidation by biological means (i.e., bacteria) may 
account for the difference.

Arsenate enrichment of cultures also caused a shift in speciation within the cell. Generally, increased As(V) caused the inorganic/ organic ratio to shift (Table 2,3 ) from approximately $50 / 50$ in Skeletonema costatum or 75/25 in Valonia to approximately 30/70 in $S$. costatum and 50/50 in Valonia. Phosphate additions also cause a shift in arsenic speciation. $S$. costatum grown with phosphate enrichment (Table 5) had an inorganic/organic arsenic ratio of $65 / 35$, which did not change with $A s(V)$ additions up to $15 \mu g \cdot 1^{-1}$.

Cultures enriched with As(III) follow patterns of incorporation, and speciation changes similar to that observed for As(V) enrichments, but cells grown in DMA show no increase in arsenic content or speciation changes (Table 2). It is difficult to determine whether the uptake of arsenic in As(III) enriched cultures is due to uptake of As(III) or As $(V)$, formed by oxidation of the former. It is more likely that arsenic is taken up as As(V) since the most logical uptake pathway is via the phosphate active transport system.

Arsenate is a chemical analogue of phosphate, and studies have shown that $A s(V)$ and phosphate compete for uptake by algal cells (Blum, 1966, this study). The As-P test tube experiment demonstrated that, at As (V) concentrations up to $25 \mu \mathrm{g} \cdot \mathrm{7}^{-1}$, competition occurred between arsenic and phosphate for cellular uptake (Table 11). This is also borne out by the results of the two independent radiotracer uptake studies (Tables 4, 13, Figures 1, 17). Arsenate uptake by skezetonema costation was cut by $15 \%$ when $3 \mu \mathrm{M}$ phosphate was added to the system. It is also clearly demonstrated by the very low total arsenic concentrations in $5 C-17-77$ (Table 5), which were grown under phosphate enrichment. The 
competitive inhibition of $A s(V)$ uptake by phosphate demonstrated above was not seen by Andreae (in press), however, as mentioned above, he was hampered by high phosphate levels in the system with which he worked.

Arsenate has been shown to inhibit phytoplankton production, both in the long-term by lowering the population density of a batch culture, and in the short-term by depressing the ${ }^{14} \mathrm{C}$ uptake and photosynthesis of Skeletonema costatum. This is the first report demonstrating arsenic toxicity at near ambient levels; other investigators have found arsenic effects at much higher levels (Schroeder and Balassa, 1966; Conway, 1978; Irgolic et al., 1977; Bottino et al., in press). Their studies, however, were performed under conditions of phosphate enrichment. The enrichment therefore reduced the uptake of arsenic and its corresponding toxicity, as has been demonstrated in the present study, over both the long-term and the short-term (Table 4, Figures 12, 15).

Hollibaugh et al. (in press) have recently demonstrated inhibition due to $A s(V)$ and $A s$ (III) in conjunction with the arsenic experiments at CEPEX during 1977. Both As(III), and As(V) under conditions of low phosphate $(=.5 \mu \mathrm{M})$ concentrations, inhibited the growth of Thazassiosira aestevalis, a marine diatom, at concentrations greater than $22.5 \mu \mathrm{g} \cdot 1^{-1}$. Arsenate was not toxic at concentrations up to $75 \mu \mathrm{g} \cdot \mathrm{7}^{-1}$ when added to cultures enriched with phosphate $(2.7 \mu \mathrm{M})$. The arsenic concentrations required for an inhibitory response are higher than those determined here, likely due to the higher concentration of phosphate found in Saanich Inlet, and possibly to the different algal species used.

Arsenate additions of as little as $5 \mu \mathrm{g} \cdot \mathrm{l}^{-1}$ significantly inhibited the photosynthesis and ${ }^{14} \mathrm{C}$-uptake of Skeletonema costatum both in $\mathrm{log}$ and stationary growth phases. This is equivalent to 3-5 times the 
63.

ambient As(V) level, and is the lowest concentration studied. It is possible that even lower As(V) concentrations could cause decreased cell activity under conditions of phosphate limitation. Cells in stationary growth phase are less affected by arsenic additions (Figures 12, 13), probably due to lowered metabolic activity, and subsequently decreased As (V) uptake. Low $A s(V)$ additions also affect the long-term growth of $S$. costatum. Although an increase in growth occurred initially in culture 2-77-As at an As (V). addition of $6 \mu \mathrm{g}^{\cdot} \mathrm{l}^{-1}$, the population crashed early, never establishing a stationary phase. Peridinium trochoidium was not as affected by the $A s(V)$ additions as was $S$. costation. $P$. trochoidium grows more slowly, and therefore its initial phosphate uptake (and As(V) uptake) may be much slower than that for $S$. costatzon.

The importance of the phosphate concentration in reducing $A s(V)$ toxicity is demonstrated in the As-P test tube experiment. The results of the experiment also indicate that $A s(V)$ additions at levels as low as $5 \mu \mathrm{g} \cdot \mathrm{1}^{-1}$ can inhibit growth rate when concentrations of phosphate are very low. When phosphate concentrations are greater than $0.3 \mu$ the growth rate is apparently not affected by small additions of As(V). Arsenate additions, however, did cause an increase in $K_{S}$, from 0.02 MM to $0.08 \mu \underline{\mu}$ at $5 \mu \mathrm{g} \cdot 1^{-1} \mathrm{As}(\mathrm{V})$ and $0.62 \mu \mathrm{M}$ at $25 \mu \mathrm{g} \cdot 1^{-1}$ As(V) (Table 12). The increase in $K_{s}$ and constancy of $\mu_{\max }$ for low levels of As (V) addition indicate that $A s(V)$ competitively inhibits phosphate uptake (Lehninger, 1970). Competitive inhibition is reduced by high concentrations of the inhibited substrate, phosphate. High levels of $A s(V)$ addition, however, depressed $\mu_{\max }$ and increased $K_{S}$, indicating that non-competitive inhibition may also be occurring (Fisher et az., 1976).

The environmental significance of small additions of As(V) are 
clearly demonstrated by this experiment. If enough phosphate is present to reduce the $A s(V)$ toxicity, the population will still be hampered by the increased requirement for phosphate (as shown by the increased $K_{S}$ values above). Since half-saturation constants are thought to be a measure of the relative ability of a species to compete for nutrients (Dugdale, 1967; Perry, 1976), increased phosphate requirement caused by As $(V)$ could reduce a species ability to compete with a more resistant species. The effect of As(V) on multi-species populations could lead to success and dominance of resistant species which normally would not be as successful. These interrelationships, and the effect of As(V) on community structure, especially during phosphate limitation, need to be further studied before the impact of As(V) additions to the nearshore environment can be estimated.

Arsenite is also toxic to phytoplankton. As discussed previously, it is difficult to determine whether the toxicity is due to As(III) or As(V) formed by oxidation. All forms of arsenic, however, are not toxic to marine algae. Concentrations of DMA up to $25 \mu \mathrm{g} \cdot \mathrm{j}^{-1}$ appear to have little or no effect on phytoplankton productivity.

The non-toxicity of the DMA ion is probably due to its larger size, its relative stability, and most importantly, its chemical dissimilarity to phosphate. When As( $V)$ is taken up by an algal cell in excess, it has several adverse effects. It inhibits the phosphate active transport system by not releasing from the transport molecule (Rothstein, 1963) and it inactivates the glucose metabolism system (Scarborough, 1975) and oxidative phosphorylation (DaCosta, 1972). Arsenite, al though not so close an analogue of phosphate, may react in a similar fashion. DMA, on the other hand, is not actively taken up, and seems to participate in 
no reactions that affect cell productivity.

The large changes in arsenic speciation caused by marine algae also appear to be a product of the As( $V$ ) effect on productivity. Marine algae, along with fungi (Challenger, 1945), bacteria (McBride et al., 1971; Johnson, 1972), corals ( $\mathrm{Pilson}, 1974$ ), and some freshwater algae (Blasco et al., 1971, 1972) have the ability to reduce $A s(V)$ to $A s(I I I)$ and then methylate it, forming DMA and other methylated arsenicals. This reduction and subsequent methylation is a means by which $A s(V)$ that enters the cell and inhibits its functions can be altered so that its toxicity is reduced.

Changes in arsenic speciation were observed in all cultures studied, and indicate that the above mechanism does exist in marine phytoplankton. This may also be the mechanism by which the brown algae collect so much organic arsenic. Since their phosphorus content is higher than either the red or green algae, it is possible that they also indiscriminately incorporate larger amounts of $A s(V)$. This $A s(V)$ may then be reduced to an organic form and stored in the tissue. The inorganic arsenic content of brown algae $\left(2.2 \mathrm{ng} \cdot \mathrm{mg}^{-1}\right)$ is quite similar to that of red $\left(0.7 \mathrm{ng} \cdot \mathrm{mg}^{-1}\right)$ and green $\left(1.5 \mathrm{ng} \cdot \mathrm{mg}^{-1}\right)$. This concentration of $1-2 \mathrm{ng} \cdot \mathrm{mg}^{-1}$ may represent the highest level of inorganic arsenic that can be accomodated by macro-algae, and therefore any excess above this amount, as in brown algae; is stored in the methylated form. The lower concentrations of organic arsenic in red and green algae may be due to less As(V) uptake, or to increased removal of organic compounds from their tissues.

Several investigators have determined that the organic arsenic compounds in algae contain both lipid and water soluble fractions (Lunde, 1973; Irgolic et al., 1977; Edmonds et al., 1977). There is still some question as to the exact nature of these arsenic compounds. Edmonds 
et al. (1977) have identified arsenobetaine from marine lobster, and Irgolic et al. (1977) suggest that the compound is an arseno-lipid, and perhaps an arsenocholine. Whatever the configuration, the compounds appear to be stable, largely non-reactive, and relatively non-toxic. (Edmonds and Francesconi, 1977; Lunde, 1977; Penrose et al., 1977; Woolson, 1974).

The reduction of $A s(V)$ and the subsequent production of $A s(I I I)$ and DMA occurs in natural populations, not just in cultures, as evidenced by their appearance in the marine environment. Under the oxidized conditions found in surface marine waters, neither As(III) nor DMA is chemically produced, and must be a product of the biota. Since both of these arsenic species can occur in large concentrations in highly productive areas, it is possible to estimate the contribution made by the phytoplankton. Since arsenic reduction takes place only when the phytoplankton population is in the log phase of growth, the spring bloom in coastal and shelf waters off Georgia should contribute a large majority of the reduced arsenic species, with a smaller contribution from the smaller fall bloom. Estimates of the phytoplankton contribution of As(III) to continental shelf waters of the South Atlantic using two separate approaches are presented below:

1. According to results of culture SC-1-78, during log phase of growth, $2.2 \times 10^{-3} \mathrm{pg} \cdot \mathrm{As}(\mathrm{V}) \cdot \mathrm{cel1} \mathrm{1}^{-1}$ is reduced per day. Algal blooms off Georgia run an average of 75 days, with cell populations increasing from $0.5 \times 10^{6}$ to $1.5 \times 10^{6}$ cells.1-1 (W.M. Dunstan, pers. comm.). Therefore, the cell number increase is $1 \times 10^{6} \mathrm{cells} \cdot \mathrm{1}^{-1} \cdot 2.2 \times 10^{-3} \times 1 \times 10^{6}=$ $2.2 \mathrm{ng} \cdot 1^{-1} \cdot$ day $^{-1} \times 75$ days $=.165 \cdot \mathrm{ng} \cdot 1^{-1}$ during the course of the spring bloom, $=165 \mu \mathrm{g} \cdot \mathrm{m}^{-3}$. 
The Georgia Bight $=1.8 \times 10^{12} \mathrm{~m}^{3}$ (Cape Fear to Cape Kennedy), therefore $3.0 \times 10^{14} \mathrm{\mu g}$ are reduced in the Georgia Bight. The total arsenic concentration of the Bight $=2 \times 10^{15} \mu \mathrm{g}$ (Waslenchuk, 1977), so, 15\% of the total arsenic is reduced in the spring bloom.

The smaller fall bloom (cell increase approximately $0.5 \times 10^{6}$ cells $\cdot 7^{-1}$ ) is of shorter duration, approximately 30 days, so $3 \%$ of the total arsenic can be reduced during this bloom, making a total of $18 \%$.

2. Cultures $5 \mathrm{C}-1-78, \mathrm{SC}-2-78$ had ${ }^{14} \mathrm{C}$ uptake in four hours $=1.44 \%$ of tota. ${ }^{14} \mathrm{C}$, so $\frac{(.0144)\left(101 \mathrm{mg} \mathrm{CO}_{2} \cdot \mathrm{1}^{-7}\right)(12)(1.05)}{(4 \mathrm{hr})(44)}=$ $.104 \mathrm{mg} \mathrm{C} \cdot 1^{-1} \cdot \mathrm{hr}^{-1} \times 10 \mathrm{hr}$ day $=1.04 \mathrm{mg} \mathrm{C} \cdot 1^{-1}=1.0 \mathrm{~g} \mathrm{C} \cdot \mathrm{m}^{-3} \cdot \mathrm{day}^{-1}$. According to Ryther (1969), primary productivity $=300 \mathrm{~g} \mathrm{c} \cdot \mathrm{m}^{-2} \cdot \mathrm{yr}^{-1}$, $=10 \mathrm{~g} \mathrm{C} \cdot \mathrm{m}^{-3} \cdot \mathrm{yr}^{-1}$, assuming average depth of $30 \mathrm{~m}$ in the Georgia Bight, and that productivity is the same through the entire depth. $10 \mathrm{~g}$ $c \cdot \mathrm{m}^{-3} \cdot \mathrm{yr}^{-1}=27 \mathrm{mg} \mathrm{C} \cdot \mathrm{m}^{-3} \cdot \mathrm{day}^{-1},=2.7 \%$ of culture productivity. Cultures reduced an average of $80 \mathrm{ng} \cdot 1^{-1} \cdot \mathrm{day}^{-1}$, so $(.027)(80)=2.16 \mathrm{ng} \cdot 7^{-1} \cdot$ day $^{-1}$ $\times 75$ days $=162 \mathrm{ng} \cdot \mathrm{l}^{-1}=162 \mathrm{ng}^{\circ} \mathrm{m}^{-3},=15 \%$ of the total arsenic reduced.

The shorter fall bloom would add an additional 6\%, making a total of $21 \%$ of the total arsenic reduced. This method assumes that the primary productivity is constant from day to day, which is clearly not the case, this approach therefore only serves as an estimate.

-The fact that both of the calculations arrived at similar values is merely coincidental, however, $15-20 \%$ is probably a reasonable. estimate for the amount of arsenic reduced, and indeed, is very close to the concentration of As(III) and DMA found in the spring in Georgia coastal waters (Waslenchuk, 1977, in press).

- Using equations 1 and 2 calculated above for As(III) oxidation, the 
68.

As(III) produced during the spring bloom should degrade slowly, becoming undetectable in approximately 120 days, and the As(III) produced from the fall bloom should become undetectable in approximately 90 days. Although the data are not complete, As(III) is often detected year-round. It is possible that some uptake and reduction of $A s(V)$ occurs at all times in phytoplankton populations, not just during logarithmic growth, which would lessen the "apparent" oxidation rate of As(III). Arsenite in SC-1-78 (Figure $2 \mathrm{~b}$ ) remained nearly constant while cells were in the stationary growth phase; similar results were seen in CEE-C. The apparent constancy of As(III) tends to support this theory. If this is the case, the large pulse of As(III) in the early spring and the smaller one in the fall would appear to be oxidized more slowly than predicted; therefore productive marine systems would always contain some detectable As (III).

Further work is necessary before the biogeochemistry of arsenic is fully understood. The results of this study indicate that $A s(V)$ is actively taken up by marine algae, reduced, and methylated. Some of this arsenic is incorporated into the algal tissue, and some is ingested by other trophic levels feeding on the algae, although organic arsenic compounds are probably readily excreted (Penrose et al., 1977). A large portion of the reduced and methylated species are released to the water column, where they are slowly oxidized back to As(V). There is also loss of arsenic from the euphotic zone due to sinking of cells, and feeding by higher trophic levels. The rate of this biological cycle is determined by the primary productivity of the phytoplankton population, and the ambient phosphate concentration.

All of the above, coupled with the geochenical sources and sinks, 
69.

must be taken into account when an attempt to model arsenic speciation in-productive systems is made. Although the preliminary studies have been completed, further experiments into the uptake of arsenic by various phytoplankton species, interrelationships between algal and microbial populations, and the incorporation and release rates of arsenic need to be conducted before the role of algae in arsenic biogeochemistry can be fully understood. 


\section{SUMMARY AND CONCLUSIONS}

The arsenic concentration and speciation in marine algae varies greatly, especially in marine macro-algae. Variation in total arsenic ranged from 0.4 to $23 \mathrm{ng} \cdot \mathrm{mg}^{-1}$ in macro-algae, and from 5 to $23 \mathrm{ng} \cdot \mathrm{mg}^{-1}$. in phytoplankton cultures grown in unenriched media. The wide range observed is probably not due to geographic variations in arsenic concentration, but rather to differences in the algae themselves.

The concentration of arsenic in macro-algae varies directly with the concentration of phosphate. This is likely due to competitive uptake between phosphate and arsenic as demonstrated in this study and others.

Although the Phaeophyceae contain significantly more arsenic than either the Chlorophyceae or the Rhodophyceae, the concentration of inorganic arsenic within the three classes is relatively constant. This concentration may indicate the maximum permissible levels of inorganic arsenic for marine algae, with the excess being reduced and methylated. The larger concentrations of organic arsenic observed in the Phaeophyceae is probably due to greater uptake, or to less successful excretion of the organic forms.

The arsenic speciation in phytoplankton and valonia macrophysa changes when cultures are enriched with As(V). The addition generally causes an increase in the proportion of organic arsenic and an increase in total arsenic concentrations.

Similar speciation and concentration changes occur when As(III) is 
added; however, additions of DMA cause no significant changes.

Marine algae produce arsentc speciation changes within the surrounding media as a result of uptake followed by reduction, methylation, and release. Arsenic occurring initially as DMA, however, is not affected.

The speciation changes are likely in response to the demonstrated toxicity of $A s(V)$ at near ambient levels under phosphate-limited conditions. The reduction and methylation of $A s(V)$ to DMA produces a stable, non-reactive compound, and reduces its toxicity, since DMA is not toxic at the concentrations studied.

Arsenate and phosphate compete for uptake by algal cells. Arsenate also competitively inhibits cell growth at low phosphate concentrations. At higher phosphate concentrations (above $0.3 \mu \underline{M}$ for $5 \mu \mathrm{g} \mathrm{As}(\mathrm{V}) \cdot 1^{-1}$ ), no inhibition occurs. Concentrations of As $(V)$ of as much as $25 \mu \mathrm{g} \cdot 1^{-1}$ cause some inhibition, even at phosphàte concentrations exceeding $30 \mu \underline{M}$, suggesting that non-competitive inhibition may also occur.

The reduction of As $(V)$ toxicity by phosphate is an example of the type of problems that are encountered but often overlooked in bioassay or toxicity studies. Studies of this kind cannot be routinely run under high nutrient conditions without first determining if effects occur at ambient nutrient levels.

The uptake rate of ${ }^{74}$ As (as $A s(V)$ ) calculated for cultures of Skeletonema costatum is similar to the rate of $A s(V)$ reduction in batch cultures of $S$. costation. In addition, the rate of $A s(V)$ reduction in large volume (CEPEX) enclosures was also similar.

Using the rates calculated for $A s(V)$ uptake and reduction and As(III) oxidation, we can begin to predict arsenic speciation. The above functions, coupled with knowledge of the phosphate concentration, 
72.

primary productivity, loss rates of arsenic from the euphotic zone, and arsenic geochemistry should enable us to model the arsenic speciation in productive systems. Further work, however, is required before arsenic biogeochemistry can be fully understood. Necessary studies include:

1. The determination of factors responsible for wide variations in arsenic concentration and speciation in algae,

2. The measurement of uptake and reduction rates for other algal species,

3. The determination of the interrelationships between the algal and microbial populations,

4. The monitoring of competition and succession of multi-species populations subjected to arsenic stress,

5. The characterization of the organic arseno-lipid compounds produced by algae, and,

6. A seasonal study of arsenic speciation in a productive area. 


\section{LITERATURE CITED}

Anderson, D.M. and F.M.M. More1. 1978. Copper sensitivity of GonyauZax tamarensis. Limmol. Oceanogr. 23: 283-295.

Andreae, M.0. 1978. Distribution and speciation of arsenic in natural waters and some marine algae. Deep-Sea Res. 25: 391-402:

and D. Klumpp. Arsenic metabolism by marine phytoplankton species. Submitted to Science.

Azam, F. and R.E. Hodson. 1977. Size distribution and activity of marine microheterotrophs. Limnol. Oceanogr. 22: 492-501.

Blasco, F., C. Gaudin, and R. Jeanjean. 1971. Absorption des ions arséniate par les Chlorelles. Réduction partielle de 1 'arséniate en arsénite. Comptes Rendus 273, Série D: 812-815.

R. Jeanjean, and C. Gaudịn. 1972. Absorption des ions arséniate par les Chlorelles. Réduction partielle de l'arséniate en arsénite. Caracteristiques. Comptes Rendus 275, Série D: 12231226.

Blum, J.J. 1966. Phosphate uptake by phosphate-starved Euglena. J. Gen. Physiol. 49: 1125-1136.

Bottino, N.R., R.D. Newman, E.R. Cox, R. Stockton, M. Hoban, R.A. Zingaro, and K.J. Irgolic. The effects of arsenate and arsenite on the growth and morphology of the marine unicellular algae Tetraselmis chui (Chlorophyta) and Hymenomonas carterae (Chrysophyta). J. exp. mar. Biol. Ecol., in press.

Braman, R.S. 1975. Arsenic in the environment, p. 108-123. In: E.A. Woolson (ed.), Arserical Pesticides. American Chemical Socicty Symposium Series \#7. Washington, D.C.

O.L. Jọhnșnn, C.C. Foreback, J.M. Ammons, and J.L. Bricker. 1977. Separation and determination of nanogram amounts of inorganic arsenic and methylarsenic compounds. Anaz. Chem. 49: 621-625.

Button, D.K., S.S. Dunker, and M.L. Morse. 1973. Continuous culture of Rhodotomila mubra: kinctics of phosphate-arsenate uptake, inhibition, and phosphate-limited growth. J. Bacteriol. 113: 599-611.

Challenger, F. 1945. Biological methylation: Chem. Rev. 36: 315-361. 
Conway, H.L. 1978. Sorption of arsenic and cadmium and their effects on growth, micronutrient utilization, and photosynthetic pigment composition of Asterionella formosa. J. Fish. Res. Bd. Canada 35: $286-294$.

Da Costa, E.W.B. 1972. Variation in the toxicity of arsenic compounds to microorganisms and the suppression of the inhibitory effects by phosphate. Appl. Microbiol. 23: 46-53.

Dugdale, R.C. 1967. Nutrient limitation in the sea: dynamics, identification, and significance. Limnoz. Oceanogr. 12: 685-695.

Edmonds, J.S. and K.A. Francesconi. 1977. Methylated arsenic from marine fauna. Nature 265: 436.

, K.A. Francesconi, J.R. Cannon, C.L. Raston, B.W. Skelton, and $A . H$. White. 1977. Isolation, crystal structure and synthesis of arsenobetaine, the arsenical constituent of the western rock lobster, Panulimus longipipes cygnus George. Tetrahedron Lett. 18: $1543-1546$.

Eppley, R.W. and J.D.H. Strickland. 1968. Kinetics of marine phytoplankton growth, p. 23-62. In: M.R. Droop and E.J.F. Wood (eds.), Advances in Microbiology of the Sea, Vol. 1. Academic Press. London.

Ferguson, J.F. and J. Gavis. 1972. A review of the arsenic cycle in natural waters. Water Res. 6: 1259-1274:

Fisher, N.S., R.R.L. Guillard, and C.F. Wurster. 1976. Effects of a chlorinated hydrocarbon pollutant on the growth kinetics of a marine diatom, p. 305-317. In: R.P. Canale (ed.), Modeling Biochemical Processes in Aquatic Ecosystems. Ann Arbor Science. Ann Arbor, Michigan.

Fondekar, S.P. and C.V.G. Reddy. 1974. Arsenic content in the coastal and estuarine waters around Goa. Mahasagar 7: 27-32.

Fritsch, F.E. 1971. The Structure and Reprodustion of the Algae. Vols. 1 and 2. Cambridge University Press. Cambridge.

Gorgy, S., N.W. Rakestraw, and D.L. Fox. 1948. Arsenic in the sea. J. Mar. Res. 7: 22-31.

Guillard, R.R.L. and J.H. Ryther. 1962. Studies on marine planktonic diatoms. Can. J. Microbioz. 8: 229-239.

Hollibaugh, J.T., D.L.R. Seibert, and W.H. Thomas. A comparison of the acute toxicities of ions of ten heavy metals to phytoplankton from Saanich Inlet, B.C., Canada. Submitted to J. exp. mar. Biol. Ecol. 
Irgoilic, K.J., E.A. Woolson, R.A. Stockton, R.D. Nerman, N.R. Bottino, R.A. Zingaro, P.C. Kearney, R.A. Pyles, S. Maeda, M.J. McShane, and E.R. Cox. 1977. Characterization of arsenic compounds formed by Daphnia magna and Tetraselmis chui from inorganic arsenate. Env. Health Persp. 19: 61-66.

Johnson, D.L. 1972. Bacterial reduction of arsenate in seawater. Nature 240: 44-45.

and R.S. Braman. 1975. The speciation of arsenic and the content of germanium and mercury in members of the pelagic Sargassum Community. Deep-Sea Res. 22: 503-507.

and M.E.Q. Pilson. 1975. The oxidation of arsenite in seawater. Env. Lett. 8: 157-171.

Jones, A.J. 1922. The arsenic content of some of the marine algae. Pharm. J. Pharmacist 109: 86-87.

Jung, C. and A. Rothstein. 1965. Arsenate uptake and release in relation to the inhibition of transport and glycolysis in yeast. Biochem. Pharmacol. 14: 1093-11112.

Lehninger; A.L. 1970. Biochemistry. Worth Publishers. New York.

Lewin, J.C. 1954. Silicon metabolism in diatoms. I. Evidence for the role of reduced sulfur compounds in silicon utflization. J. Gen. Physioz. 37: 589-599.

- 1955. Silicon metabolism in diatoms. III. Respiration and silicon uptake in Navicula pelliculosa. J. Gen. Physiol. 39: 1-10.

Lowenthal, D.H., M.E.Q. Pilson, and R.H. Byrne. 1977. The determination of the apparent dissociation constants of arsenic acid in seawater. J. Mar. Res. 35: 653-669.

Lunde, G. 1973. The synthesis of fat and water soluble arseno-organic compounds in marine and limnetic algae. Acta Chim. Scand. 27: 1586-1594.

- 1977. Occurrence and transformation of arsenic in the marine environment. Env. Health Persp. 19: 47-52.

McBride, B.C. and R.S: Wolfe. 1971. Biusynthesis of dimethylarsine by Methanobacterium. Biochemisimy 10: 4312-4317.

Menzel, D.H. and J. Case. 1977. Concept and design: controlled ecosystem pollution experiment, Bulz. Har. Sci, 27: 1-7.

Morel, N.M., J.E. Reuter, and F.M. Morel. 1978. Copper toxicity to Skeletonema costatum. J. Phycol. 14: 43-48. 
Penrose, W.R., H.B.S. Conacher, R. Black, J.C. Meranger, W. Miles, H.M. Cunningham, and W.R. Squires. 1977. Implications of inorganic/ organic inter-conversion on fluxes of arsenic in marine food webs. Env. Health Persp. 19: 53-60.

Perry, M.J. 1976. Phosphate utilization by an oceanic diatom in phosphorus limited chemostat culture and in the oligotrophic waters of the central North Pacific. Limnol. Oceanogr. 21: 88-107.

Pilson, M.E.Q. 1974: Arsenate uptake and reduction by Pocizlopora verucosa. Limnol. Oceanogr. 19: 339-341.

Portmann, J.E. and J.P. Riley. 1964. Determination of arsenic in sea water, marine plants and silicate and carbonate sediments. Anal. Chim. Acta 31: 509-519.

Rakestraw, N.W. and F.B. Lutz. 1933. Arsenic in seawater. Bioz. Bulz. 5: $397-408$.

Rothstein, A. 1963. Interactions of arsenate with the phosphatetransporting system of yeast. J. Gen. Physioz. 46: 1075-1085.

Ryther, J.H. 1969. Photosynthesis and fish production in the sea. Science 166: 72-76.

Scarborough, G.A. 1975. The mechanism of arsenate inhibition of the glucose active transport system in Neurospora crassa. Arch. Biochem. Biophys. 166: 245-250.

Schroeder, H.A. and J.J. Balassa. 1966. Abnormal trace metals in man: arsenic. J. Chronic Dis. 19: 85-106.

Sunda, W. and R.R.L. Guillard. 1976. The relationship between cupric ion activity and the toxicity of copper to phytoplankton. J. Mar. Res. 34: $511-529$.

Tagawa, S. and Y. Kojima. 1976. Arsenic content and its seasonal variation in seaweed. J. Shimonoseki Univ. Fisheries 25: 67-74.

Trefry, J.H. and B.J. Presley. 1976. Heavy metal transport from the Mississippi River to the Gulf of Mexico, p. 39-76. In: H.L. Windom and R.A. Duce (eds.), Marine Polzutant Transfer. Lexington Books. Lexington, Massachusetts.

Vinogradov, A.P. 1953. The Elementary Chemical Composition of Marine Organisms. Sears Foundation for Marine Research Memoir \#2. New Haven, Connecticut.

Waslenchuk, D.G. 1977. The geochemistry of arsenic in the continental shelf environment. PhD Thesis, Georgia Institute of Technology. Atlanta. 
- The geochemistry of arsenic in the continental shelf. environment. Mar. Chem., in press.

Whyte, J.N.C. and J.R. Englar. 1974. Elemental composition of the marine alga Nereocystis luetkeana over the growing season. Environment Canada, Fisheries and Marine Service Technical Report $\# 509$.

- 1975. Composition of the non-metallic inorganic components of the marine alga Nereocystis luctkeana over the growing season. Environment Canada, Fisheries and Marine Service Technical Report \#568.

Williams, K.T. and R.R. Whetstone. 1940. Arsenic distribution in soils and $i$ ts presence in certain plants. U.S. Department of Agriculture, Technical Bulletin \#732.

Wood, J.M. 1974. Biological cycles for toxic elements in the environment. Science 183: 1049-1053.

Woolson, E.A. 1975. Bioaccumulation of arsenicals, p. 97-107. In: E.A. Woolson (ed.), Arsenical Pesticides. American Chemical Society Symposium Series \#7. Washington, D.C.

Young, E:G. and W.M. Langille. 1958. The occurrence of inorganic elements in marine alga of the Atlantic provinces of Canada. Can. J. Bot. 36: 301-310. 
APPENDIX II 